


\title{
A Second Chance? Labor Market Returns to Adult Education Using School Reforms*
}

\author{
Patrick Bennett $^{\dagger} \quad$ Richard Blundell ${ }^{\ddagger} \quad$ Kjell G. Salvanes ${ }^{\S}$
}

August 3, 2020

\begin{abstract}
Roughly one third of a cohort drop out of high school across OECD countries, and developing effective tools to address prime-aged high school dropouts is a key policy question. We leverage high quality Norwegian register data, and for identification we exploit reforms enabling access to high school for adults above the age of 25 . The paper finds that considerable increases in high school completion and beyond among women lead to higher earnings, increased employment, and decreased fertility. As male education remains unchanged by the reforms, later life education reduces the pre-existing gender earnings gap by a considerable fraction.
\end{abstract}

JEL.CLASS.NO: I26, I28, J13

KEYwords: Adult Education, Returns to Education, Fertility, Gender inequality

\section{Introduction}

Across the OECD area, 20-30\% of each birth cohort drop out of high school before graduating (OECD, 2017). High school dropouts face severe labor market conditions and lower labor market prospects are an important reason behind the widening earnings gaps between college and non-college educated workers in recent years (Acemoglu and Autor, 2011; Blundell, Joyce, Keiller, and Ziliak, 2018). An important policy challenge is how to provide a second chance to low-educated workers and limit their dependency on welfare programs such as unemployment, disability, and sickness benefits. Developing

${ }^{*}$ This work was partially supported by the Norface grant HuCIAW, and the Research Council of Norway through its Centres of Excellence Scheme, FAIR project No. 262675. Blundell is also grateful for support from the ESRC Centre for the Microeconomic Analysis of Public Policy at IFS (grant number R000239865). The authors thank the audience of the Norwegian School of Economics, the University of Bergen, and the 2020 EALE/SOLE/AASLE conference.

${ }^{\dagger}$ Norwegian School of Economics and FAIR. Email: Patrick.Bennett@nhh.no

${ }^{\ddagger}$ University College London and IFS. Email: r.blundell@ucl.ac.uk

${ }^{\S}$ Norwegian School of Economics and FAIR. Email: Kjell.Salvanes@nhh.no 
effective tools to tackle the declining labor market prospects of prime-aged high school dropouts is a key policy question.

In this paper, we evaluate the causal impact of a second chance of completing high school as adults in Norway by leveraging high quality Norwegian register data and exploiting reforms enabling access to high school for adults above the age of 25 . Our focus is on the high school completion-vocational or academic - within the formal education system and thus externally verified by a third party. This approach requires real investment in human capital by attending courses (day time or evening as well as workplace training for the vocational track) within the formal education system and nationally graded tests.

While the labor market returns to education from on-time education are well established (see Card, 1999), causal evidence on the impacts of second chance education is scarce. ${ }^{1}$ The education program we examine is distinct from programs in other countries which are not verified within the formal education system as in the UK (Blanden, Buscha, Sturgis, and Urwin, 2012) and distinct from the General Education Development (GED) program in the US, which is usually considered to be signaling without any human capital accumulation (Heckman, Humphries, and Mader, 2011; Tyler, Murnane, and Willett, 2000). ${ }^{2}$ The existing GED literature finds little evidence of GED certification on labor market outcomes (Heckman and LaFontaine, 2006; Jepsen, Mueser, and Troske, 2016). ${ }^{3}$

In addition to contributing to the literature on assessing the returns to a second chance within the formal education system, we also document how the completion of college education evolves over the life cycle following the late completion of an academic high school degree. In particular, we are interested in whether the timing of returning to academic high school, which includes an option for entering higher education, affects the probability of entering and completing college education. This perspective adds to the literature on returns to education at a fixed age ignoring that the timing may matter. Moreover, we focus on the gender difference in how high school completion evolves over time for boys and girls, and whether the second chance option widens or closes the gender gap in earnings. In general, we assess gender differences in the interplay between timing of fertility and completing high school. For instance, the timing of fertility affects the timing of completing high school for women, and

\footnotetext{
${ }^{1}$ See Schwerdt, Messer, Woessmann, and Wolter (2012) for the impacts of education vouchers in Switzerland.

${ }^{2}$ It has similarities to the extensive adult education program from 1997 to 2002 in Sweden which funded one year of high school for 25 to 55 year olds in Sweden. However, this program focused for the most part on unemployed, it was not within the education system but organized more as a job market program by the municipalities. Moreover, it was not necessarily aimed at a completed high school degree. There are several studies evaluating this either using structural models or matching techniques, and they find some positive employment effect for the lowest skilled Stenberg and Westerlund (2008); Albrecht, van den Berg, and Vroman (2009). The program is also different from an alternative route in Norway where you obtain a vocational degree through workplace training, and the degree externally verified by the education system. See Bratsberg, Nyen, and Raaum (2020) for details on this route.

${ }^{3}$ Relying on the assumption that, conditional on controls, the year an individual decides to return to education is random, Albæk, Asplund, Barth, Lindahl, Strøm, and Vanhala (2019) suggest that adult education in the Nordic countries prevents labor force dropout.
} 
the second chance option may enhance earnings and facilitate mothers back to work (Blundell, Dias, Goll, and Meghir, 2019). At the same time, returning to education may also impact future fertility decisions: Black, Devereux, and Salvanes (2008) find that additional on-time education causes declines in fertility. Indeed, there exist strong gender differences in returning to education over the life cycle.

Causally estimating the benefits of education when individuals return to complete levels of education they previously dropped out of presents an empirical challenge. First, high school completion and the timing of later life completion are clearly endogenous decisions. Second, it is not straightforward to isolate a suitable counterfactual for late high school graduates. Third, the sequential nature of education implies that those who complete high school on-time may return to higher education later in life. Finally, prior research has demonstrated the importance of when earnings are measured when estimating the returns to education (Bhuller, Mogstad, and Salvanes, 2017).

We address each of these concerns and exploit two major policy reforms which introduce the legal right to enroll in education over the age of 25 and overhaul the student support system which increased the amount of unconditional student support for those over the age of 19. Within an event study framework, we measure earnings both prior to and after the completion of education over a long time horizon and examine both short- and long-run impacts of education on earnings. We exploit variation in the age at which different birth cohorts are first exposed to the two policy reforms to exploit later exposed cohorts as a counterfactual for early exposed cohorts. ${ }^{4}$ As the event study framework exploits variation across different birth cohorts, changes in demographic characteristics over time may affect the similarity of early and later treated. As such, pre-treatment differences in the composition of the sample between early and later treated cohorts may affect the dynamics of the outcome variable post-reform, violating the parallel trends assumption. Abadie (2005); Blundell and Dias (2009) show that weighting the regression by the propensity score estimated as a first step can account for such differences, and we follow a similar approaches taken Mastrobuoni and Pinotti (2015); Goodman-Bacon and Cunningham (2019).

As a background and starting point for the causal analysis, we first provide descriptive evidence on who returns to education, when in life individuals return to education, and what qualifications they return to. We focus on the potential importance of differences by gender, parental education levels, childbearing, cognitive ability, child health, as well as differences in academic/vocational high school track. The paper also describes how the earnings of individuals who endogenously return to complete high school evolves prior to and after the completion of high school from the ages 20-45.

The descriptive analysis highlights several key findings. First, there are distinct patterns for men

\footnotetext{
${ }^{4}$ We show that on-time high school graduates are not a suitable counterfactual by exploiting a rich set of characteristics include cognitive test scores
} 
and women. For cohorts born between the mid 1960s and 1970, between one third of women and almost half of men who drop out of high school go on to complete high school by the age of 45 . Men also return to complete high school to a much higher degree than women between 20-25 and close the gender gap in on-time high school completion by age 25. However, women return to high school at especially high rates from the age of 30 , overtaking men in completion by this age.

Second, a large fraction of late high school completers continue on to higher education. Attending higher education is much more common for women than men, increasing both over the life-cycle for each birth cohort and increasing over cohorts. The earlier high school is completed for an adult, the higher the probability to return attain higher education, and again, women in particular go on to higher education. As such, the timing of completing high school matters. Third, completing high school for women late in life is strongly related to the timing of fertility.

Finally, in terms of earnings, late high school graduates are able to close some of the pre-existing gap with on-time graduates. Based on descriptive OLS results where people endogenously return to complete high school, relatively soon after completion late high school graduates see a rapid increase in earnings. While late graduates match the growth of earnings over the life cycle of on-time graduates, there is a persistent levels difference in life-time earnings over time.

Next, we estimate the causal impacts of later life education on labor market outcomes and subsequent fertility, exploiting two major policy reforms which reduce the opportunity cost of returning to high school. Comparing early treated to later treated cohorts, such reforms significantly increase education among high school dropouts in their early 30s. Increases in education are concentrated among females, with no observed change in education for males. A primary reason for this is that the vast majority of male dropouts return to complete high school at younger ages prior to 30. A majority of early treated women who return to complete high school following the reforms also continue in the education system to complete some higher education, suggesting a relationship between returning to high school younger and the probability of continuing with higher education.

We find improved labor market prospects for women with both increases in labor earnings and employment. The observed increase in earnings attributed to later life education is driven almost entirely by increases in employment among women rather than increases in wages. Female high school dropouts are weakly attached to the labor force prior to the reform, and such changes in employment vary across pre-reform levels of attachment: while those with low attachment see increases in labor force participation post-reform, those with stronger attachment remain in full-time employment at higher rates. As men do not return to education post-reform, the two policy reforms considerably reduce the pre-existing gender gap in earnings as male earnings remain unchanged post-reform. In 
addition to improving labor market prospects, fertility is also impacted: returning to education reduces future fertility among women. Given the strong relationship between children and employment, a considerable portion of the increase in employment can operate through the joint decision of fertility and employment.

Similar to Blundell, Dias, Goll, and Meghir (2019) who document that job training can close the gender wage gap among females, we provide evidence that later in life human capital accumulation through formal education has the potential to impact the gender wage gap. An extensive literature documents considerable gaps in the labor market outcomes by gender and underlying reasons for such differences (Goldin, 2006; Blau and Kahn, 2017). Recent papers have emphasized the importance of the child wage penalty as an important underlying factor behind gender wage differences (Angelov, Johansson, and Lindahl, 2016; Kleven, Landais, and Søgaard, 2019). By inducing female high school dropouts to return to education, the paper finds that women return to high school more than men at later ages. As a result, the pre-existing gender gaps in earnings were considerably reduced as labor market outcomes of women improve relative to men.

The paper proceeds as follows. Section 2 describes Norwegian register data as well as the education system in Norway. Section 3 presents descriptive evidence on returning to education over the life cycle and how the earnings of those who endogenously return to education evolve over time. Section 4 identifies the impact of exogenous policy reforms on the probability of returning to high school, examines how gender gaps in earnings are impacted by returning to education, and provides causal estimates of the labor market returns to returning to education. Section 5 details heterogeneity in returning to education and the robustness of the baseline results. Section 6 concludes.

\section{Norwegian Register Data and Education in Norway}

\subsection{Norwegian Register Data}

In order to analyze the phenomenon of later life education, the paper makes use of administrativebased Norwegian Register Data. The data is linked by Statistics Norway across different sources by an anonymized personal identification number. The paper merges information across several different registers to create an individual-level panel following people from birth to age 45 . The focus of the empirical analysis are cohorts born between 1964 to 1970 since these cohorts are covered by the educational reforms we use for identification. We have earnings data up to 2015, and this is the reason we measure educational attainment and earnings up to the age of 45 . In the descriptive analysis we extend the cohorts up to 1980 . 
We extract population information from the central population register which contains information such as an individual's birth year, gender, age, citizenship, municipality of residence in a given year, and municipality of birth. Information is available for any person who is legally resident in Norway. The central population register also links families across generations, which links parents to children. Such linkage permits the construction of measures for parental education as well as information on any children born to both mothers and fathers.

The Level of Education Register provides information, in each year, on ongoing student status as well as years of education and the exact qualification achieved. ${ }^{5}$ Qualifications are measured at the detailed field of study level, and correspond to the International Standard Classification of Education (ISCED) system. Schools have a legal requirement to report any information enrollment and graduation to Statistics Norway, which minimizes the potential for measurement error. Annual data is measured at the start of October in a given year. Throughout the paper, educational qualifications at the high school level are grouped into academic or vocational.

Data on earnings is extracted from the tax and earnings register, where annual labor earnings are recorded. We use two alternative measures of earnings. Gross earnings includes pre-tax total labor earnings, including any earnings from self-employment, and includes some transfers such as taxable benefits received in a given year such as parental leave, unemployment, or sickness benefits. Gross market income excludes any transfers. Employment data is provided from the Register of Employers and Employees. This provides information on employment status, hours worked, and industry of employment.

The paper measures cognitive ability for all males at age 18 from compulsory military testing data. Cognitive ability is comprised of three examinations: an arithmetic test similar to the arithmetic test in the Wechsler Adult Intelligence Scale (WAIS), a word similarities test similar to the same test in the WAIS, and a figures test similar to the Raven Progressive Matrix test. The cognitive ability measure is measured on a 9 point scale, with a mean of 5 and a standard deviation of 2. Finally, for cohorts born from 1967, the medical birth register provides information on birth weight which we use a measure for child health.

\subsection{The Norwegian Education System}

Following a 1959 reform (see Black, Devereux, and Salvanes (2005) for further details), compulsory schooling in Norway is composed of 6 years of primary school and 3 years of secondary school for our birth cohorts. After the completion of compulsory schooling, a student decides whether or not to

\footnotetext{
${ }^{5}$ Years of education are measured as the number of years it should take a student to achieve a given qualification.
} 
continue into upper secondary education or drop out. All birth cohorts considered in this paper are under this compulsory schooling system, such that an individual may drop out at roughly age 16 to join the labor force.

After completing compulsory education, students may progress to high school. High school is comprised of both academic and vocational high school programs and lasts 3 to 4 years. Academic high school is geared towards future enrollment in university education and lasts 3 years. Vocational high school leads to professional employment in a given vocation after the completion of high school. The vocational route is based on a combination of school and apprenticeship. The main model is 2 years in school, followed by a 2-year apprenticeship. During the apprenticeship period, the apprentice is employed in an approved firm responsible for providing training of sufficient quality. Employer associations and trade unions take part in governing structures at both the national and county levels, but educational authorities formally have the final word. Formal qualifications are obtained by passing exams and a final practical-theoretical test of occupation-specific skills. All formal vocational qualifications based on apprenticeships are aimed at matching the requirements of specific occupations. Prior a reform in 1994 examined in Bertrand, Mogstad, and Mountjoy (2019), the system was very divided between academic and vocational education with little progression to higher education from vocational. All birth cohorts born prior to 1978 are enrolled in education under the divided pre-reform system, as the reform defined eligibility according to birth year.

For obtaining a vocational high school degree as an adult above 25, there are two different routes. One is adult apprenticeship and the experience-based route. First, the program we are analyzing in addition to academic high school, is adult apprentices, and have all their training at the workplace. In addition, they attend classes in general theoretical subjects. The number of hours of theoretical classes depends on the qualification already obtained in high school. Such apprenticeship training takes from 1 to 4 years full time at the workplace. The number of years depends on the qualification and the competence each individual has previously acquired through school and work practice where years is the mean. They need to pass both a written exam specific to their trade and the main practical-theoretical test, which is assessed by an external assessment committee. Second, adults who can document long and varied practice as unskilled workers within a relevant trade can register for the trade examination and acquire the trade certificate, usually after taking a shorter theoretical course. They need to pass both a written exam specific to their trade and the main practical-theoretical test, which is assessed by an external assessment committee of experienced skilled workers within the industry. This experience-based route accounts for about one-third of all new trade certificates each year. In terms of formal qualifications, both the adult apprenticeship and the experience-based routes 
provide the same trade certificates as completing the upper secondary vocational track as a regular student/apprentice. This route is analyzed in Raaum et al.

Tertiary education in Norway includes both university colleges which specialize in shorter higher education programs such as engineering, nursing, and teaching and universities. For instance, in order to become a nurse or a teacher, an academic high school degree is required. The direct costs of attending are close to zero, as there are no tuition charges and most students qualify for grants and loans from the government.

\section{Descriptive Evidence on Returning to Education and Lifetime Earnings}

Do those who leave school to join the labor market terminate education for life or do some return to education later in life? Figure 1 reveals returning to education is an important phenomenon across many OECD countries: on average, 7\% of those aged 30-39 in 2017 are enrolled in any formal education across the OECD members. While there exist substantial differences across the OECD members states - for instance, Finland has the highest enrollment later in life, the United States is roughly in line with the OECD average, and France has the lowest enrollment in formal educationreturning to education later in life is an important phenomenon in all countries.

Figure 1: Enrollment in Any Education Across OECD Countries

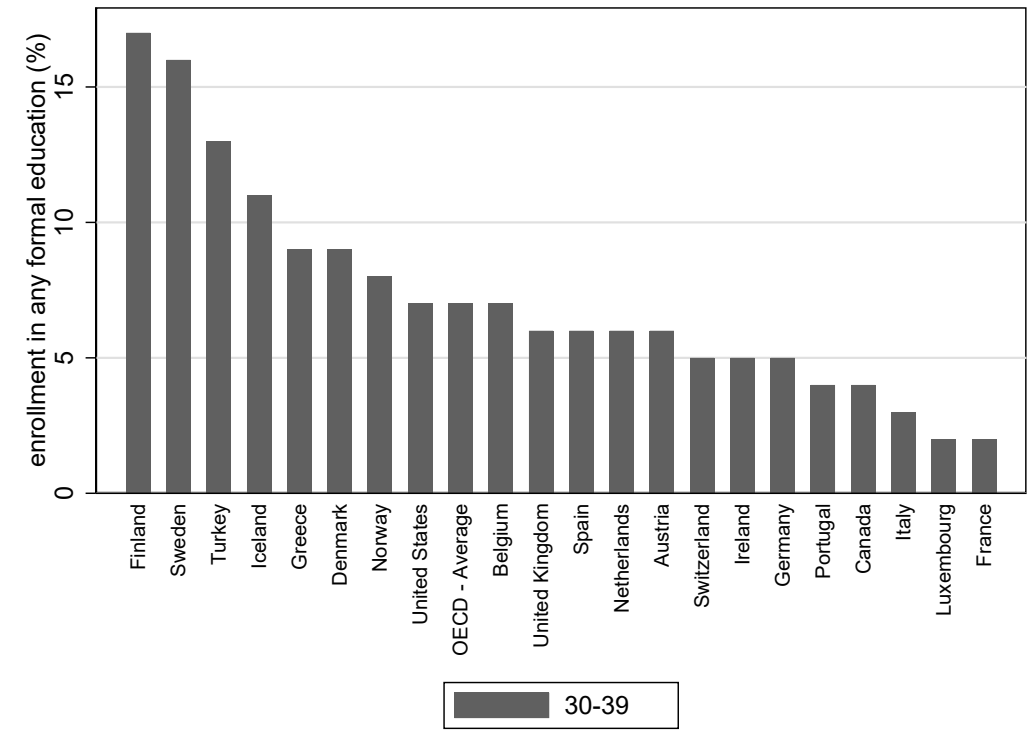

Percent of age group enrolled in any formal education in 2017. Source - OECD.Stat, Adult education and learning (https://stats.oecd.org/index.aspx). Founding OECD member countries and Finland reported, OECD average calculated as average across all OECD members in 2017.

Section 3.1 provides descriptive evidence on who returns to education and at what ages while Section 3.2 details what qualifications and fields of study they return to. Section 3.1 focuses on 
differences in returning to education across important factors such as gender, socioeconomic status, childbearing, cognitive ability, and birth weight. Section 3.2 documents whether individuals return to academic or vocational high school and how both university education and years of education change over the life cycle.

\subsection{Who returns to education and at what ages?}

Figures $2 \mathrm{a}$ and $2 \mathrm{~b}$ plot the high school completion rate for females and males respectively. Figure 2 reveals returning to education is an important phenomenon over the course of the life cycle: across 20 years of birth cohorts in Norway from 1961-80, the final year of upper secondary education completion rate (a level equivalent to the completion of high school) increases by $6-17$ percentage points between the ages of $20-25$, by an additional $7-10$ p.p. between the ages of $25-35$, and by an additional $2-7$ p.p. from $35-45 .{ }^{6}$ While the high school completion rate begins to flatten over the course of the life cycle, individuals continue to complete high school through age 45, well after an "on-time" student would. ${ }^{7}$ Among those born 1961-1970 who drop out of high school and do not graduate on-time, 39\% of women and $47 \%$ of men go onto complete high school by age 45 .

Figure 2: Evolution of the Completion of High School Over the Life Cycle

\section{(a) Female}

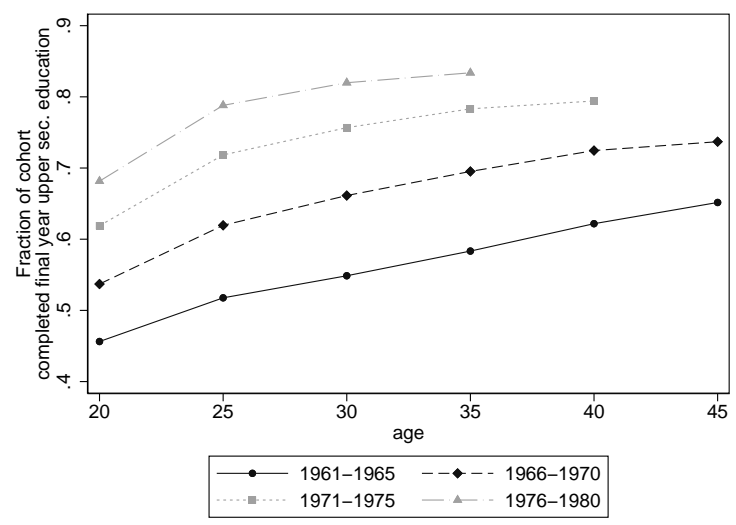

(b) Male

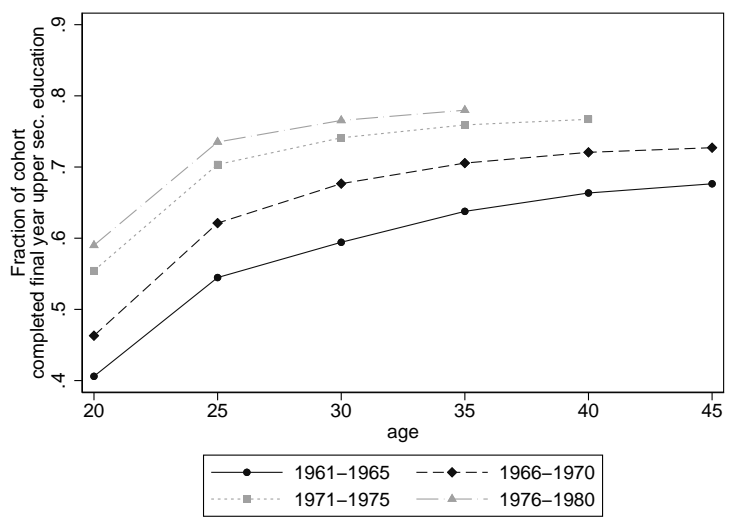

Figure plots the high school completion rate over the life cycle for birth cohorts 1961-1980 for women and men respectively. Sample is balanced to include those observed at all points from age 20 onward. 1976-1980 cohorts are followed until age 35 and 1971-1975 cohorts are followed until age 40 in the data.

Across different birth cohorts, on-time high school completion increases from older to younger cohorts. Most of the differences in eventual high school completion across birth cohorts are due to the level shift in on-time completion. However, age-education profiles are not parallel across cohorts: as on-time completion has increased, returning to high school over the life cycle has declined. This

\footnotetext{
${ }^{6}$ Throughout the paper, final year of upper secondary education and completion of high school are used interchangeably.

${ }^{7}$ The figures throughout follow individuals until age 45, where the 1971-1975 cohorts are missing data for age 45 and the 1976-1980 cohorts are missing data for age 40 and 45.
} 
appears to be more true for men than for women, though high school completion continues into older ages even for men. As the cohorts 1961-1970 closely correspond to the cohorts who are impacted by the two reforms described in Section 4, we focus mainly on these birth cohorts.

There exist considerable gender differences in high school completion from on-time completion up until age 45. Across all birth cohorts, females complete high school on-time at a higher rate than males. Irrespective of gender, high school education continues to increase over the life cycle, but at a slightly decreasing rate.

However, the age at which women and men return to education differs greatly. From 20-25, men tend to return to high school from 20-25 at much higher rates than women do. The high school completion rate of men increases rapidly between 20 and 25 such that the large gap in high school completion at age 20 between men and women is reversed by age 25 . Women, on the other hand, tend to return to high school at higher rates than men at later stages in the life cycle. For instance, from ages 30 onwards, women return to high school substantially more than men. This is especially true from 35-45, where the high school completion rate of women is nearly double that of men.

Important differences in when in the life cycle women and men return to education suggest different considerations in the decision of women and men at the margin of returning to high school. Relative to men, returning to high school is more common for women in their 30 s and early 40s. Section 3.1 examines differences in the importance of childbearing for women relative to men as a potential reason behind this. Relative to women, on-time high school dropout is more problematic for men. This suggests that the returns to high school education may not be large enough to justify investments in human capital for young boys or that the labor market opportunities available in youth may be more appealing to men than women. However, by age 25, a large fraction of male dropouts have returned to complete high school, suggesting that some of these dropouts quickly see the need for additional human capital. Section 3.2 examines the importance of returning to vocational high school, a group where dropouts are most problematic.

\section{The importance of socioeconomic status}

Given the intergenerational link in education and earnings (see Black and Devereux, 2011, for an overview), socioeconomic status (SES) may be an important factor in returning to education over the life cycle. Do gaps in high school completion between high and low SES families persist over the life cycle, or do lower SES families catch up over time? Figures 3 and 4 plot the gaps in education by socioeconomic status (SES) over the life cycle for women and men respectively. SES is measured by parental education, where parental education is defined as the highest level of parental education ever attained, such that either the mother, the father, or both parents may have the indicated level of 
education. Figures 3 and 4 separate the sample into two groups of parental education: low-educated families, where the highest parental education is less than high school, and high-educated families, where the highest parental education is post-secondary education. ${ }^{8}$

Unsurprisingly, there are sizable gaps in on-time high school completion by SES: those from loweducated families complete high school by age 20 at much lower rates. This is true for both men and women. SES gaps in high school completion decrease over time, as the completion gap is wider for the 1961-1970 cohorts compared to the 1971-1980 cohorts. Over the course of the life cycle, the SES gap in high school completion decreases, as those from low-educated families complete high school at higher rates than those from higher educated families later in life. For women born 1961-1970 (Figure 3a), the SES gap in high school completion is 34 p.p. at age 20, 31 p.p at age 35, and 26 p.p by age 45 . As seen before, men tend to return to education at younger ages relative to women.

While high school completion is key, it is informative to also understand how SES gaps evolve over the life cycle including all margins of education. As such, panels (c) and (d) in Figures 3 and 4 plot the SES gaps measured in terms of years of education. Unlike high school completion, SES gaps measured in years of education widen over the life cycle, as those from high-educated families continue to complete higher education beyond the high school level.

\section{The importance of childbearing}

Figure 5 plots the relationship between child birth and education separately for women and men for the birth cohorts 1961-1970. The figure presents the distribution of age at first birth for four separate samples: on-time high school graduates (age 20 or less) and those who completed high school from 2125, 26-30, and 31-35. While men tend to have their first child at slightly older ages, the distribution of age at first birth is relatively similar for male and female on-time graduates.

For later in life graduates of all ages, childbirth is more important among women who complete education later in life than men. For those who complete high school from 21-25, there is a clear mass of women who have their first child in their late teenage and early 20 s. The same is not true for men. The distributions of age at first birth differ even more among those who complete high school from 26-30 and 31-35: the vast majority of women who complete education at these ages had their first child in their teens and early 20s. Again, the same cannot be said of men. Interestingly, women who complete high school from 26-30 also exhibit a second peak in age of first birth in their late 20s, suggesting that late in life education and childbirth may also be linked.

Results of Figure 5 reveal that childbirth is much more interruptive to on-time education for women

\footnotetext{
${ }^{8}$ Omitted are families where the highest level of parental education is the completion of high school. The high school completion of children in such families lies in between the high- and low-SES families.
} 
Figure 3: Completion of High School/Years of Education Females, by Highest Parental Education

(a) 1961-1970

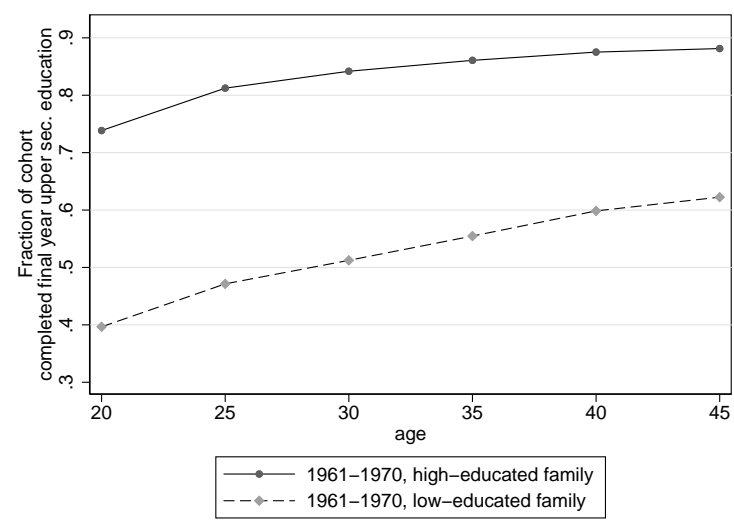

(c) $1961-1970$

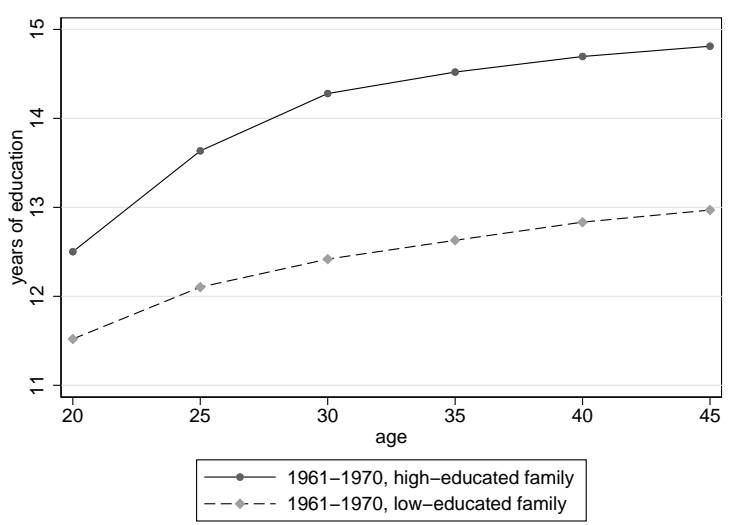

(b) 1971-1980

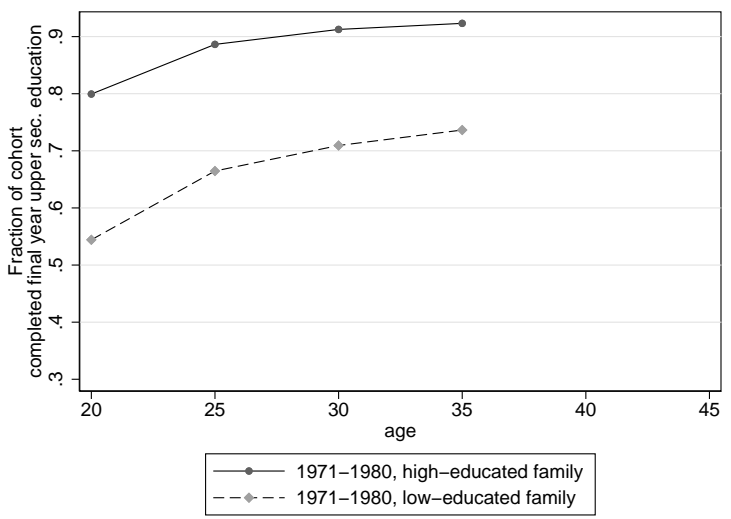

(d) $1971-1980$

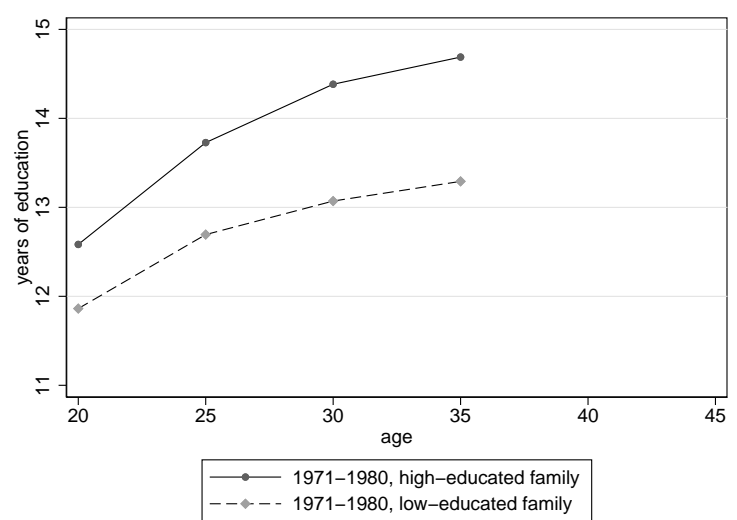

Figure plots the high school completion rate/years of education over the life cycle for birth cohorts 1961-1980 for females by the level of family education. Low-educated family: highest parental education is less than high school. High-educated family: highest parental education is any post-secondary education. 
Figure 4: Completion of High School/Years of Education Males, by Highest Parental Education

(a) 1961-1970

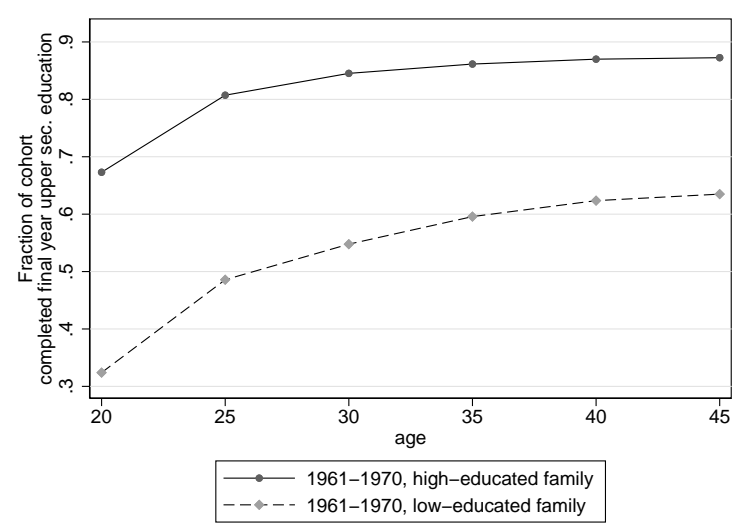

(c) 1961-1970

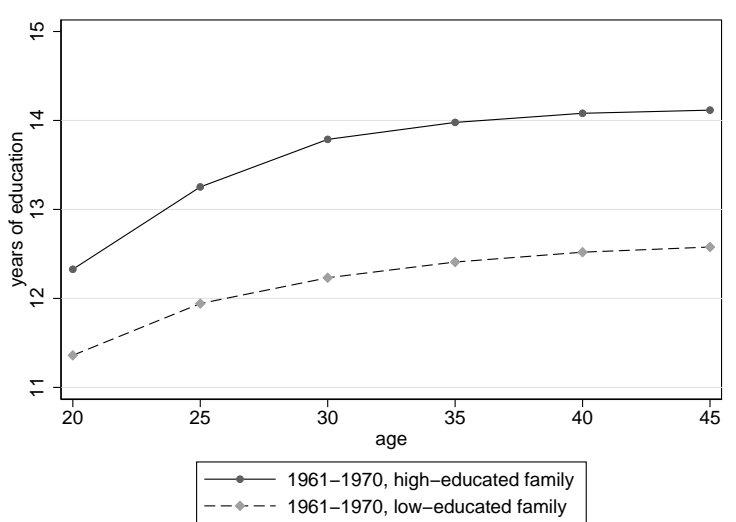

(b) 1971-1980

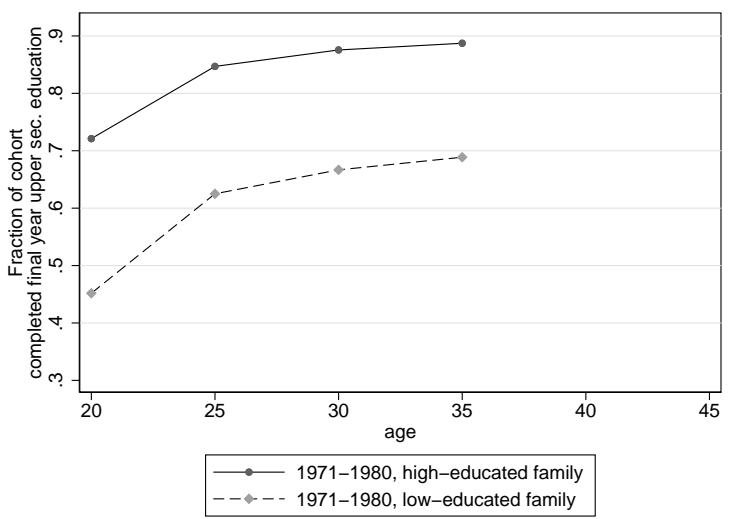

(d) $1971-1980$

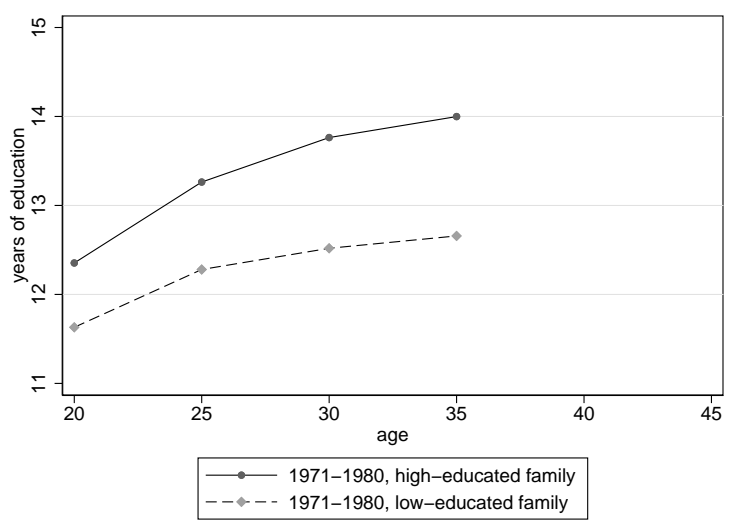

Figure plots the high school completion rate/years of education over the life cycle for birth cohorts 1961-1980 for males by the level of family education. Low-educated family: highest parental education is less than high school. High-educated family: highest parental education is any post-secondary education. 
compared to men and there exists a strong relationship between age of first birth and age of high school completion for women and, to a lesser extent, men. In particular, fertility during the teenage years and the early 20 s is much more common among women who return to education later in life. ${ }^{9}$

Figure 5: Distribution of Age at First Birth for Different Ages of High School Completion

(a) Females

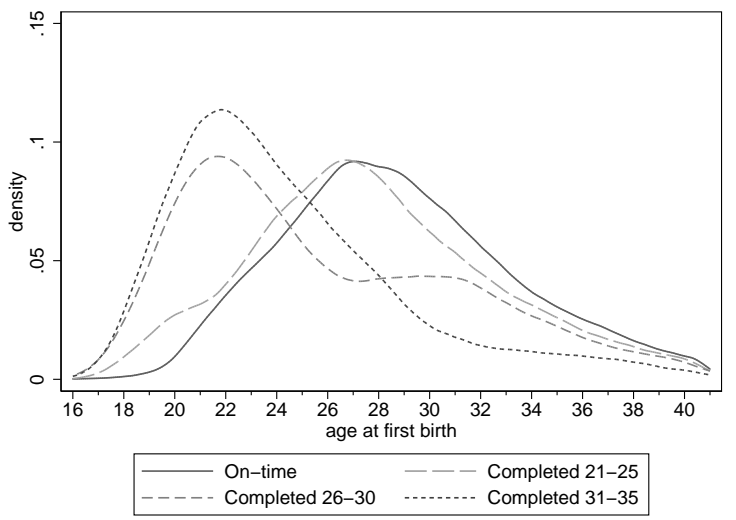

(b) Males

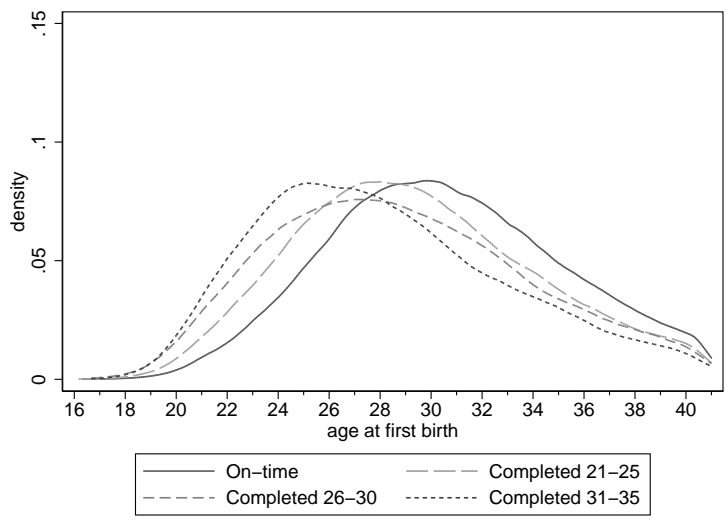

Figures plots the age distribution of age at first birth separately for females and males by four groups of age of high school completion: on-time (age 20 or younger), 21-25, 26-30, and 31-35. Includes all first-births between 16 and 41 , birth cohorts 1961-1970.

\section{The Importance of Cognitive Ability}

Using data available for men from compulsory military testing at age 18, Figure 6 plots the distribution of cognitive ability measures across different ages of high school completion for the birth cohorts 1961-1970. The Figure compares the distribution of cognitive ability between on-time graduates and four groups: those who completed high school from 21-25, 26-30, 31-35, and those who never complete high school. Figure 6 reveals clear differences in the underlying cognitive ability of ontime graduates, late completers, and never completers. On-time graduates are positively selected from the IQ distribution, with a median of cognitive ability of 6 and very few with ognitive ability score below the national mean of 5 . As age of high school completion increases, the cognitive ability distribution shifts leftwards. While there are clear differences in the distributions of on-time and late completers aged 21-25 (Figure 6a), where late completers have lower IQ scores, these differences are even more prevalent comparing on-time and late completers aged 26-30 and 31-35 (Figures 6b and 6c respectively).

Figure $6 \mathrm{~d}$ compares the cognitive abilities of those who never complete high school to those who graduate on-time. While on-time graduates are positively selected, those who never complete high school by age 45 are negatively selected from the cognitive ability distribution. Such stark differences

\footnotetext{
${ }^{9}$ Figure A presents adolescent fertility rates among the OECD founding member states and Finland in 1990. Norway ranks in the middle of the distribution of teenage fertility across the founding member states with 16.5 births per 1000 women aged 15-19.
} 
in cognitive ability complicate the comparison of late high school completers to on-time and never completers, and Section 4 discusses the choice of counterfactual for late high school completers in estimating the returns to later in life education.

Figure 6: Distribution of IQ for Different Ages of High School Completion

(a) Completed HS On-time and 21-25

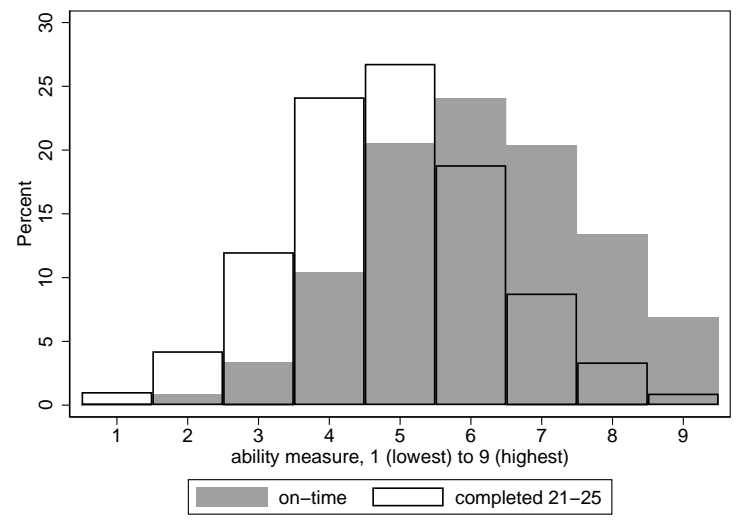

(c) Completed HS On-time and 31-35

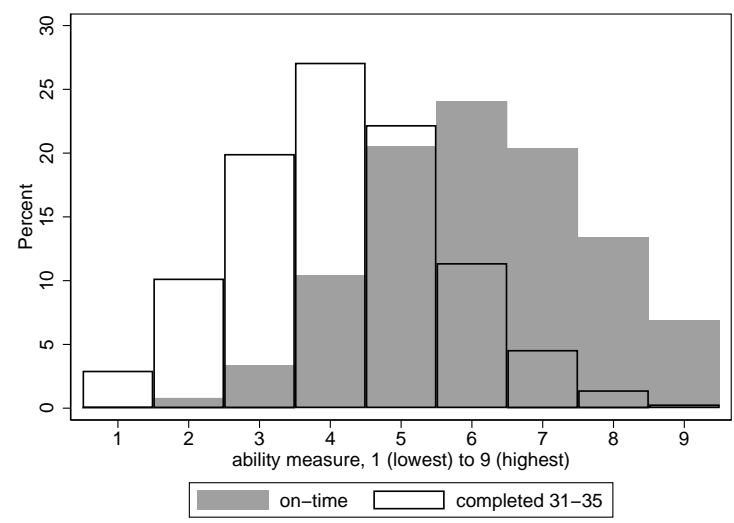

(b) Completed HS On-time and 26-30

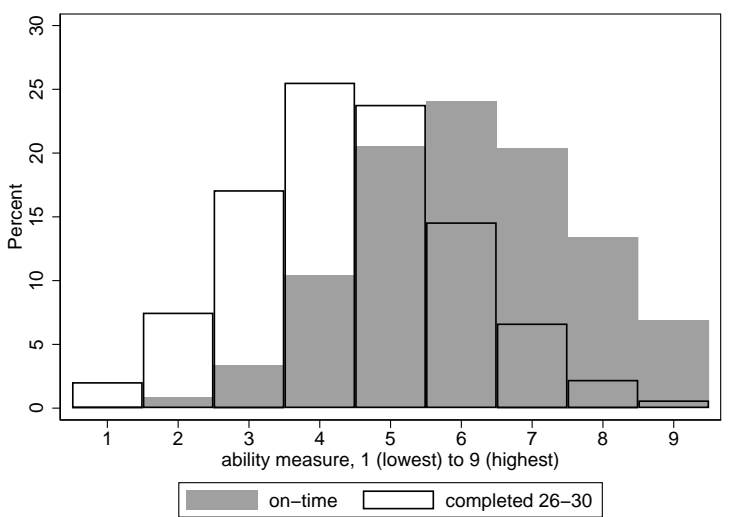

(d) Completed HS On-time and Never Completed

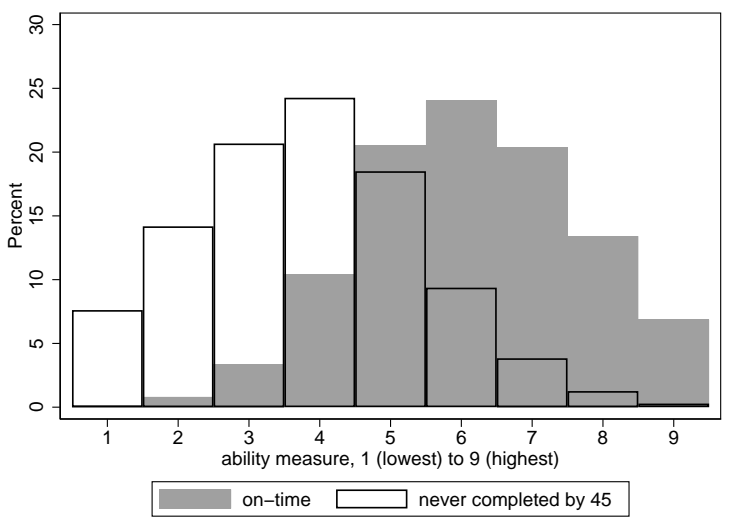

Figure compares the distribution of cognitive ability for men for on-time high school completers to four different groups: high school completers from 21-25, from 26-30, from 31-35, and those who never complete high school by age 45 . Cognitive ability measured for all males at age 18 from compulsory military testing. Cognitive ability is measured on a 9 point scale, mean of 5 and standard deviation of 2 . Measure is comprised of 3 examinations: an arithmetic test, a word similarities test, and a figures test as described in Section 2. Birth cohorts 1961-1970.

\section{The importance of factors at birth}

Figure 7 examines the importance of initial health conditions measured at birth in the completion of high school over the life cycle (see Black, Devereux and Salvanes, 2005), for an analysis of the importance of birth weight on adult education and income. Making use of data on birth weight for those born 1967-1970, the Figure divides the sample into quartiles of birth weight. ${ }^{10}$ Birth factors matter in terms of on-time high school completion for both women and men, where children with higher birth weights complete high school at higher rates. However, even when comparing the highest to lowest birth weight quartiles, the differences in on-time high school completion are small compared to

\footnotetext{
${ }^{10}$ Data is first available from the 1967 birth cohort.
} 
the stark differences by SES seen previously. Apart from these initial differences in on-time completion, returning to high school is remarkably stable across the different birth weight quartiles. This is true both for high school completion as well as years of education (Figures 7c and 7d) as, apart from the lowest birth weight quartile, initial gaps in on-time completion persist over the life cycle.

Figure 7: Completion of High School/Years of Education by Birth Weight

(a) High School, females

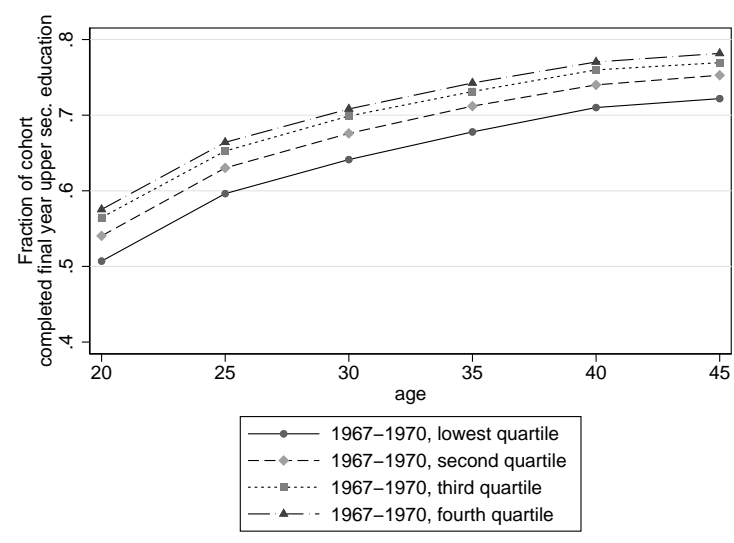

(c) Years of Education, females

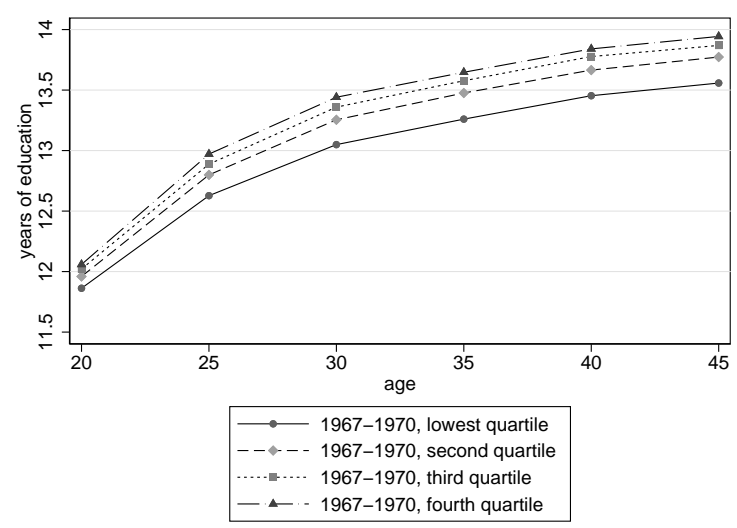

(b) High School, males

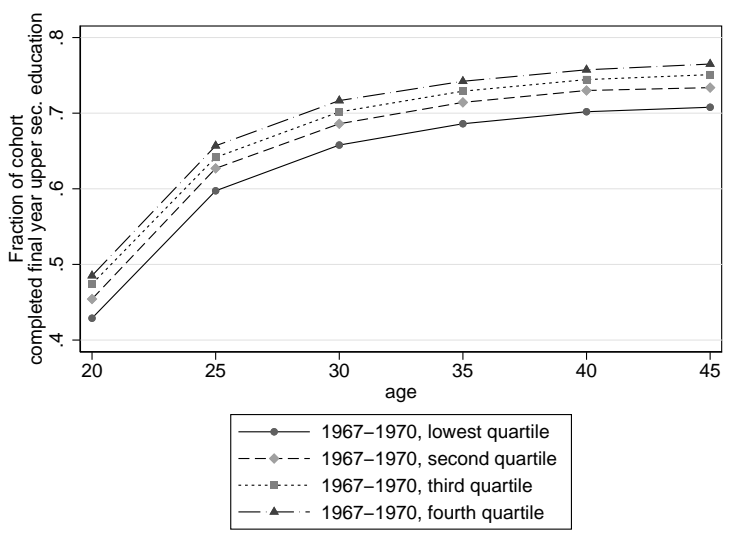

(d) Years of Education, males

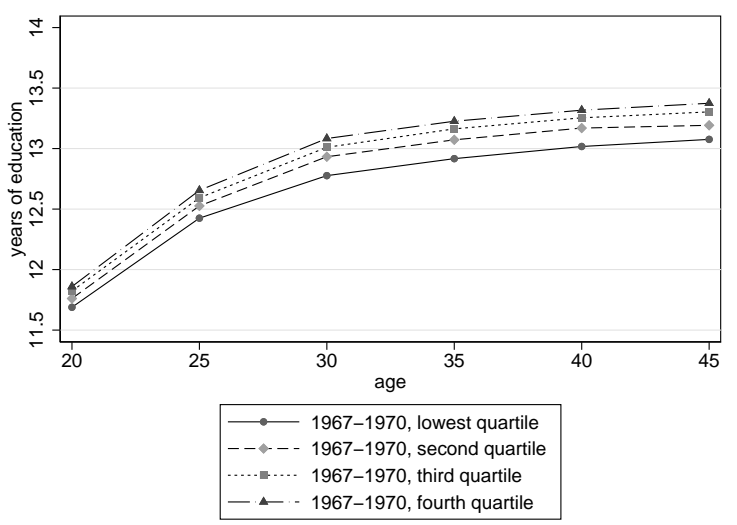

Figure plots the high school completion rate over the life cycle for birth cohorts 1967-1970 for women and men of different birth weights. $25^{\text {th }}$ percentile of birth weight: 3170 grams. Median birth weight: 3500 grams. $75^{\text {th }}$ percentile of birth weight: 3840 grams.

\subsection{What qualifications do individuals return to?}

Corresponding to the two different types of high school in the Norwegian education system, Figure 8 shows the evolution of academic and vocational high school completion rates for both women and men born 1961-1970. Females return to complete academic high school, which is geared towards higher education, primarily from the ages of 20-30. After age 30, the academic high school completion continues to increase for women until age 45, albeit at a slightly lower rate with age. Men, who have much lower levels of academic high school completion relative to females, see small increases in their academic high school completion rate from 20-25. However, academic high school completion rates 
are relatively similar at the ages of 25 and 45 for men.

In contrast, both females and males return to complete vocational high school later in life. At age 20, men complete vocational high school at a higher rate than women, and men also return to complete vocational high school prior to 35 at higher rates than women do. This is particularly true from ages 20-25, and increases in vocational high school among men are driving the increase in high school completion seen in Figure 2. For instance, the vocational high school completion rate more than doubles from 20-35, increasing by roughly 15 percentage points for males. In addition, men continue to complete vocational high school into older ages, though at a decreasing rate. Women also return to complete vocational high school over the life cycle, though at lower rates than men from 20-35. Interestingly, women return to complete vocational education from 35-45 at a slightly higher rate than from 25-35, and the completion of vocational high school actually increases with age for women.

Figure 8: Fraction of Birth Cohort Completed Relevant Margin of Education - Academic/Vocational

(a) Academic - Females

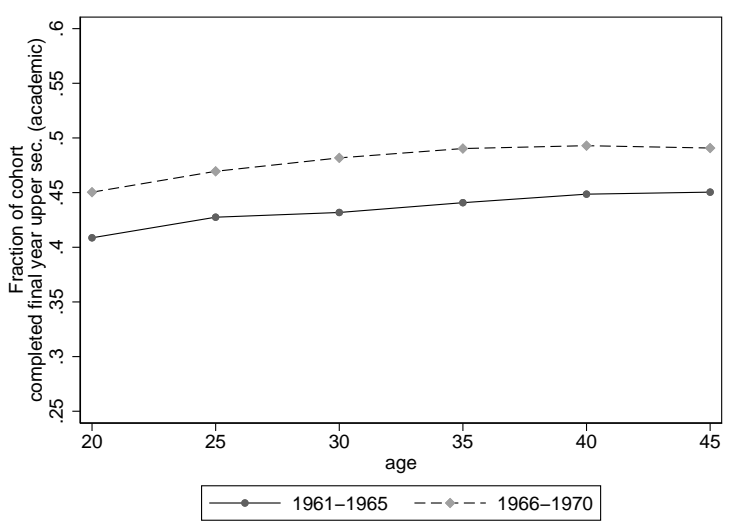

(c) Vocational - Females

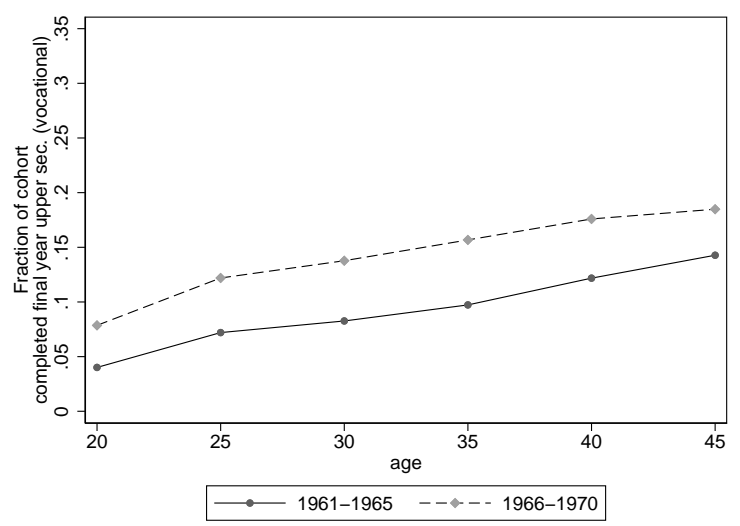

(b) Academic - Males

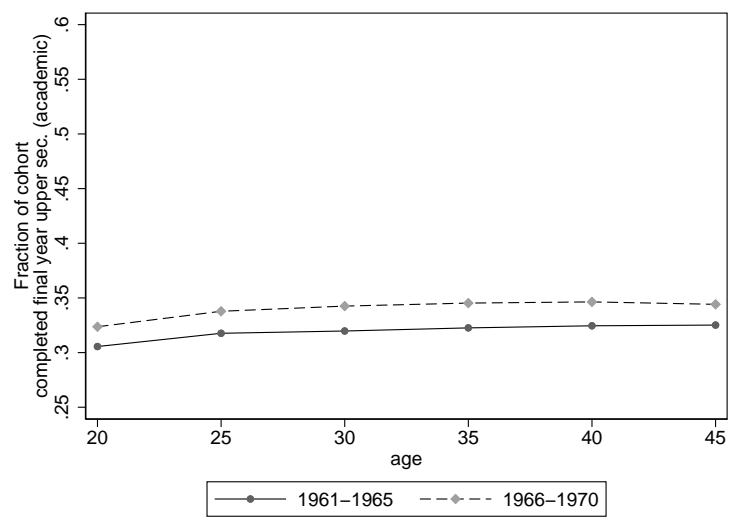

(d) Vocational - Males

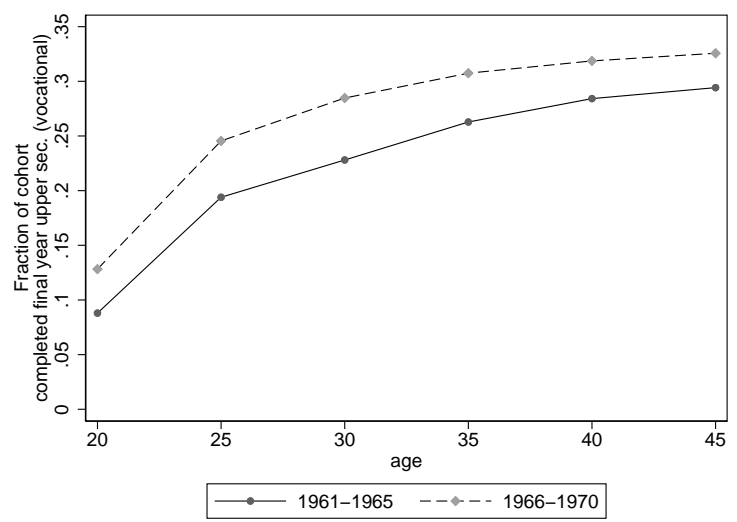

Figure plots the high school completion rate over the life cycle for birth cohorts 1961-1970 for academic and vocational high school, for women and men respectively. Academic high school prepares students for university education, while vocational high school is geared towards entry into the labor market directly after high school. 


\subsubsection{Years of Education and University Education}

Figure 9a replicates Figure 9b for years of education rather than high school completion. For females, increases in years of education later in life does not flatten off compared to high school completion while increases in years of education begin to flatten for men. Between 30-45, after the typical student has had the opportunity to complete university education, years of education increases by roughly 0.5 years for women and 0.25 years for men. Women complete more years of education than men at age 20, and this gender gap is expanding over the life cycle as years of education increases more for women than men.

Figure 9: Evolution of Years of Education Over the Life Cycle

(a) Female

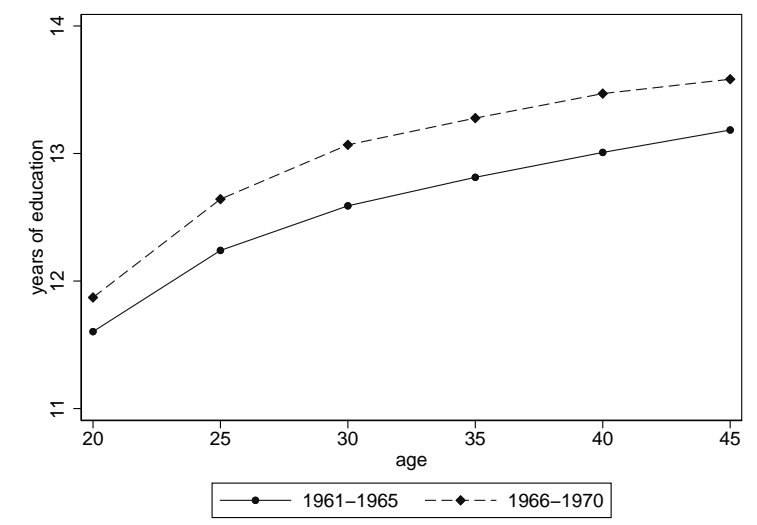

(b) Male

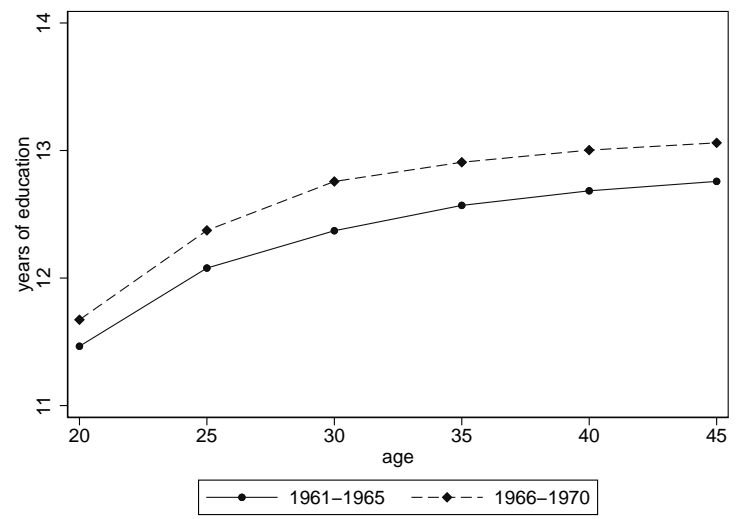

Figure plots average years of education over the life cycle for birth cohorts 1961-1970 for women and men respectively. Years of education measured as the typical number of years it takes a student to complete a specific qualification.

This suggests that, in addition to returning high school more at later ages, women may also return to higher education more than men later in life. Figures $\mathrm{Ba}$ and $\mathrm{Bb}$ in Appendix $\mathrm{C}$ plots the fraction of each birth cohort from 1961-1980 who complete any higher education at different ages for women and men respectively. Indeed, females complete higher education at a much higher rate than males. In addition, females also return to higher education later in life at much higher rates than men, as the age-education profile is much steeper later into the life cycle for women.

\subsection{Describing the Lifetime Earnings of Those Who Return to Education}

Traditionally, the completion of high school is thought to occur at (roughly) a similar age for all individuals. All else equal, earlier investments in education will have larger benefits over the life cycle as younger individuals who complete education on-time have more prime-age employment years to reap the labor market returns of the additional education relative to older individuals who return to education. In addition, the opportunity cost of completing high school, foregone wages while studying, 
will depend on the age of the worker. This cost of forgone earnings is likely lower at younger ages, as earnings potential increases with labor market experience.

When students all complete high school at the same age, the impact of completing high school on earnings can be estimated after completing high school, comparing those who graduate high school to those who drop out (abstracting from endogeneity concerns). Departing from the notion of ontime completion to later life completion complicates the estimation of education on lifetime earnings. However, understanding to what extent late completers can close the gap in earnings to on-time graduates, and to what extent younger late completers fare better than older late completers, is crucial to understand the labor market returns to returning to education. To do so requires a comparison of the evolution of earnings prior to study, during study, and after the completion of education. The subsequent figures focus on the evolution of earnings over the life cycle, from the ages of $18-45$, for all individuals born 1964-1970 who complete high school at different ages. ${ }^{11}$

While individuals here all endogenously return to high school, it remains informative to compare the evolution of earnings between on-time graduates and late completers of different ages over time. ${ }^{12}$ Throughout, age of high school completion is grouped into five bins: completed high school at 20 or younger (on-time), 24-26, 30-32, 36-38, and not completed by 45 .

\subsubsection{Final Year of Upper Secondary Education}

Figures 10a and 10b plot high school completion among the five groups including those who go onto complete higher education after high school. Excluding those who complete higher education, reported in Figures 10c and 10d, ignores the fact that the completion of high school leads to additional higher education. Indeed only $36 \%$ of those who finish high school on-time still have high school as their highest education level by age 45 .

For both women and men, those who return to education to complete high school at different ages later in life experience a slowdown in earnings growth prior to the completion of education. Prior to completing high school at $24-26$ and $30-32$, as indicated by the shaded regions of Figure 10, those who complete high school experience a decline in log earnings. Those who complete high school from 36-38 experience a slowdown in earnings growth prior to returning to education, particularly when compared to those who never complete high school by age 45 .

Quickly after completing high school education, earnings grow rapidly and continue to do so in

\footnotetext{
${ }^{11}$ Results using other birth cohorts display similar patterns.

${ }^{12}$ If one is willing to assume that age of completion is as good as random, then this is causal impact of returning to high school on earnings. However, the extent to which this assumption holds is questionable. Those who complete high school at age 30 had the opportunity to also complete high school at each age from 21-29, but chose not to do so. There are good reasons to believe why one returns to education later in life rather than earlier in life is due to a host of explanations (e.g. changing personal or family situations, changes in employment status, etc).
} 
Figure 10: Evolution of average earnings by different ages completed high school

(a) Females, Including Higher Education

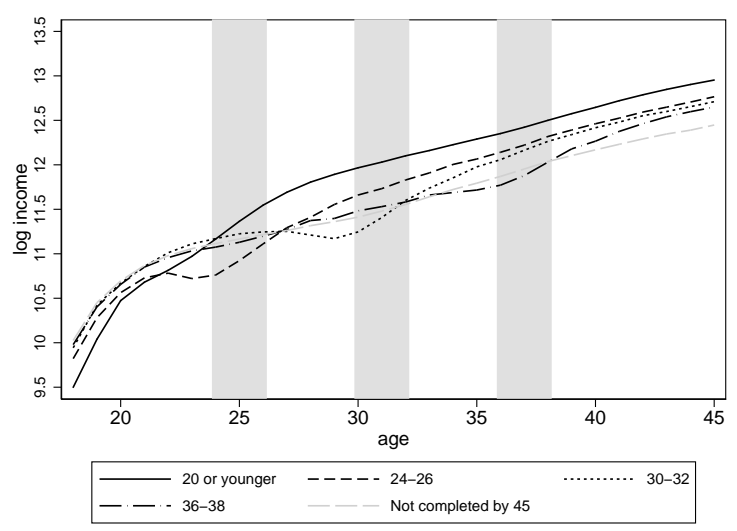

(c) Females, Excluding Higher Education

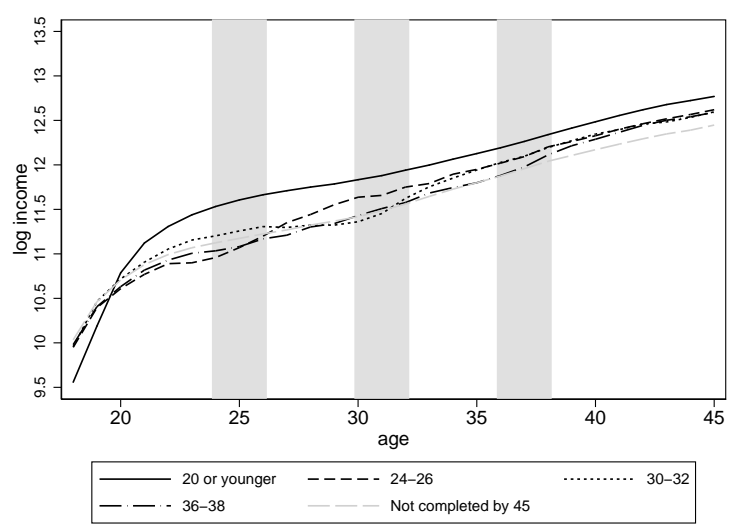

(b) Males, Including Higher Education

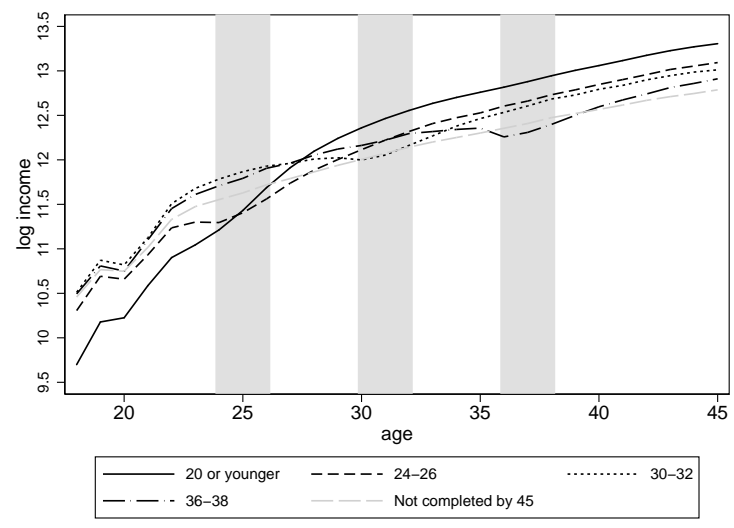

(d) Males, Excluding Higher Education

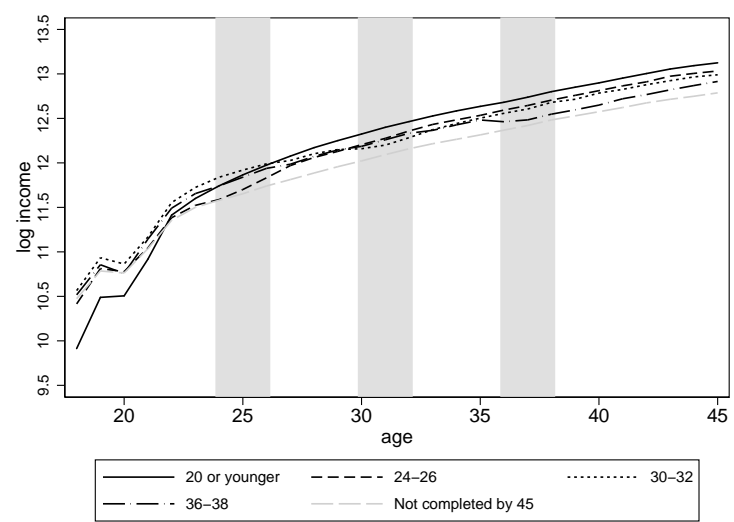

Figure plots, for women and men respectively, average of log earnings for on-time high school graduates, late graduates aged 24-26, 30-32, 36-38, and those who never complete high school by 45. Panels (a) and (b) exclude any person who continues after the completion of high school with a post-secondary degree, while panels (c) and (d) include all high school graduates irrespective of their eventual final degree by age 45. Birth cohorts 1964-1970. 
the years immediately after completing high school. As time goes on, the earnings growth of late completers slowly stabilizes to the earnings profile of on-time graduates. Despite this strong growth after completion, later completers never fully catch up to earnings levels of on-time graduates: while the earnings growth of late completers reaches the slope of on-time graduates, there is a persistent levels difference compared to on-time graduates. Despite this, the earnings of each of the late completer age groups is substantially higher than those who have not completed high school by age 45. Additionally, the age an individual returns to complete high school matters for their earnings by age 45 , as those who return earlier have earnings which more closely resemble earnings of on-time graduates. Those who endogenously return to education later in life experience short-run earnings penalties while studying which are more than compensated by higher earnings in each subsequent year after completion.

Figures 10c and 10d plot the earnings of those who complete high school at different ages, excluding those who continue onto any further education after high school. Such a sample permits the comparison of the value of a high school degree completed at different ages. ${ }^{13}$ Compared to Figures 10a and 10b which include higher education, the differences in age-earnings profiles across different ages of high school completion are much smaller. To the extent that late high school completers were to return to high school and go no further in the education system, then the age-earnings profiles of late completers between the Figures 10a and 10c for women and 10b and 10d for men would be exactly the same. Clearly this is not the case, suggesting that a fraction of late high school completers from ages 24-26, 30-32, and 36-38 also continue with education beyond high school.

Abstracting from endogeneity concerns, the difference between any two curves in Figures 10c and 10d represents the labor market premium to completing high school (and no further education) at a given age relative to another age. For instance, those who complete high school after 20 have higher earnings at younger ages than those who complete high school on-time. However, already by the early 20s, this difference has reversed and on-time graduates begin to earn higher levels.

Relative to each age of completion, there exists a discount rate $(\rho)$ which equalizes the present value of the two age-earnings profiles. We calculate the discount rate as in Bhuller, Mogstad, and Salvanes (2017):

$$
\sum_{a=18}^{45} \frac{\beta_{a}}{(1+\rho)^{a-17}}=0
$$

Table 1 reports the discount rates required to equalize the present value of earnings of on-time graduates to later life completers. Panel (a) calculates the required discount rate over the ages 18-45 while panel (b) calculates the discount rate over ages 18-64, assuming a stable difference in earnings from age 46 on. For simplicity, we focus on the discount rates in panel (b).

\footnotetext{
${ }^{13}$ The sample restricts to those who by age 45 still have high school as their highest level of education.
} 
First, the paper calculates the discount rate which equalizes the present value of earnings of ontime graduates and late completers 24-26. For females, a large discount rate is required to equalize the earnings of the two groups: $45 \%$ in Figure 10c (excluding higher education) and 27\% in Figure 10a (including higher education). Compared to women, the earnings penalty incurred by male on-time graudates is much larger and the lifetime gains compared to late completers are much smaller. As such, a much lower discount rate is required to equalize the present value of earnings of the two groups for men: $6.7 \%$ in Figure 10d (excluding post-secondary education) and 5.6\% in Figure 10b (including post-secondary). For comparison, Bhuller, Mogstad, and Salvanes (2017) report a discount rate of 9.3\% to equate the present value of earnings between two individuals with one year differences of education.

Second, the paper calculates the discount rate which equalizes the age-earnings profiles of on-time graduates and late completers aged 30-32. For both women and men, the discount rates which equalize the earnings of the two groups are lower compared to those which equalize on-time graduates and late completers 24-26. For women, a discount rate of 30\% in Figure 10c and 14\% in Figure 10a equalizes the age-earnings profiles. For men, a discount rate of $3.5 \%$ in Figure $10 \mathrm{~d}$ and $3 \%$ in Figure $10 \mathrm{~b}$ equalizes the age-earnings profiles.

While there are clearly selection issues in comparing late completers of different ages and ontime graduates, it is interesting that the discount rates are considerably lower for men compared to women. Among late completers 24-26, an age range when considerably more men return to complete high school relative to women, discount rates of $5-7 \%$ equalize the present value of earnings to ontime graduates. Such low discount rates suggest that more present-biased men may actually find it worthwhile to drop out of high school and return later in life, while the same cannot be said for women.

\subsubsection{Late Completion of Higher Education}

Figures 11a and 11b present the evolution of earnings for those who complete any post-secondary education from age 28 or younger, 29-31, 32-34, and 35-37 for women and men respectively. The dip in earnings among later life completers relative to those who graduate post-secondary education at 28 or younger is quite large. As before, late completers catch up in terms of the slope of lifetime earnings, but not the level.

\section{Returning to education and labor market outcomes}

Having described the phenomenon of returning to education and the age-earnings profiles of those who endogenously return to education throughout the life cycle, the paper exploits two major policy 
Table 1: Required Discount Rates to Equalize Earnings of Different Age of HS Completion Groups Discount Rate to Equal Age Group On-Time HS Graduates

(1) (2)

Females

\begin{tabular}{cc}
\hline Excluding & Including \\
Post-Secondary & Post-Secondary \\
(Figure 10c) & (Figure 10a)
\end{tabular}

$(3)$

\begin{tabular}{cc}
\multicolumn{2}{c}{ Males } \\
\hline Excluding & Including \\
Post-Secondary & Post-Secondary \\
(Figure 10d) & (Figure 10b)
\end{tabular}

\begin{tabular}{|c|c|c|c|c|}
\hline \multirow[b]{2}{*}{ On-time graduate } & \multicolumn{4}{|c|}{ Panel (a): earnings 18--45 } \\
\hline & \multicolumn{4}{|c|}{ ref. } \\
\hline $24-26$ & 0.4506 & 0.2743 & 0.0555 & 0.0356 \\
\hline \multirow[t]{2}{*}{$30-32$} & 0.3042 & 0.1405 & 0.0089 & 0.0005 \\
\hline & \multicolumn{4}{|c|}{ Panel (b): earnings 18-64 (assuming stable difference 46-64) } \\
\hline On-time graduate & \multicolumn{4}{|c|}{ ref. } \\
\hline $24-26$ & 0.4507 & 0.2746 & 0.0674 & 0.0552 \\
\hline $30-32$ & 0.3044 & 0.1441 & 0.0348 & 0.0304 \\
\hline Observations On-Time & 37195 & 120322 & 37734 & 108021 \\
\hline Observations $24-26$ & 2506 & 6685 & 7393 & 12745 \\
\hline Observations $30-32$ & 2722 & 5003 & 4797 & 6196 \\
\hline
\end{tabular}

Panel (a) measures earnings from 18-45, panel (b) assumes that the earnings difference at 45 persists in each future age.

Figure 11: Evolution of average earnings by different ages completed any post-secondary education

(a) Female

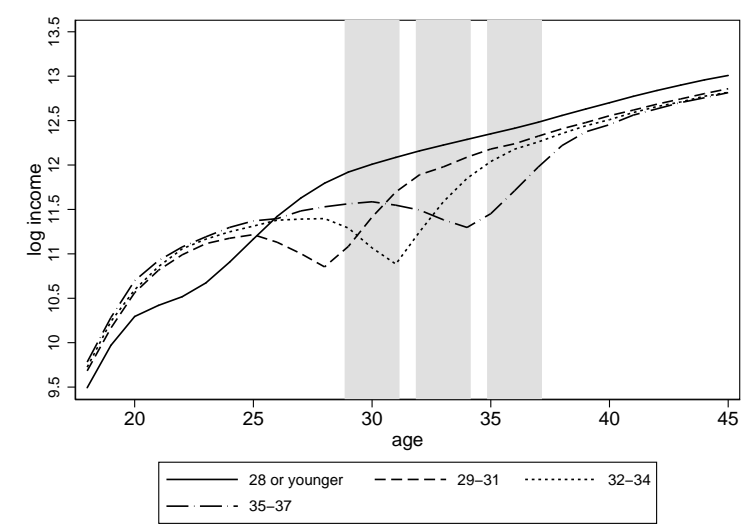

(b) Male

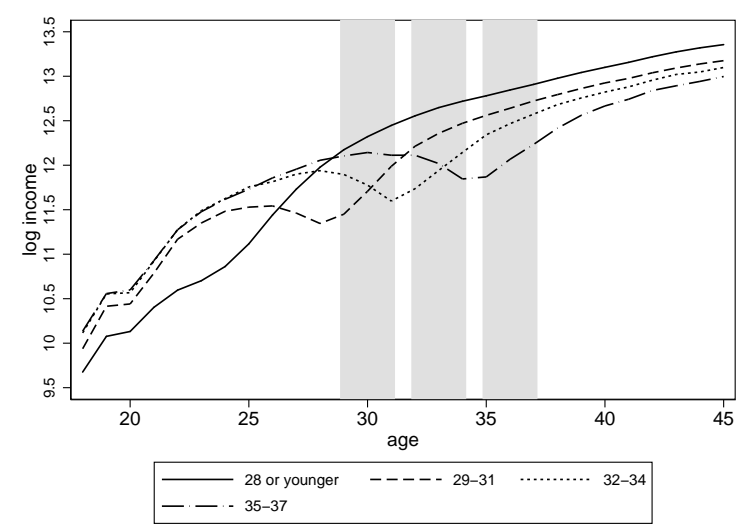

Figure plots, for women and men respectively, average of log earnings for on-time higher education graduates, late graduates aged 29-31, 32-34, and 35-37. Birth cohorts 1964-1970. 
reforms in the education system to assess whether returning to education at later stages in life has a causal impact on future labor market outcomes.

First, the Norwegian government introduced a law extending the legal right to enroll in high school education for any individual 25 or older (Lov 30 juni 2000 nr. 63, Kirke-, utdannings- og forskningsdepartementet, 2000). Coming into force in the 2000/2001 academic year, the law represented a marked change in policy. ${ }^{14}$ Prior to this change, the previous provision of education for those 25 and older was at the discretion of the county and reports at the time explicitly mention a lack of flexibility in the provision of such education from counties (Kirke-, utdannings- og forskningsdepartementet, 1999).

Second, from the 2003/2004 academic year, we exploit an overhaul of the student support system for students enrolled in upper secondary education. Such reform resulted in substantial changes in the level of financing and the criteria to be eligible to student support. Following this reform, any student aged 19 or older who lives away from their parents' home is entitled to an unconditional monthly stipend of 3,450NOK. Prior to this, those over 19 living away from home were only entitled means-tested support. The majority of students living away from home were employed and, after means-testing, this group was eligible to very little support. To put this into perspective, $3,450 \mathrm{NOK}$ represents a considerable stipend as it corresponds to $12 \%$ and $14 \%$ of median monthly earnings of similar aged workers. ${ }^{15}$ In addition to this unconditional monthly stipend, students remain eligible to means-tested grants up to a maximum of $1,730 \mathrm{NOK}$ depending on their own income.

Both reforms lower the opportunity cost of returning to education for those who have not yet completed high school. The introduction of the right to upper secondary education required counties to accept any student who was willing to return to high school where their prior inflexibility represented a barrier to enrollment. The overhaul of the student support system directly lowered the earnings penalty incurred from a reduction in hours spent in employment by providing a generous unconditional monthly stipend to return to education. In what follows, we allow for the possibility that both reforms impacted the probability that students will re-enroll in education and follow them before and after the implementation of both reforms.

\subsection{Defining the counterfactual}

Estimating the causal impacts of these two policy reforms on the education and labor market outcomes of high school dropouts requires a suitable counterfactual. Isolating such a counterfactual requires a

\footnotetext{
${ }^{14}$ The law is passed on 30 June 2000, after being proposed on 24 April 2000, and comes into force immediately after on 1 August 2000.

${ }^{15}$ Median income at the time of the change in 2003 of those aged $30-34$ is 28,185 NOK for men and $25,052 \mathrm{NOK}$ for women (Statistics Norway, Table 05218: Average monthly earnings for employees, full-time equivalents, by working hours, age-group and sex).
} 
similar group who is, at the same time, unimpacted by the reforms. Figure 10 suggests three potential groups: those who have completed high school on-time, those who never return to high school, and those who return to high school at even later ages.

On-time high school graduates are unlikely to be a suitable counterfactual. Figure 6 highlights the substantial differences in cognitive ability between on-time and on-time high school dropouts. As such, while on-time graduates are unimpacted by the two policy reforms examined as they have already completed high school, they also will have different trends in income compared to on-time high school dropouts in the absence of the educational reforms. This can be seen in Figures 10a and 10b. Likewise, those who never complete high school are also unsuitable as they choose not to take up the reform and using such a group is selected on post-reform outcomes (never returning to high school).

Given the incomparability of on-time graduates and never completers, we exploit variation in the age at which different birth cohorts are first exposed to the two policy reforms to use later exposed cohorts as a counterfactual for early exposed cohorts. Such an approach, combined with the educational reforms in the 2000s, provides a source of exogenous variation in the age at which different birth cohorts are exposed to the reforms. For instance, high school dropouts of the 1970 birth cohort are aged 30 at the first reform while dropouts of the 1967 cohort are aged 33. Thus, while all cohorts are eventually treated, the age at which they are exposed to the reform differs. The variation exploited is similar to recent papers exploiting the timing of the event in an event study framework (see e.g. Angelov, Johansson, and Lindahl, 2016; Kleven, Landais, and Søgaard, 2019), however, with the difference that we use educational reforms for identification.

\subsection{Empirical Specification}

To exploit variation in the age at which high school dropouts are exposed to the education reforms, we define two groups: early and later treated cohorts. Early treated cohorts are treated by the 2000 reform at age $a^{0}$ while later treated cohorts are treated by the 2000 reform from $a^{0}+\delta, \delta$ years later. In our baseline specification, $\delta=3$, and later treated cohorts are exposed to the same reforms three years after early treated cohorts. Early treated is defined as:

$$
\text { earlytreated }_{i}=\left\{\begin{array}{l}
1, \text { if } a^{0}=a \text { in year } 2000 \\
0, \text { otherwise }
\end{array}\right.
$$

As later treated are assigned 0 throughout time period, our estimated treatment effects compare differences in exposure to the two treatments, where later treated cohorts always serve as the counter- 
factual for early treated cohorts. ${ }^{16}$ Variation comes from the fact that while all cohorts are exposed at the same calendar year, the reforms affect different cohorts at different ages. Thus, we compare early and later treated cohorts at the same ages, and the panel dimension of the data is age, rather than calendar year.

Event time is calculated relative to $a^{0}=30,31,32,33$, a "base age" which indicates the age at which the early treated cohort is first treated in $2000 .{ }^{17}$ Event time is defined as time $=a-a^{0}$. As such, at time $=0$, the treated cohort is first treated by the 2000 reform. At time $=3$, the treated cohort is first treated by the 2003 reform, while the later treated cohort is first treated by the first 2000 reform. At time $=6$, the treated cohort continues to be treated by the 2003 reform while the later treated cohort is first treated by the 2003 reform. Table 2 depicts the variation of age at exposure for different birth cohorts from 1964-1970 included in the estimation sample.

Table 2: Variation in Exposure to Educational Reforms by Birth Cohort

\begin{tabular}{|c|c|c|c|c|c|c|c|c|}
\hline \multirow{2}{*}{$\begin{array}{c}\text { base age } a^{0}: \\
\text { cohort: } \\
\text { (early/later treated) } \\
\text { age }\end{array}$} & \multicolumn{2}{|c|}{30} & \multicolumn{2}{|c|}{31} & \multicolumn{2}{|c|}{32} & \multicolumn{2}{|c|}{33} \\
\hline & $\begin{array}{c}1970 \\
\text { (early) }\end{array}$ & $\begin{array}{c}1967 \\
\text { (later) }\end{array}$ & $\begin{array}{c}1969 \\
\text { (early) }\end{array}$ & $\begin{array}{l}1966 \\
\text { (later) }\end{array}$ & $\begin{array}{c}1968 \\
\text { (early) }\end{array}$ & $\begin{array}{c}1965 \\
\text { (later) }\end{array}$ & $\begin{array}{c}1967 \\
\text { (early) }\end{array}$ & $\begin{array}{c}1964 \\
\text { (later) }\end{array}$ \\
\hline 26 & -4 & -4 & & & & & & \\
\hline 27 & -3 & -3 & -4 & -4 & & & & \\
\hline 28 & -2 & -2 & -3 & -3 & -4 & -4 & & \\
\hline 29 & -1 & -1 & -2 & -2 & -3 & -3 & -4 & -4 \\
\hline 30 & 0 & 0 & -1 & -1 & -2 & -2 & -3 & -3 \\
\hline 31 & +1 & +1 & 0 & 0 & -1 & -1 & -2 & -2 \\
\hline 32 & +2 & +2 & +1 & +1 & 0 & 0 & -1 & -1 \\
\hline 33 & +3 & +3 & +2 & +2 & +1 & +1 & 0 & 0 \\
\hline 34 & +4 & +4 & +3 & +3 & +2 & +2 & +1 & +1 \\
\hline 35 & +5 & +5 & +4 & +4 & +3 & +3 & +2 & +2 \\
\hline 36 & +6 & +6 & +5 & +5 & +4 & +4 & +3 & +3 \\
\hline 37 & +7 & +7 & +6 & +6 & +5 & +5 & +4 & +4 \\
\hline 38 & +8 & +8 & +7 & +7 & +6 & +6 & +5 & +5 \\
\hline 39 & +9 & +9 & +8 & +8 & +7 & +7 & +6 & +6 \\
\hline$\vdots$ & $\vdots$ & : & $\vdots$ & : & $\vdots$ & : & $\vdots$ & $\vdots$ \\
\hline 44 & +14 & +14 & +13 & +13 & +12 & +12 & +11 & +11 \\
\hline Number of Females & 2633 & 3049 & 2806 & 3163 & 2864 & 3040 & 3014 & 3101 \\
\hline Number of Males & 2325 & 2489 & 2245 & 2323 & 2166 & 2199 & 2263 & 2161 \\
\hline
\end{tabular}

Table depicts the variation in age at exposure among early and later treated cohorts of base ages $a^{0}=30, \ldots, 33$. Dark gray corresponds to ages outside of the sample window. Light gray corresponds to ages prior to the introduction of the first of the two education reforms. Dark blue corresponds to exposure to the first education reform, while light blue corresponds to exposure to the second education reform.

By defining time with respect to $a^{0}$, the event study approach compares the age-education and age-earnings profiles among high school drop outs of different birth cohorts who are exposed to the educational reforms of the 2000s at different ages. The paper estimates the following event study regression separately for women and men:

\footnotetext{
${ }^{16}$ Similar approaches are taken in Nekoei and Seim (2018); Fadlon and Nielsen (2019), where the counterfactual group is treated in the future.

${ }^{17}$ Section 5.5 details the comparison of younger and older base ages.
} 


$$
y_{i j l t}=\sum_{k=-4}^{14} \delta_{k} D_{i t}^{k \text { years after } 2000 \text { reform }}+\tau_{t}+\psi_{j}+\gamma_{l}+u_{i j l t}
$$

where the estimated $\delta_{k}$ coefficients corresponds to the treatment effect comparing early to late treated in time $t$ ( $k$ years after the 2000 reform) for individual $i . D_{i t}^{k}$ years after 2000 reform is defined as:

$$
\left\{\begin{array}{l}
=1, \text { if } \text { earlytreated }_{i}=1 \text { and } \text { time }=k \\
=0, \text { otherwise. }
\end{array}\right.
$$

In results that follow, $y_{i t}$ corresponds to one of five different outcomes of individual $i$ in year $t$ : three education measures - years of completed education, a binary variable indicating the completion of high school, and a binary variable indicating the completion of higher education - and two labor market outcomes - log of annual labor earnings and a binary variable indicating employment.

The coefficient $\delta_{k}$ for $k=0, \ldots, 14$ is the impact of the educational reform $k$ years after the 2000 reform on one of these outcomes. The pre-reform coefficients $\delta_{-4}, \ldots, \delta_{-1}$ reveal whether early and later treated individuals had any existing pre-reform trends in the relevant outcome variable. The coefficient $\delta_{-1}$ is conventionally set to zero, such that the estimated difference is interpreted relative to the difference between early treated and later treated individuals in $k=-1$. That is, we fix the difference in outcomes at age $a^{0}-1$ to be constant and ask whether the differences over time are significantly different between the early and later treated groups (relative to the difference between the two groups). $\tau_{t}$ corresponds to age fixed effects within a given base age $a^{0} . \psi_{j}$ corresponds to pre-reform sector fixed effects, where sector is defined as manufacturing, public, employed in any other sector, or non-employed (no sector). $\gamma_{l}$ corresponds to fixed effects for the age which a student first left the education system and dropped out of high school, where $l=16, \ldots, 20$. Standard errors are clustered at the municipality level.

Exploiting the variation in the ages at which different birth cohorts are exposed to the same reforms requires the identifying assumption that in the absence of the first education reforms in 2000, the education/labor market outcomes of early and later treated groups would have evolved the same over the life cycle. This implies that had early treated cohorts (and eventually later treated groups) not been exposed to the reform in 2000, they would have continued to experience the same changes in education/labor market outcomes over the same ages. The parallel trends assumption hinges on the fact that the age at which high school dropouts of different birth cohorts are exposed to the first educational reform is as good as random. Given the speed at which the law in 2000 was passed and implemented - the eventual change was proposed 28 April 2000, passed 30 June, and came into force as of 1 August - this seems plausible. The rapid implementation of the law and the inflexibility of the 
education system prior to the change (St.meld. nr. 32 (1998-99)) also limits the scope for anticipation.

\subsubsection{Defining the sample}

The paper isolates a sample of on-time high school dropouts by imposing three sample restrictions. First, the sample is restricted to those who have completed either one or two years of high school, but left education at age 20 or younger having not finished high school. Second, the sample is restricted to those who, at time -6 , have still not completed high school prior to the reform. To the extent that high school dropouts return to education at different levels prior to the 2000 reform, this will be reflected in the estimated pre-reform coefficients $\delta_{-4}, \delta_{-3}$, and $\delta_{-2}$. Third, we exclude anyone, among both early and later treated cohorts, who completed a vocational education qualification under the Practical Candidate Scheme (PCS). The PCS offers an out of classroom opportunity for workers in a specific vocation to document their on the job knowledge and skills and received a vocational education diploma at the high school level. The comparison between early and later treated is complicated by the expansion of the PCS in the 1990s prior to these reforms. To abstract from the potential confounding of the expansion of the practical candidate scheme, any individual who completes a vocational qualification under the Practical Candidate Scheme is dropped from the analysis below.

Table 3 describes the estimation sample of high school dropouts in time -1 for women and men, comparing early and later treated cohorts. Early and later treated cohorts are similar on observable characteristics, while early treated cohorts come from slightly more educated families and are slightly less likely to be married. There exist strong gender differences in the sample of high school dropouts. On average, women have 1.6 children while men have only 0.9 children and while $51 \%$ of women are employed, $70 \%$ of men are. Unsurprisingly, the sample of high school dropouts in Table 3 are in the lower part of the national earnings distribution, where the average labor earnings of women correspond to the $28^{\text {th }}$ percentile while men correspond to the $22^{\text {nd }}$ percentile (see Figure $\mathrm{G}$ ).

\subsubsection{Accounting for comparability of different birth cohorts}

As the event study framework exploits variation across different birth cohorts, changes in demographic characteristics over time may affect the similarity of early and later treated. For instance, early treated cohorts have slightly higher levels of parental education than later treated cohorts in Table 3 . One potential reason for this is that parental education levels are slowly increasing over time as younger birth cohorts become increasingly educated. ${ }^{18}$ As such, pre-treatment differences in the composition of the sample between early and later treated cohorts may affect the dynamics of the outcome variable post-reform, violating the parallel trends assumption. Abadie (2005); Blundell and Dias (2009) show

\footnotetext{
${ }^{18}$ Figure 2 suggests this is the case as the on-time completion rate increases from birth cohorts 1961-1965 to 1976-1980.
} 
Table 3: Describing the Estimation Sample

\begin{tabular}{|c|c|c|c|c|c|c|}
\hline & \multicolumn{3}{|c|}{ Female } & \multicolumn{3}{|c|}{ Male } \\
\hline & $\begin{array}{c}(1) \\
\text { Early } \\
\text { Treated }\end{array}$ & $\begin{array}{c}(2) \\
\text { Late } \\
\text { Treated }\end{array}$ & $\begin{array}{c}(3) \\
\text { Both }\end{array}$ & $\begin{array}{c}(4) \\
\text { Early } \\
\text { Treated }\end{array}$ & $\begin{array}{c}(5) \\
\text { Late } \\
\text { Treated }\end{array}$ & $\begin{array}{c}(6) \\
\text { Both }\end{array}$ \\
\hline \multicolumn{7}{|l|}{ Parental Education: } \\
\hline Frac. at least one parent highly educated & $\begin{array}{c}0.327 \\
(0.469)\end{array}$ & $\begin{array}{c}0.288 \\
(0.453)\end{array}$ & $\begin{array}{c}0.306 \\
(0.461)\end{array}$ & $\begin{array}{c}0.342 \\
(0.474)\end{array}$ & $\begin{array}{c}0.293 \\
(0.455)\end{array}$ & $\begin{array}{c}0.317 \\
(0.465)\end{array}$ \\
\hline \multicolumn{7}{|l|}{ Fertility and Household: } \\
\hline Frac. first birth age 25 or younger & $\begin{array}{c}0.563 \\
(0.496)\end{array}$ & $\begin{array}{c}0.546 \\
(0.498)\end{array}$ & $\begin{array}{c}0.554 \\
(0.497)\end{array}$ & $\begin{array}{c}0.258 \\
(0.438)\end{array}$ & $\begin{array}{c}0.263 \\
(0.440)\end{array}$ & $\begin{array}{c}0.261 \\
(0.439)\end{array}$ \\
\hline number of children & $\begin{array}{c}1.559 \\
(1.053)\end{array}$ & $\begin{array}{c}1.550 \\
(1.055)\end{array}$ & $\begin{array}{c}1.554 \\
(1.054)\end{array}$ & $\begin{array}{c}0.910 \\
(1.010)\end{array}$ & $\begin{array}{c}0.948 \\
(1.026)\end{array}$ & $\begin{array}{c}0.929 \\
(1.018)\end{array}$ \\
\hline Frac. with children & $\begin{array}{c}0.802 \\
(0.398)\end{array}$ & $\begin{array}{c}0.798 \\
(0.402)\end{array}$ & $\begin{array}{c}0.800 \\
(0.400)\end{array}$ & $\begin{array}{c}0.539 \\
(0.498)\end{array}$ & $\begin{array}{c}0.554 \\
(0.497)\end{array}$ & $\begin{array}{c}0.547 \\
(0.498)\end{array}$ \\
\hline Frac. married & $\begin{array}{c}0.436 \\
(0.496)\end{array}$ & $\begin{array}{c}0.475 \\
(0.499)\end{array}$ & $\begin{array}{c}0.457 \\
(0.498)\end{array}$ & $\begin{array}{c}0.271 \\
(0.444)\end{array}$ & $\begin{array}{c}0.317 \\
(0.466)\end{array}$ & $\begin{array}{c}0.295 \\
(0.456)\end{array}$ \\
\hline \multicolumn{7}{|l|}{ Base Ages: } \\
\hline Frac. base age 30 & $\begin{array}{c}0.233 \\
(0.423)\end{array}$ & $\begin{array}{c}0.243 \\
(0.429)\end{array}$ & $\begin{array}{c}0.238 \\
(0.426)\end{array}$ & $\begin{array}{c}0.258 \\
(0.438)\end{array}$ & $\begin{array}{c}0.267 \\
(0.443)\end{array}$ & $\begin{array}{c}0.263 \\
(0.440)\end{array}$ \\
\hline Frac. base age 31 & $\begin{array}{c}0.248 \\
(0.432)\end{array}$ & $\begin{array}{c}0.255 \\
(0.436)\end{array}$ & $\begin{array}{c}0.252 \\
(0.434)\end{array}$ & $\begin{array}{c}0.251 \\
(0.434)\end{array}$ & $\begin{array}{c}0.253 \\
(0.435)\end{array}$ & $\begin{array}{c}0.252 \\
(0.434)\end{array}$ \\
\hline Frac. base age 32 & $\begin{array}{c}0.253 \\
(0.435)\end{array}$ & $\begin{array}{c}0.247 \\
(0.431)\end{array}$ & $\begin{array}{c}0.250 \\
(0.433)\end{array}$ & $\begin{array}{c}0.241 \\
(0.428)\end{array}$ & $\begin{array}{c}0.241 \\
(0.428)\end{array}$ & $\begin{array}{c}0.241 \\
(0.428)\end{array}$ \\
\hline Frac. base age 33 & $\begin{array}{c}0.266 \\
(0.442)\end{array}$ & $\begin{array}{c}0.255 \\
(0.436)\end{array}$ & $\begin{array}{c}0.260 \\
(0.439)\end{array}$ & $\begin{array}{c}0.250 \\
(0.433)\end{array}$ & $\begin{array}{c}0.239 \\
(0.426)\end{array}$ & $\begin{array}{c}0.245 \\
(0.430)\end{array}$ \\
\hline Frac. early treated & $\begin{array}{c}1 \\
(0)\end{array}$ & $\begin{array}{c}0 \\
(0)\end{array}$ & $\begin{array}{c}0.475 \\
(0.499)\end{array}$ & $\begin{array}{c}1 \\
(0)\end{array}$ & $\begin{array}{c}0 \\
(0)\end{array}$ & $\begin{array}{c}0.492 \\
(0.500)\end{array}$ \\
\hline \multicolumn{7}{|l|}{ Labor Market: } \\
\hline employed $20+$ hours/week & $\begin{array}{c}0.502 \\
(0.500)\end{array}$ & $\begin{array}{c}0.516 \\
(0.500)\end{array}$ & $\begin{array}{c}0.509 \\
(0.500)\end{array}$ & $\begin{array}{c}0.715 \\
(0.451)\end{array}$ & $\begin{array}{c}0.686 \\
(0.464)\end{array}$ & $\begin{array}{c}0.700 \\
(0.458)\end{array}$ \\
\hline log of labor earnings & $\begin{array}{c}11.47 \\
(1.102)\end{array}$ & $\begin{array}{c}11.46 \\
(1.061)\end{array}$ & $\begin{array}{c}11.46 \\
(1.081)\end{array}$ & $\begin{array}{c}12.16 \\
(0.839)\end{array}$ & $\begin{array}{c}12.08 \\
(0.782)\end{array}$ & $\begin{array}{c}12.12 \\
(0.811)\end{array}$ \\
\hline \multicolumn{7}{|l|}{ Education: } \\
\hline years of education & $\begin{array}{c}12.21 \\
(1.033)\end{array}$ & $\begin{array}{c}12.22 \\
(0.942)\end{array}$ & $\begin{array}{c}12.22 \\
(0.987)\end{array}$ & $\begin{array}{c}12.15 \\
(1.076)\end{array}$ & $\begin{array}{c}12.17 \\
(1.064)\end{array}$ & $\begin{array}{c}12.16 \\
(1.070)\end{array}$ \\
\hline Frac. completed HS & $\begin{array}{c}0.128 \\
(0.334)\end{array}$ & $\begin{array}{c}0.115 \\
(0.319)\end{array}$ & $\begin{array}{c}0.121 \\
(0.326)\end{array}$ & $\begin{array}{c}0.146 \\
(0.353)\end{array}$ & $\begin{array}{c}0.140 \\
(0.347)\end{array}$ & $\begin{array}{c}0.143 \\
(0.350)\end{array}$ \\
\hline age first dropped out & $\begin{array}{c}17.90 \\
(1.142)\end{array}$ & $\begin{array}{c}17.89 \\
(1.178)\end{array}$ & $\begin{array}{c}17.90 \\
(1.161)\end{array}$ & $\begin{array}{c}17.91 \\
(1.131)\end{array}$ & $\begin{array}{c}17.75 \\
(1.188)\end{array}$ & $\begin{array}{c}17.83 \\
(1.162)\end{array}$ \\
\hline Individuals & 11358 & 12565 & 23923 & 9041 & 9326 & 18367 \\
\hline
\end{tabular}

Sample: base ages 30-33 who dropped out of high school as described in Section 4.2.1. All variables measured at time -1 , unless otherwise indicated. 
that weighting the regression by an estimated propensity score accounts for such differences. ${ }^{19}$

Focusing on later treated cohorts 3 years after limits the scope for major differences, as the cohorts are not born that far apart. However, the paper accounts for potential differences between early and later treated cohorts by weighting the event study regression by the inverse propensity score. As a first step, we estimate propensity scores predicting the probability of being in the early treated group (compared to the later treated group). The propensity score is estimated using data one year prior to the 2000 reform in time $=-1$ and used in all time periods from time $=-4, \ldots,+14$. The propensity score is estimated by matching early and later treated individuals in on: 3 binary variables indicating at least one highly educated parent, first birth at age 25 or younger, and married (measured at -1 ); binary variables for age of first drop outs (5 categories, 16-20); binary variables for broad field of study left high school with (10 broad categories); the number of children (measured at -1 , including zeros); birth municipality; 2 digit industry dummies (measured at -1); and base age.

Following Mastrobuoni and Pinotti (2015), the inverse propensity scores are then used to weight the event study regression by:

$$
\text { treated } \frac{p}{P\left(X_{i}\right)}+(1-\text { treated }) \frac{1-p}{1-P\left(X_{i}\right)}
$$

where $p$ is the unconditional probability of early treatment and $P\left(X_{i}\right)$ is the conditional probability of treatment (the estimated propensity score). Intuitively, this method increases the weight of those in the later treated group with similar characteristics to the early treated group and weights down those in the later treated group with differences in the estimated propensity score. Appendix Figure H plots the estimated propensity scores, revealing substantial overlap between early and later treated. This suggests that, on the whole, the two groups are relatively similar in terms of the matching variables. ${ }^{20}$

Busso, DiNardo, and McCrary (2014) show that with a large number of observations, non-bootstrapped standard errors are a reasonable approximation when weighting by the inverse propensity score. ${ }^{21}$ The paper reports non-bootstrapped standard errors throughout. Indeed, Mastrobuoni and Pinotti (2015) establish the similarity between bootstrapped and non-bootstrapped standard errors.

\subsubsection{Controlling for differences in local economic conditions}

A limitation of exploiting variation across ages and using age as the panel dimension is that at the same time $t$, early and later treated cohorts are in different calendar years. For instance, at $t=0$,

\footnotetext{
${ }^{19}$ Similar approaches are taken in Mastrobuoni and Pinotti (2015); Pohlan (2019); Goodman-Bacon and Cunningham (2019).

${ }^{20}$ As such, results are similar when using the unweighted event study regression.

${ }^{21}$ While typically bootstrapping does not produce valid standard errors in matching, this is not the case when weighting by the inverse propensity score (Abadie and Imbens, 2008).
} 
the early treated cohort is in year 2000 while the later treated cohort is in year 1997. This implies that two people who live in the same local area face different economic conditions at the same point in event time. Likewise, two people who are in the same employment sector face different economic conditions. Note that time and year effects cannot be separated, as there is no group in the estimation sample which is never treated. To account for such differences, we make use of the population data and construct, separately for each gender, two fixed effects which we then merge into our base age sample.

Using data on all workers aged 25-54 who have not completed high school from 1993-2014, we construct two fixed effects: (a) municipality $\times$ year and (b) initial field of study $\times$ year. We define field of study at high school as the field of study an individual in the base age sample first dropped out of education with, as they all completed some high school yet did not finish. These two fixed effects account for differences in local economic conditions and time-varying shocks which affect early and later treated who dropped out of education in the same field of study and live in the same municipality differently. We make use of these fixed effects estimated on the entire population of dropouts in the estimation for income (Figure 13a) and employment (Figure 13b).

\subsection{The Estimated Impact of Educational Reforms on Education and Labor Mar- ket Outcomes}

Figure 12 reports estimates of equation 2 for the three education variables for the sample of women: the completion of high school, years of education, and the completion of higher education. Immediately after the reform in 2000, high school completion and years of education remain unchanged (Figures 12a and $12 \mathrm{~b}$ respectively). Following the 2003 student financing reform, education begins to increase among early treated and peaks at +6 . Six years after the first reform, high school completion among early treated increases by $1.3 \mathrm{ppt}(10.5 \%$ of the mean in -1$)$ and years of education increases by 0.084 years $(0.7 \%)$. Both effects are significant at 5 and $1 \%$ respectively. Importantly, estimated pre-event coefficients are small in magnitude and not significantly different from zero, indicating that the age-education profiles of early and later treated cohorts are parallel before the first reform in 2000.

As time goes on and the later treated cohort is also exposed to the second reform, increases in education among early treated begin to fade out. In the longer run, high school completion of early treated is not significantly different from zero. Years of education, however, remains higher among early treated compared to later treated individuals, an effect which is significant at the $5 \%$ level. The difference between the two sets of results can be explained by differences in the probability of continuing with higher education among the early treated cohorts, reported in Figure 12c. While 
some later treated individuals also continue into higher education, as evidenced by the decline in the estimated coefficient from its peak at +6 , the probability of continuing past high school is higher among early treated women. As such, there are persistent increases in the probability of completing higher education among early treated women: 14 years after the reform in 2000, early treated women are 1 ppt more likely to have higher education ( $24 \%$ of the mean in -1$)$.

Differences in the completion of higher education between early and later treated women reveal that the age of returning to high school may matter for the probability of continuing further in the education system. Such results suggest that in order to maximize educational attainment later in life, policies encouraging individuals to return to finish high school at younger ages would have larger effects on higher education. As later treated are exposed 3 years later to each of the two reforms, they are also 3 years closer to retirement. As such, those in the later treated group may find it too costly to forego additional years of earnings to return to higher education while the early treated group may not. However, age of exposure to the two reforms seems to matter less for returning to high school, as both early and later treated women complete high school at roughly the same rates.

Corresponding with the observed increases in education, labor earnings (Figure 13a) and full-time employment, defined as at least 30 hours per week, (Figure 13b) also increase among women. The timing of the changes in labor market outcomes coincide with changes in education: as early treated women complete education, labor market outcomes begin to increase and when later treated cohorts return to education, the increases in labor market outcomes stabilize or even decline. In the long run 14 years after the early treated cohorts are exposed to the 2000 reform, earnings increase by roughly $5 \%$ and employment increases by 3 ppt (8.3\%) relative to later treated cohorts. Increases in earnings are similar irrespective of whether or not benefits are included in the measure of labor earnings.

\subsubsection{Reducing the Gender Earnings Gap}

Results for males are reported in Appendix G. On the whole, the two education reforms have no discernible impact on the education of men. Figure 2 provides insight into why: a substantial fraction of male high school dropouts already return to high school at earlier ages in the life cycle compared to women. As men are substantially more likely to return to high school from 20-30 compared to women, it is unsurprising that men are not induced by the two education reforms examine to return to high school education in their early 30s. For instance, for those born 1966-1970, the early treated birth cohorts, the high school completion rate of men is 7.4 percentage points less than that of women at age 20 . However, by age 30, the gap has reversed and men are 1.6 percentage points more likely to have completed high school.

Taking the reduced form coefficients for labor earnings for women and for men, Figure 14 plots 
(a) Completion of High School

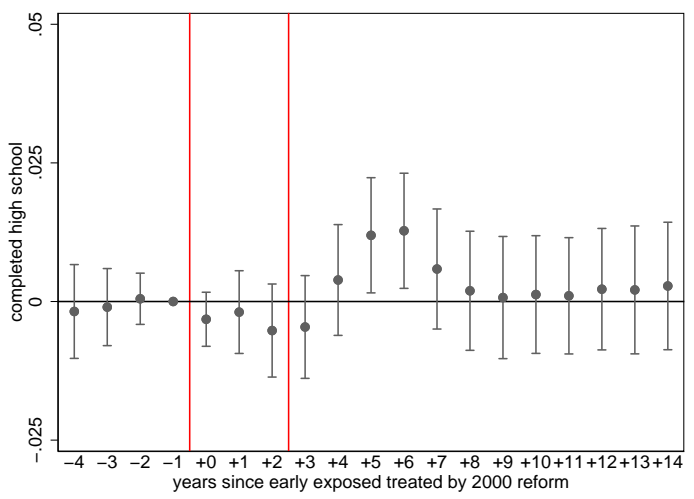

(b) Years of Education

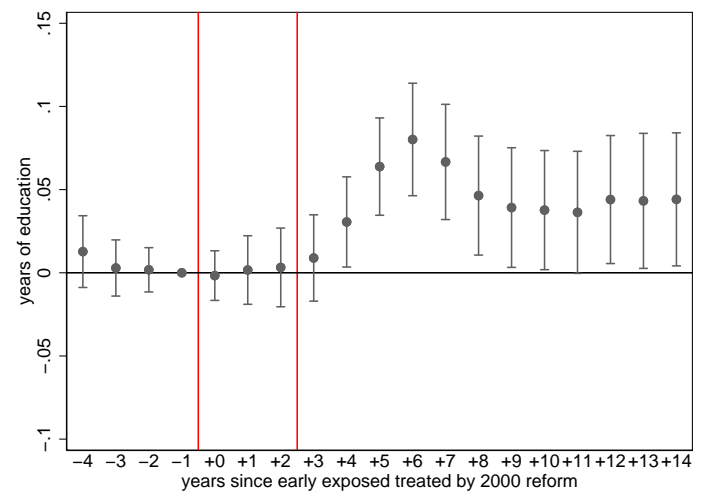

(c) Completion of Higher Education

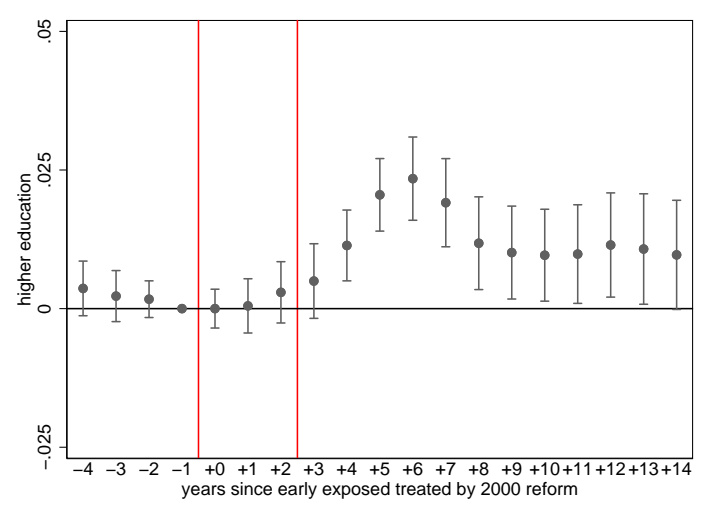

Figure plots estimates of equation (2), weighted by estimated propensity score in -1 as described in Section 4.2.2. Each point represents the difference in the outcome variable between early and later treated cohorts at a specific point in time, relative to the same difference in -1. Panel (a) defines education as equal to 1 if completed the final year of high school. Panel (b) defines education as the number of years of education. Panel (c) defines education as equal to 1 if completed higher education. Sample of females of base ages 30-33. 95\% confidence interval reported.

Figure 13: Labor Market Outcomes

(a) Log of Labor Earnings

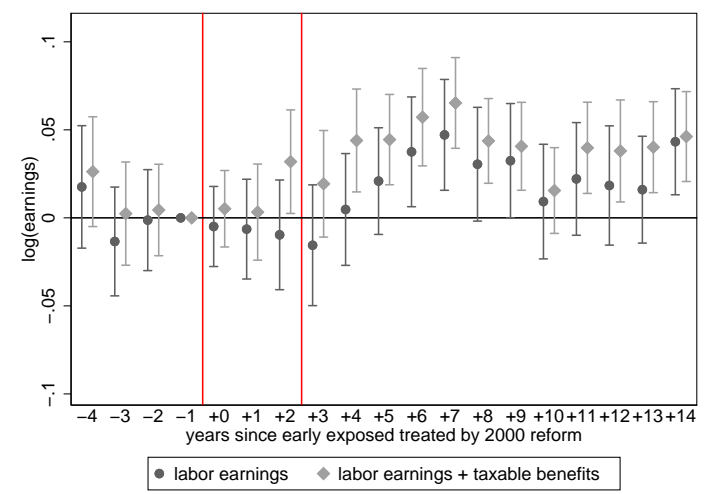

(b) Employed Full-Time

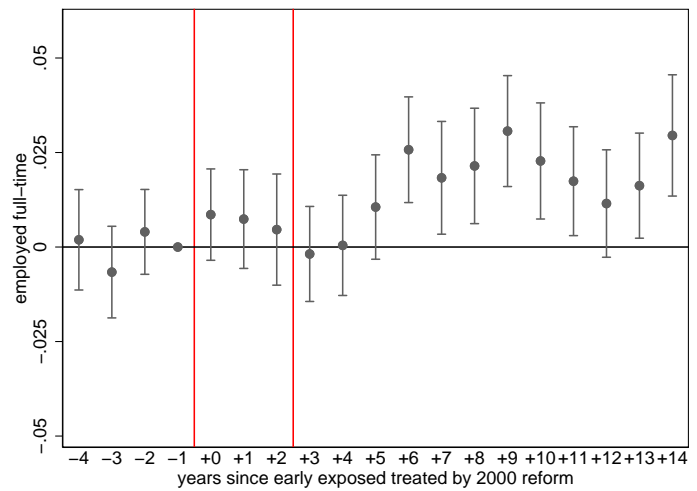

Figure plots estimates of equation (2), weighted by estimated propensity score in -1 as described in Section 4.2 .2 . Each point represents the difference in the outcome variable between early and later treated cohorts at a specific point in time, relative to the same difference in -1 . Controls for municipality $\times$ year and initial field of study $\times$ year fixed effects as described in Section 4.2.3. Two earnings measures in panel (a) correspond to the log of annual labor earnings and the log of annual labor earnings also including sickness, unemployment, and parental leave benefits. Panel (b) defines employment as equal to 1 if working at least 30 hours per week. Sample of females of base ages 30-33. 95\% confidence interval reported. 
the comparison of predicted log earnings over the life cycle for early treated women and men. As men do not return to education, their earnings steadily increase post-reform, while women see much larger growth in earnings after returning to education. As such, later life education closes the gap in labor earnings between early treated women and men: by +14 , the gender gap has closed by $42 \%$ from its -1 value, from $0.53 \log$ points to $0.31 \log$ points.

Figure 14: Log of Labor Earnings, Gap Between Women and Men as Predicted by Reduced Form Regression

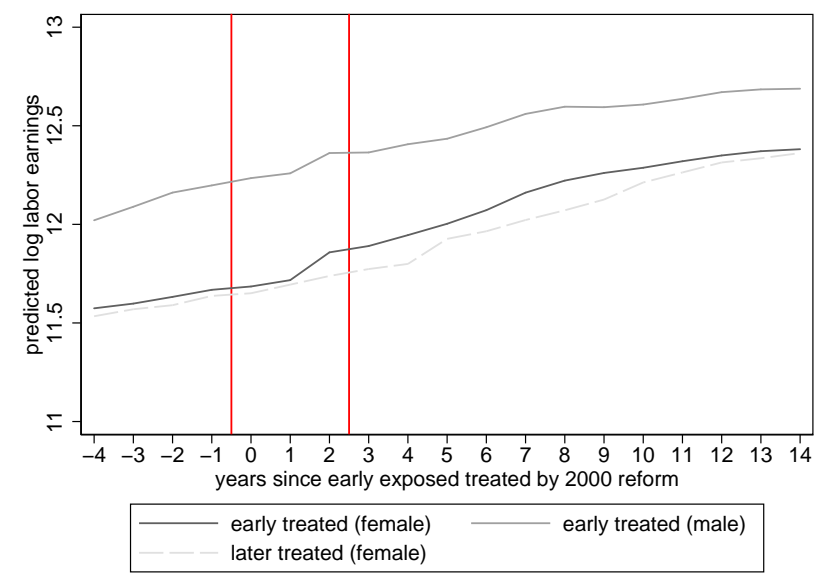

Figure plots the log of annual labor earnings (including taxable benefits), as predicted by estimation of equation (2), for early treated females, early treated males, and late treated females (for comparison). Gender gap in log earnings is 0.53 $\log$ points in -1 .

\subsection{The Channels From Later Life Education to Labor Market Outcomes}

We first present the reduced form estimates of the impact on years of education, earnings, hours and employment. We use this analysis to estimate the impact of additional years of education on employment and earnings, as well as on the quality of jobs. To further understand the estimated impacts we examine the employment impacts by pre-reform number of children. We develop this analysis by estimating the impact of the education reforms on fertility.

\subsubsection{The impact on later life education, earnings and employment}

Table 4 presents the reduced form estimates across four outcomes: annual earnings, hourly labor earnings, a binary variable indicating full-time employment, and years of education. These regressions reflect the labor market responses seen in Figure 13. The results in Table 4 correspond to a differencein-differences regression over all time periods, where the reported estimates represent the interaction between an indicator for early treated and the entire post-reform period. As later treated cohorts always serve as a counterfactual for early treated cohorts and their treatment status never changes, the reduced form coefficients of Table 4 represent the average of all $\delta_{k}$ for $k \geq 0$ in equation (2). 
Table 4: Estimated Impact on Labor Market and Education Outcomes, Averaged Over Post-Reform Period

\begin{tabular}{|c|c|c|c|c|}
\hline & \multicolumn{3}{|c|}{ Labor Market Outcomes } & \multirow{2}{*}{$\begin{array}{c}\text { Education } \\
(4) \\
\text { Years } \\
\text { of } \\
\text { Education }\end{array}$} \\
\hline & $\begin{array}{c}\text { (1) } \\
\text { Log } \\
\text { Annual } \\
\text { Earnings }\end{array}$ & $\begin{array}{c}(2) \\
\text { Log } \\
\text { Hourly } \\
\text { Earnings }\end{array}$ & $\begin{array}{c}(3) \\
\text { Employed } \\
\text { Full } \\
\text { Time }\end{array}$ & \\
\hline Early Treated $\times$ Post & $\begin{array}{c}0.0276^{* * *} \\
(0.0095)\end{array}$ & $\begin{array}{c}0.0029 \\
(0.0111)\end{array}$ & $\begin{array}{c}0.0159^{* * *} \\
(0.0053)\end{array}$ & $\begin{array}{c}0.0361^{* * *} \\
(0.0135)\end{array}$ \\
\hline $\mathrm{N}$ & 295594 & 295594 & 378630 & 378630 \\
\hline Avg. Reduced Form Outcome in -1 & 11.813 & 4.892 & 0.361 & 12.215 \\
\hline \multicolumn{5}{|c|}{$\begin{array}{l}\text { Sample of early and later treated women, base ages } 30-33 \text {, from }-1-+14 \text {. Column }(1) \text { additionally } \\
\text { restricts to women who have positive hours worked in a given year. Each column regresses one of } 3 \\
\text { outcomes on the interaction between early treated and a post-reform indicator equal to } 1 \text { from time } \\
+0-+14 \text {. Column (1) measures annual earnings from employment and column (2) measures hourly } \\
\text { labor earnings, }(\text { annual earnings } \\
\text { than hours } 30 \text { hours per week. Column }(3) \text { measure employment as equal to } 1 \text { if working more } \\
\text { thame mosures years of education. Coefficients interpreted relative to } \\
\text { omitted }-1 \text {. Employment outcome variables measured as hours worked per week in a worker's main } \\
\text { employment relationship at end of November. }\end{array}$} \\
\hline
\end{tabular}

Compared to the increase in annual labor earnings in Figure 13a, the increase in hourly labor earnings is much smaller, and not significantly different from zero. ${ }^{22}$ Such a large change when accounting for differences in hours worked between early and later treated suggests that the bulk of the labor market impact of later life education comes through employment response rather than through an increase in wages. Early treated women see increases in full-time employment post-reform and, on average over the post-reform period, full-time employment is $4.5 \%$ higher relative to a low pre-reform level of 0.36 . Indeed, the sample of high school dropouts is not that attached to the labor force, as $31 \%$ of women are classified as outside of the labor force in -1 (column (1), Table 5).

Table 5 presents the estimated employment response across 4 variables corresponding to different measures of labor market status: outside of the labor force, employed less than 20 hours per week, 20-29 hours per week, and 30+ hours per week (full-time employment). The results of Table 5 reveal whether the observed increase in full-time employment in Table 4 originates from increasing labor market attachment (a decline in the probability of being outside the labor force) or increasing hours worked (a decline in employment less than full-time). Though not significant, increases in full-time employment originate from declines in the probability of being outside the labor force and working less than 20 hours per week (columns (1) and (2) respectively).

\footnotetext{
${ }^{22}$ Appendix Figure $\mathrm{J}$ reveals that while there is a long-run increase in cumulative labor earnings from all periods $0-+14$, this is not the case for hourly labor earnings.
} 
Table 5: Employment Response, Averaged Over Post-Reform Period

\begin{tabular}{lcccc}
\hline & $(1)$ & $\begin{array}{c}(2) \\
\text { Employed } \\
\text { Outside } \\
\text { of L.F. }\end{array}$ & $\begin{array}{c}(3) \\
\text { 20 hrs/week } \\
\text { Employed } \\
20-29 \\
\text { hrs/week }\end{array}$ & $\begin{array}{c}(4) \\
\text { Employed } \\
\text { Full } \\
\text { Time }\end{array}$ \\
\hline Early Treated $\times$ Post & -0.0035 & -0.0077 & -0.0005 & $0.0159^{* * *}$ \\
& $(0.0064)$ & $(0.0051)$ & $(0.0046)$ & $(0.0053)$ \\
\hline $\mathrm{N}$ & 378630 & 378630 & 378630 & 378630 \\
Avg. Reduced Form Outcome in -1 & 0.311 & 0.180 & 0.148 & 0.361 \\
\hline $\begin{array}{l}\text { Sample of early and later treated women, base ages 30-33, from -1-+14. } \\
\text { of 4 outcomes on the interaction between early treated and a post-reform indicator equal to 1 from }\end{array}$ \\
time +0-+14. Column (1) measures outside the labor force as equal to 1 if working 0 hours. Columns \\
$\begin{array}{l}\text { (2)-(4) measure employment as equal to 1 if working less than 20, 20-29, and more than 30 hours } \\
\text { per week respectively. Coefficients interpreted relative to omitted -1. Employment outcome variables } \\
\text { measured as hours worked per week in a worker's main employment relationship at end of November. }\end{array}$
\end{tabular}

\subsubsection{Distribution of Occupations in +14}

Previous results conclude that later life education increases full-time employment among early treated women. Table D displays the distribution of occupations between early and later treated women in +14 using occupation data available from the mid 2000s. While there is a considerable causal effect of later life education on labor force participation among women, the distribution of occupations between early and later treated women in +14 is relatively similar. As such, Table D suggests that labor force participation is the primary reason behind the large labor market returns observed in Table 4 .

\subsubsection{The Estimated Impact of Educational Reforms on Fertility}

The results of Table 4 suggest large returns to later life education which originate, primarily, from increases in employment among early treated women. Indeed, only $36 \%$ of the sample is employed fulltime prior to the reforms, so there is scope for large increases in employment. The education literature estimates sizable reductions in fertility following additional education in addition to increased labor market prospects (Black, Devereux, and Salvanes, 2008). A natural question is whether early treated women, who complete higher education at higher rates than later treated women, also experience a decline in fertility. If so, the joint decision of employment and fertility among higher educated early treated women may be behind the large increase in employment. Indeed, Figure K reveals a strong negative relationship between number of children and employment probability.

Reduced form results in Figure 15 reveal stable and significant declines in the intensive margin, number of children, in the long-run. However, there is no significant impact on the extensive margin, the probability of having any children, though the average woman in the sample has 1.5 children in time -1 . Scaling the average reduced form impact in column (3) of Table 6 by the estimated first- 
(a) Number of Children

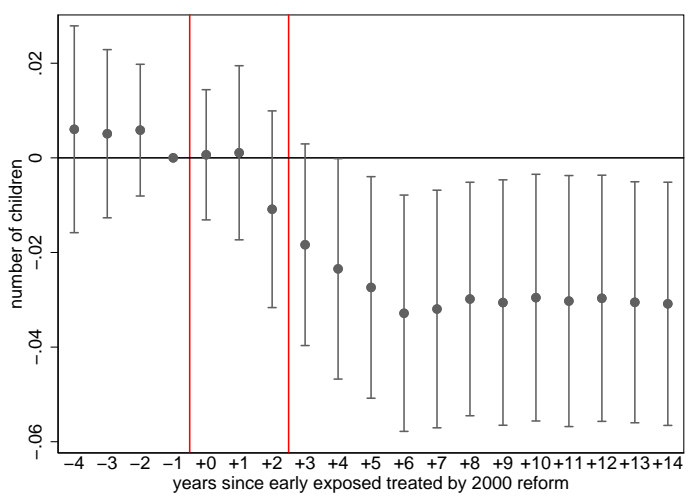

(b) Any Children

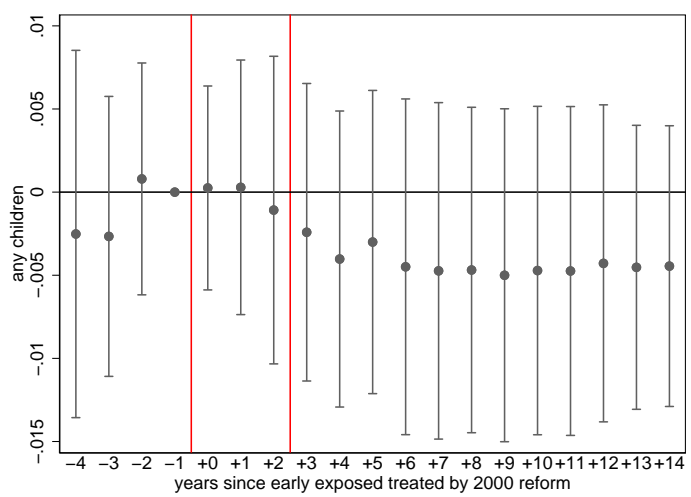

Figure plots estimates of equation (2), weighted by estimated propensity score in -1 as described in Section 4.2.2. Each point represents the difference in the outcome variable between early and later treated cohorts at a specific point in time, relative to the same difference in -1 . Panel (a) defines children as the number of children, including zeros. Panel (b) defines children as any children, equal to 1 if a parent has at least one child. Sample of females of base ages 30-33. 95\% confidence interval reported.

stage regression reveals a large implied LATE of later life education on fertility: one additional year of education reduces the number of children by 0.66 .

Table 6: Estimated Impact on Fertility, Averaged Over Post-Reform Period

\begin{tabular}{lcc}
\hline & $(1)$ & $(2)$ \\
& Any & Children \\
& $\begin{array}{c}\text { Number of } \\
\text { Children }\end{array}$ \\
\hline Early Treated $\times$ Post & -0.0031 & $-0.0234^{* *}$ \\
& $(0.0043)$ & $(0.0103)$ \\
\hline $\mathrm{N}$ & 378630 & 378630 \\
Avg. Reduced Form Outcome in -1 & 0.800 & 1.553 \\
\hline
\end{tabular}

Sample of early and later treated women, base ages 30-33, from $-1-+14$. Reduced-form regresses one of 2 outcomes on the interaction between early treated and a post-reform indicator equal to 1 from time $+0-+14$. Column (1) measures the presence of any children, column (2) measures the number of children. Coefficients interpreted relative to omitted -1. Employment outcome variables measured as hours worked per week in a worker's main employment relationship at end of November.

As both early and later treated women are, at a minimum, 44 in time +14 , the vast majority of births are completed by the end of the sample period. Such large declines in fertility suggest that a substantial portion of the increases in employment from later life education are due to declining fertility. While fertility and employment are clearly decisions made together, the reduced form impact on fulltime employment compares early treated women-who have less children as a result of additional education - with later treated women - who have more children. Given a correlation of - 0.25 between employment and number of children prior to the reform, a back of the envelope calculation suggests that the difference in children between early and later treated women can account for $37 \%$ of the 
reduced-form increase in full-time employment in column (2) of Table $4 .^{23}$ Indeed, a substantial portion of the observed increase in full-time employment in Table 4 among early treated women operates via the joint decision of fertility and employment.

\subsubsection{The impact of returning to education on women's earnings and employment}

We can use the reduced form results on the impact of the reform on years of education as a first stage in the calculation of the local treatment effect of years of education on the outcomes of interest. Table 7 presents the estimated reduced form labor market impacts scaled by the estimated impact of the reforms on years of education. Results correspond to the implied Local Average Treatment Effect (LATE): the labor market benefit from additional education among the "treatment group switchers", the compliers who return to high school education if and only if they are exposed to the education reform (using notation from de Chaisemartin and D'Haultf(Euille, 2017). Such an exercise asks whether there is a change in labor market outcomes as predicted by the increase in education among early treated cohorts. ${ }^{24}$

Table 7: Implied Local Average Treatment Effect

\begin{tabular}{lccc}
\hline & $(1)$ & $(2)$ & $(3)$ \\
& Employed & Log & Log \\
& Full & Annual & Hourly \\
& Time & Earnings & Earnings \\
\hline Local Average Treatment Effect & $0.4391^{* * *}$ & $0.5187^{* * *}$ & 0.0540 \\
& $(0.1472)$ & $(0.1780)$ & $(0.2092)$ \\
\hline $\mathrm{N}$ & 378630 & 295594 & 295594 \\
\hline
\end{tabular}

Sample of early and later treated women, base ages 30-33, from -1-+14. Each column regresses one of 4 outcomes on the interaction between early treated and a post-reform indicator equal to 1 from time $+0-+14$, scaling the estimated reduced form by the estimated impact of the reform on years of education. Years of education increases by 0.0361 in the sample of column (1) and by 0.0531 in the sample of columns (2)-(3). Coefficients interpreted relative to omitted -1 . Employment outcome variables measured as hours worked per week in a worker's main employment relationship at end of November.

Such treatment group switchers represent a policy relevant group - those who are at the margin of returning to high school and only do so as result of the reduction in the opportunity cost attributed to the reforms. However, they also represent a very particular group - women in their early to mid 30s who have previously not returned to education at any younger age. Bearing this in mind, the LATE implied by scaling the reduced form by the first-stage regression is large in magnitude and, is in large part, attributed to increases in employment. While column (1) of Table 4 implies an increase

${ }^{24} \mathrm{de}$ Chaisemartin and D'HaultfCEuille (2017) formalize the identifying assumptions of the Wald-DID estimator. In addition to the standard exclusion restriction in an IV framework-assuming that the education reform only has an impact on labor market outcomes through its impact on education-combining difference-in-differences with IV requires additional identifying assumptions in order for the Wald-DID estimator to estimate the LATE among the treatment group switchers. In particular, the Wald-DID requires a stable treatment effect over time.
} 
in annual earnings due to an additional year of education of around $50 \%$, accounting for differences in hours worked between early and later treated women dramatically reduces the implicit LATE in earnings. This is seen in column (2), which implies an additional year of education increases hourly earnings by $5 \%$. These large increases in income in column (1) are attributed to increases in full-time employment, where an additional year of later life education increases full-time employment by $45 \%$.

Though the increases in employment due to later life education among treatment group switchers are large, the magnitude of this implied LATE is unsurprising for two reasons. First, the potential for increased employment is high among the sample, as only $36 \%$ of women are employed full-time prereform and 31\% are outside the labor force. Among such a sample with weak labor force attachment, other factors may also change among early treated women as a result of the acquisition of later life education. In Section 4.4.3 below we examine one such factor-asking whether fertility also declines as a result of increases in education and, if so, how much of the observed increase in employment operates through a joint decision of employment and fertility. Indeed, Figure 5 reveals that fertility is an important factor for the educational attainment of women and Table 9 reveals a strong negative relationship between labor market attachment and children.

Second, treatment group switchers represent a specific group: women at the margin of returning to high school in their early to mid 30s. Thus, the labor market returns to education among such a group may differ from the returns among other types of women. The marginal treatment effect (MTE) literature emphasizes the importance of two forces. ${ }^{25}$ First, those who take up the reform may differ, in their underlying unobserved cost of treatment, from those who do not. This implies that, under the framework of ordering on the unobserved cost of treatment as in Kowalski (2020), those who take up the reform find it more costly to return to education than always takers, those who return to education regardless of treatment status. At the same time, treatment group switchers are those who did not return to education at all prior ages, presumably because they found it too costly relative to the gains from returning to education. When unobserved costs differ across individuals, there may be selection into treatment on the unobserved cost.

In addition, those who at the margin of returning to education may differ in their return to education compared to other types of women. That is, there may be selection on gains, such that those who take up the reform are those who find it most profitable to return to education. Thus, while the implied LATE suggests a large labor market return to education, it seems likely that those who find it more costly to return to education require a larger return to do so.

\footnotetext{
${ }^{25}$ See, for instance Bjorklund and Moffitt (1987); Heckman and Vytlacil (2001); Brinch, Mogstad, and Wiswall (2017); Cornelissen, Dustmann, Raute, and Schönberg (2018); Mogstad, Santos, and Torgovitsky (2018).
} 


\subsubsection{Employment Impacts by Pre-Reform Labor Market Attachment}

Table 8 examines the importance of pre-reform labor market status for the impacts on employment, separating the sample into low, some, and strong attachment to the labor force based on the number of hours worked in -1 . Women with different levels of pre-reform attachment to the labor market see very different changes in employment outcomes post-reform.

Table 8: Employment Response by Pre-Reform Labor Market Attachment

\begin{tabular}{lcccc}
\hline & $(1)$ & $(2)$ & $(3)$ & $(4)$ \\
& $\begin{array}{c}\text { Outside } \\
\text { of L.F. }\end{array}$ & $\begin{array}{c}\text { Employed } \\
\text { less than } \\
20 \text { hrs/week }\end{array}$ & $\begin{array}{c}\text { Employed } \\
20-29 \\
\text { hrs/week }\end{array}$ & $\begin{array}{c}\text { Employed } \\
\text { Time }\end{array}$ \\
\hline Low attachment in $-1:$ & & & & \\
Early Treated $\times$ Post & $-0.0370^{* * *}$ & 0.0064 & $0.0196^{* * *}$ & 0.0109 \\
& $(0.0123)$ & $(0.0083)$ & $(0.0060)$ & $(0.0082)$ \\
\hline $\mathrm{N}$ & 125188 & 125188 & 125188 & 125188 \\
Avg. Outcome in -1 & 0.809 & 0.106 & 0.031 & 0.054 \\
\hline Some attachment in $-1:$ & & & & \\
Early Treated $\times$ Post & -0.0051 & $-0.0182^{*}$ & -0.0125 & $0.0445^{* * *}$ \\
& $(0.0080)$ & $(0.0107)$ & $(0.0111)$ & $(0.0092)$ \\
\hline N & 125072 & 125072 & 125072 & 125072 \\
Avg. Outcome in -1 & 0.106 & 0.409 & 0.350 & 0.135 \\
\hline Strong attachment in $-1:$ & \multicolumn{3}{c}{} \\
Early Treated $\times$ Post & 0.0058 & $-0.0151^{* * *}$ & $-0.0139^{* *}$ & $0.0255^{* * *}$ \\
& $(0.0061)$ & $(0.0055)$ & $(0.0055)$ & $(0.0094)$ \\
\hline $\mathrm{N}$ & 129041 & 129041 & 129041 & 129041 \\
Avg. Outcome in -1 & 0.026 & 0.030 & 0.065 & 0.879 \\
\hline
\end{tabular}

Sample of early and later treated women, base ages 30-33, from $-1-+14$. Top panel corresponds to women with low attachment to the labor force prior to the reform in time -1, defined as having worked less than 477 hours in -1 . Middle panel corresponds to women with some attachment to the labor force in -1, defined as having worked 477-1505 hours in -1 . Bottom panel corresponds to women with strong attachment to the labor force in -1 , defined as working more than 1505 hours in -1 . Entire sample divided into 3 quantiles shown in each of 3 panels. Outcome variable measured as hours worked per week in a worker's main employment relationship at end of November.

Among early treated women with low attachment, who are primarily outside of the labor force pre-reform, the probability of remaining outside of the labor force significantly declines post-reform, translating into significant increases in part-time employment. Among women with some attachment, who are primarily employed part-time and less than 20 hours per week, the probability of working less than 20 hours per week significantly decreases post-reform, translating into significant increases in the probability of working full-time. Among those with strong labor force attachment, who are predominantly employed full-time in -1 , early treated women are significantly more likely to continue to work full-time relative to later treated women, with significant declines observed in employment less than full-time. Relative to later treated women, the labor market responses of early treated women are 
markedly different across those with different pre-reform levels of labor market attachment: labor force participation increases among those with low labor market attachment while hours worked increase among those with some and strong of labor market attachment.

\subsubsection{Employment Impacts by Pre-Reform Number of Children}

Table 9 examines the importance of the number of children pre-reform in the impacts on employment. The four panels of Table 9 correspond to women who had $0,1,2$, and 3 or more children in time -1 respectively. As with pre-reform labor market status, women with different number of children also see markedly different changes in post-reform labor market outcomes.

Table 9: Employment Response by Pre-Reform Number of Children

\begin{tabular}{lcccc}
\hline & $(1)$ & $\begin{array}{c}(2) \\
\text { Employed } \\
\text { less than } \\
\text { Outside } \\
\text { of L.F. }\end{array}$ & $\begin{array}{c}(3) \\
\text { Employed } \\
20-29 \\
\text { hrs/week }\end{array}$ & $\begin{array}{c}(4) \\
\text { Employed } \\
\text { Full } \\
\text { Time }\end{array}$ \\
\hline 0 Children in -1 : & & & & \\
Early Treated $\times$ Post & 0.0078 & -0.0064 & -0.0049 & 0.0030 \\
& $(0.0126)$ & $(0.0083)$ & $(0.0079)$ & $(0.0134)$ \\
\hline $\mathrm{N}$ & 75872 & 75872 & 75872 & 75872 \\
Avg. Outcome in -1 & 0.211 & 0.101 & 0.101 & 0.586 \\
\hline 1 child in $-1:$ & & & & \\
Early Treated $\times$ Post & $-0.0249 * *$ & -0.0051 & -0.0072 & $0.0382^{* * *}$ \\
& $(0.0115)$ & $(0.0100)$ & $(0.0086)$ & $(0.0104)$ \\
\hline $\mathrm{N}$ & 92400 & 92400 & 92400 & 92400 \\
Avg. Outcome in -1 & 0.289 & 0.147 & 0.145 & 0.418 \\
\hline 2 children in $-1:$ & & & & \\
Early Treated $\times$ Post & 0.0080 & -0.0135 & 0.0037 & 0.0083 \\
& $(0.0090)$ & $(0.0087)$ & $(0.0079)$ & $(0.0095)$ \\
\hline $\mathrm{N}$ & 146757 & 146757 & 146757 & 146757 \\
Avg. Outcome in -1 & 0.315 & 0.218 & 0.174 & 0.294 \\
\hline 3+ children in $-1:$ & & \multicolumn{3}{c}{} \\
Early Treated $\times$ Post & -0.0086 & -0.0010 & -0.0045 & $0.0205^{*}$ \\
& $(0.0163)$ & $(0.0144)$ & $(0.0124)$ & $(0.0122)$ \\
\hline $\mathrm{N}$ & 64272 & 64272 & 64272 & 64272 \\
Avg. Outcome in -1 & 0.451 & 0.233 & 0.148 & 0.168 \\
\hline
\end{tabular}

Sample of early and later treated women, base ages 30-33, from -1-+14. Four panels correspond to women who have $0,1,2$, and 3 or more children in -1 respectively. Outcome variable measured as hours worked per week in a worker's main employment relationship at end of November.

Though the average woman in the sample has 1.5 children in -1 , there are still some women who have no children pre-reform. Women with no children, who also have the strongest attachment to the labor force, see no significant changes in their post-reform employment. Increases in full-time employment are driven by women with children, in particular women with one child, though women 
with 3 or more children pre-reform also see increases in full-time employment. Increases in employment are concentrated among women with children who, prior to the reform, are increasingly less attached to the labor force as the number of children increases while women with no children see zero changes in labor market outcomes.

\section{$5 \quad$ Heterogeneity and Robustness of Results}

\subsection{Completion of post-secondary education}

To understand what levels of education both early and later treated cohorts ultimately attain, Table B compares the distribution of highest degrees for females in +14 to the same distribution in -1 in Table C. A substantial amount of women, both early and later treated, return to education as the fraction of women who have not completed high school declines by roughly 15 percentage points from -1 to +14 . Prior to the reform, early treated women have lower rates of completion for both "postsecondary, non-higher education" and "undergraduate higher education". This reverses by +14 , where early treated women complete both types of higher education at higher rates post-reform.

\subsection{Heterogeneity in Returning to Education}

Figure 16 examines the importance of three pre-determined factors in the estimated effects of the education reforms on education: parental education, age of first birth, and birth weight. Descriptive results in Section 3 reveal that parental education matters in returning to education, that childbirth and education are strongly correlated for women, and there exist little differences in returning to education by birth weight. While such differences are not statistically significant, returning to education is stronger among those who have their first child at 25 or younger (Figure 16b) and those who are above the median birth weight (Figure 16c) while results are similar among high and low educated families (Figure 16a).

Figures L and M examine the importance of two additional factors: cognitive ability (only available for men) and the importance of oil in the local labor market following the discovery of oil in Norway in $1969 .{ }^{26}$ Both cognitive ability and oil seem to matter little for the estimates of returning to education. While the returns to education may differ between high and low oil areas (Cascio and Narayan, 2015), the presence of oil does not seem to matter for returning to education for either women or men.

\footnotetext{
${ }^{26}$ Following the discovery of oil, there was substantial geographic dispersion in how important oil was to different local labor markets (Bütikofer, Dalla-Zuanna, and Salvanes, 2018).
} 
Figure 16: Estimated Impact on Higher Education by Subgroups

(a) Parental Education

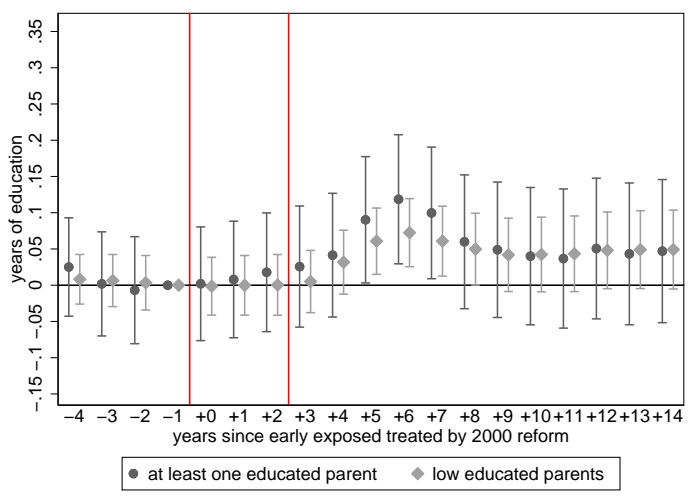

(b) Age of First Birth

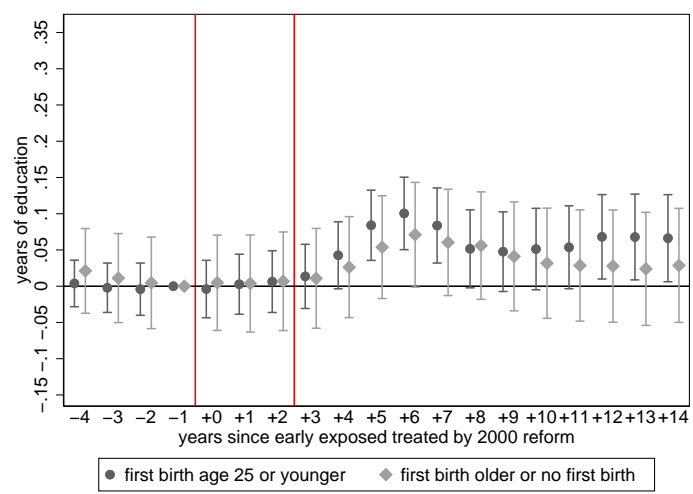

(c) Birth Weight

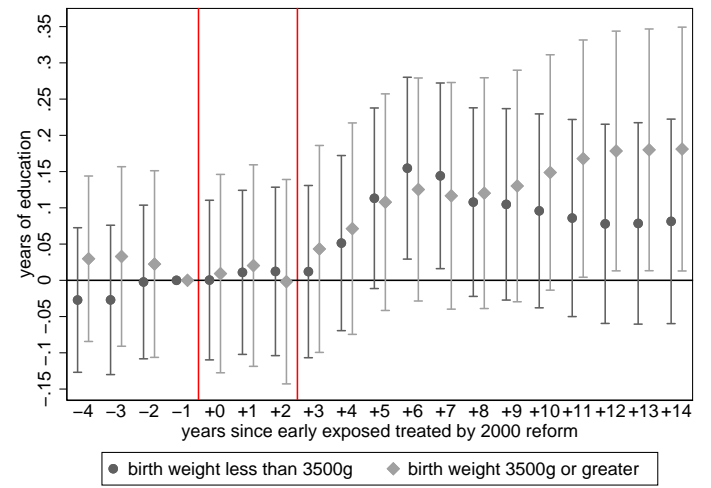

Figure plots estimates of equation (2), weighted by estimated propensity score in -1 as described in Section 4.2.2. Panel (a) plots separate estimates by educated/low educated parents for females. Panel (b) plots separate estimates by age of first birth for females. Panel (c) plots separate estimates by above/below median birth weight for females. Birth weight data available from the 1967 birth cohort onward; as such, panel (c) only includes base age 30. Panels (a) and (b) use sample of females of base ages 30-33. 95\% confidence interval reported. 


\subsection{Reduced-Form Impacts on Labor Market Outcomes for Men}

As mentioned previously, while women return to education following the education reforms, men see no corresponding increase in education. Table $\mathrm{F}$ replicates the results of Table 4 for men. While the fixed effects described in Section 4.2.3 capture differences in labor market conditions between early and later treated cohorts, it may be that other changes over time are not captured by the two included fixed effects. If this were the case, and education was not the driving force behind the increased labor market outcomes of early treated women, then similar increases in earnings and employment would be observed for men who do not return to education. Reassuringly, there are no significant changes in any measure of earnings or employment status for men, reinforcing that the increases in earnings and employment among women are due to increases in later life education.

\subsection{Robustness to Varying $\delta$}

Figure $\mathrm{N}$ examines how the results change by varying $\delta$, the number of years which have passed until the later treated cohort is exposed to the same reforms. The Figure examines how using a later treated group who is exposed even earlier $(\delta=2)$ and a later treated group who is exposed even later $(\delta=5)$ affects the results on high school completion and higher education compared to the baseline case $(\delta=3)$. In the longer run, the estimated effects on high school completion are indistinguishable when using the three different levels of $\delta$. However, the timing of when increases in high school completion fade out changes: using an even earlier later treated cohort corresponds to an earlier decline in the completion of high school while using an even later later treated cohort corresponds to a longer positive impact on high school completion. A similar picture emerges for the estimated effects on higher education.

Such variation in the timing of the estimated effects is consistent with the strength of the identification strategy: as $\delta$ increases, the peak of education moves later in time as the later treated cohorts are increasingly later exposed to the educational reforms. As high school completion fades out at similar rates, this suggests that later treated cohorts return to high school at roughly similar rates despite the fact they are older at the time they are treated. Interestingly, the longer run impact on higher education is substantially lower for the sample of $\delta=2$, reinforcing the idea that the returning to high school at younger ages increases the probability of completing additional higher education.

\subsection{Comparing to Older Base Ages}

Figures $\mathrm{O}$ and $\mathrm{P}$ compare results on education using a sample of older base ages, $a^{0}=38, \ldots, 41$, to results using the base ages used throughout the paper, $a^{0}=30, \ldots, 33$. Results for high school 
are comparable between younger and older base age sample (Figure O). However, results for higher education (Figure P) differ substantially: the increase in higher education among the younger sample is at least twice as large. Indeed, there is no significant increase in higher education for older women by +14 . This is consistent with the fact that while take up of high school completion is similar irrespective of age, returning to high school younger increases the probability of completing higher education relative to returning to high school older.

\section{Conclusion}

In this paper, we evaluate the causal impacts of a second chance of completing high school as adults on labor market outcomes in Norway by leveraging high quality Norwegian register data and exploiting reforms enabling access to high school for adults above the age of 25. 20-30\% of each birth cohort drop out of high school across OECD countries and developing effective tools to tackle the declining labor market prospects of prime-aged high school dropouts is a key policy question. We estimate the causal impacts of a second chance of completing high school (either academic or vocational) as adults within the formal high school system. We leverage high quality Norwegian register data, and exploit two major reforms enabling access to high school for adults above the age of 25 for identification.

Exploiting variation in the age at which different birth cohorts are exposed to two major education reforms in the 2000s, the paper establishes a causal link between returning to education later in life and labor market outcomes. By reducing the opportunity cost of re-enrolling in high school, these reforms significantly increased education among women, but not men. As men return to complete high school at younger ages relative to women, the vast majority of male dropouts return to complete high school prior to 30 . Results suggest that returning to high school at younger ages relative to older ages increases the probability of continuing with higher education later in life.

Increases in labor earnings and employment among women coincide with increases in education, and as a result, the pre-reform gender gap in earnings is reduced considerably. Improved labor market prospects operate primarily through increases in employment among female high school dropouts who are, on average, weakly attached to the labor force to begin with. Fertility is shown to be an important mechanism: in addition to increasing employment, returning to education also leads to a reduction in fertility among women. Given the strong relationship between children and employment, a considerable portion of the increase in employment can be attributed to the joint decisions of fertility and employment.

While the paper reveals interesting patterns of who returns to education, when in the life cycle, and to what levels of education, further research is needed to understand why individuals find it optimal 
to return to levels of education they previously dropped out of. Indeed, important differences across factors such as SES, childbearing, and cognitive ability highlight the importance of understanding what factors determine the education re-starting decision. In a classic framework of human capital decisions (Becker, 1975), a student weighs the present value of earnings with the a lower level of education compared with a higher level of education.

However, a student's education decision is made in an inherently uncertain environment and observed education decisions are a consequence of expectations, preferences, and opportunities (Manski, 1993). Many factors may complicate a student's stopping decision: a lack of information about the true returns to education such that actual and perceived beliefs differ (Jensen, 2010; Wiswall and Zafar, 2014; Boneva and Rauh, 2017), preferences which may change over time due to continued brain development (Lavecchia, Liu, and Oreopoulos, 2016), and changes in available opportunities and/or personal situations. Indeed, Bridgeland, DiIulio, and Morison (2006) find that $74 \%$ of young disadvantaged high school dropouts state they would have stayed in school longer if they could make the decision again, suggesting that the decision to drop out may be perceived differently later in life. Our results suggest that financial support may matter, as increases in student support push women back to education, and that childbearing is clearly important in both the drop out and returning decision among women. However, further research is isolate the underlying forces which change between dropout and re-enrollment later in life.

\section{References}

Abadie, A. (2005): "Semiparametric Difference-in-Differences Estimators," The Review of Economic Studies, 72(1), 1-19.

Abadie, A., And G. W. Imbens (2008): "On the Failure of the Bootstrap for Matching Estimators," Econometrica, 76(6), 1537-1557.

Acemoglu, D., And D. Autor (2011): "Chapter 12 - Skills, Tasks and Technologies: Implications for Employment and Earnings," vol. 4 of Handbook of Labor Economics, pp. 1043 - 1171. Elsevier.

Albæk, K., R. Asplund, E. Barth, L. Lindahl, M. Strøm, and P. Vanhala (2019): "Better Late Than Never? How Late Completion Affects the Early Careers of Dropouts," IZA Discussion Papers 12560, Institute of Labor Economics (IZA).

Albrecht, J., G. J. van den Berg, and S. Vroman (2009): "The aggregate labor market effects of the Swedish Knowledge Lift program," Review of Economic Dynamics, 12(1), 129 - 146. 
Angelov, N., P. Johansson, And E. Lindahl (2016): "Parenthood and the Gender Gap in Pay," Journal of Labor Economics, 34(3), 545-579.

Becker, G. S. (1975): Human Capital: A Theoretical and Empirical Analysis, with Special Reference to Education, Second Edition. NBER.

Bertrand, M., M. Mogstad, and J. Mountjoy (2019): "Improving Educational Pathways to Social Mobility: Evidence from Norway's "Reform 94"," Working Paper 25679, National Bureau of Economic Research.

Bhuller, M., M. Mogstad, and K. G. Salvanes (2017): "Life-Cycle Earnings, Education Premiums, and Internal Rates of Return," Journal of Labor Economics, 35(4), 993-1030.

Bjorklund, A., And R. Moffitt (1987): "The Estimation of Wage Gains and Welfare Gains in Self-selection," The Review of Economics and Statistics, 69(1), 42-49.

Black, S. E., and P. J. Devereux (2011): "Chapter 16 - Recent Developments in Intergenerational Mobility," vol. 4 of Handbook of Labor Economics, pp. 1487 - 1541. Elsevier.

Black, S. E., P. J. Devereux, and K. G. Salvanes (2005): "Why the Apple Doesn't Fall Far: Understanding Intergenerational Transmission of Human Capital," American Economic Review, 95(1), 437-449.

(2008): "Staying in the Classroom and out of the maternity ward? The effect of compulsory schooling laws on teenage births*," The Economic Journal, 118(530), 1025-1054.

Blanden, J., F. Buscha, P. Sturgis, and P. Urwin (2012): "Measuring the earnings returns to lifelong learning in the UK," Economics of Education Review, 31(4), 501-514.

Blau, F. D., And L. M. Kahn (2017): "The Gender Wage Gap: Extent, Trends, and Explanations," Journal of Economic Literature, 55(3), 789-865.

Blundell, R., And M. C. Dias (2009): "Alternative Approaches to Evaluation in Empirical Microeconomics," Journal of Human Resources, 44(3), 565-640.

Blundell, R., M. C. Dias, D. A. Goll, and C. Meghir (2019): "Wages, Experience and Training of Women over the Lifecycle," Working Paper 25776, National Bureau of Economic Research.

Blundell, R., R. Joyce, A. N. Keiller, and J. P. Ziliak (2018): "Income inequality and the labour market in Britain and the US," Journal of Public Economics, 162, 48 - 62, In Honor of Sir Tony Atkinson (1944-2017). 
Boneva, T., and C. Rauh (2017): "Socio-Economic Gaps in University Enrollment: The Role of Perceived Pecuniary and Non-Pecuniary Returns," CESifo Working Paper Series 6756, CESifo Group Munich.

Bratsberg, B., T. Nyen, and O. RaAum (2020): "Economic returns to adult vocational qualifications," Journal of Education and Work, 33(2), 99-114.

Bridgeland, J. M., J. J. Dilulio, and B. Morison (2006): "The Silent Epidemic Perspectives of High School Dropouts," A report by Civic Enterprises in association with Peter D. Hart Research Associates for the Bill $\mathcal{E}$ Melinda Gates Foundation.

Brinch, C. N., M. Mogstad, and M. Wiswall (2017): "Beyond LATE with a Discrete Instrument," Journal of Political Economy, 125(4), 985-1039.

Busso, M., J. DiNardo, and J. McCrary (2014): "New Evidence on the Finite Sample Properties of Propensity Score Reweighting and Matching Estimators," The Review of Economics and Statistics, 96(5), 885-897.

Bütikofer, A., A. Dalla-Zuanna, and K. G. Salvanes (2018): "Breaking the Links: Natural Resource Booms and Intergenerational Mobility," Discussion paper no. 19/2018, NHH Dept. of Economics.

CARD, D. (1999): "Chapter 30 - The Causal Effect of Education on Earnings," vol. 3 of Handbook of Labor Economics, pp. 1801 - 1863. Elsevier.

Cascio, E. U., and A. Narayan (2015): "Who Needs a Fracking Education? The Educational Response to Low-Skill Biased Technological Change," Working Paper 21359, National Bureau of Economic Research.

Cornelissen, T., C. Dustmann, A. Raute, and U. Schönberg (2018): "Who Benefits from Universal Child Care? Estimating Marginal Returns to Early Child Care Attendance," Journal of Political Economy, 126(6), 2356-2409.

de Chaisemartin, C., and X. D’Haultf CEuille (2017): "Fuzzy Differences-in-Differences," The Review of Economic Studies, 85(2), 999-1028.

Fadlon, I., And T. H. Nielsen (2019): "Family Health Behaviors," American Economic Review, 109(9), 3162-91.

Goldin, C. (2006): "The Quiet Revolution That Transformed Women's Employment, Education, and Family," American Economic Review, 96(2), 1-21. 
Goodman-Bacon, A., and J. P. Cunningham (2019): "Changes in Family Structure and Welfare Participation Since the 1960s: The Role of Legal Services," Working Paper 26238, National Bureau of Economic Research.

Heckman, J. J., J. E. Humphries, and N. S. Mader (2011): The GEDvol. 3 of Handbook of the Economics of Education, chap. 9, pp. 423-483. Elsevier.

Heckman, J. J., and P. A. LaFontaine (2006): "Bias-Corrected Estimates of GED Returns," Journal of Labor Economics, 24(3), 661-700.

Heckman, J. J., and E. Vytlacil (2001): "Policy-Relevant Treatment Effects," American Economic Review, 91(2), 107-111.

Jensen, R. (2010): "The (Perceived) Returns to Education and the Demand for Schooling," The Quarterly Journal of Economics, 125(2), 515-548.

Jepsen, C., P. Mueser, And K. Troske (2016): "Labor Market Returns to the GED Using Regression Discontinuity Analysis," Journal of Political Economy, 124(3), 621-649.

Kirke-, UtdANnings- OG FORSKNINGSDEPARTEMENTET (1999): "St.meld. nr. 32 (1998-99) Videregående opplæring," .

(2000): "Lov om endringar i lov 17. juli 1998 nr. 61 om grunnskolen og den vidaregåande opplæringa (opplæringslova) m.m.," .

Kleven, H., C. Landais, and J. E. SøgaArd (2019): "Children and Gender Inequality: Evidence from Denmark," American Economic Journal: Applied Economics, 11(4), 181-209.

Kowalski, A. E. (2020): "Reconciling Seemingly Contradictory Results from the Oregon Health Insurance Experiment and the Massachusetts Health Reform," Working Paper 24647, National Bureau of Economic Research.

Lavecchia, A., H. Liu, and P. Oreopoulos (2016): "Chapter 1 - Behavioral Economics of Education: Progress and Possibilities," vol. 5 of Handbook of the Economics of Education, pp. 1 - 74. Elsevier.

Manski, C. F. (1993): Adolescent Econometricians: How Do Youth Infer the Returns to Schooling?pp. 43-60. University of Chicago Press.

Mastrobuoni, G., And P. Pinotti (2015): "Legal Status and the Criminal Activity of Immigrants," American Economic Journal: Applied Economics, 7(2), 175-206. 
Mogstad, M., A. Santos, and A. Torgovitsky (2018): "Using Instrumental Variables for Inference About Policy Relevant Treatment Parameters," Econometrica, 86(5), 1589-1619.

Nekoei, A., And D. Seim (2018): "How do Inheritances Shape Wealth Inequality? Theory and Evidence from Sweden," CEPR Discussion Papers 13199, C.E.P.R. Discussion Papers.

OECD (2017): Education at a Glance $201 \%$.

Pohlan, L. (2019): "Unemployment and social exclusion," Journal of Economic Behavior E Organization, 164, 273 - 299.

Schwerdt, G., D. Messer, L. Woessmann, and S. C. Wolter (2012): "The impact of an adult education voucher program: Evidence from a randomized field experiment," Journal of Public Economics, 96(7), $569-583$.

Stenberg, A., and O. Westerlund (2008): "Does comprehensive education work for the long-term unemployed?," Labour Economics, 15(1), 54 - 67.

Tyler, J. H., R. J. Murnane, and J. B. Willett (2000): "Estimating the Labor Market Signaling Value of the GED*," The Quarterly Journal of Economics, 115(2), 431-468.

Wiswall, M., And B. Zafar (2014): "Determinants of College Major Choice: Identification using an Information Experiment," The Review of Economic Studies, 82(2), 791-824. 


\section{Appendix}

\section{A Summary Statistics By Gender and Age Completed High School}

Table A present differences in characteristics such as parental education levels, fertility, ability, and demographics for women and men who complete high school at 3 different ages (on-time, 21-25, 26-30) and for those who have not completed high school by 45. Parental education is defined as the highest level of parental education and is divided into three categories: less than high school, high school, and post-secondary education. Fertility is defined as the age of first birth across 6 different age bins. Ability is measured as an IQ score for all men who have compulsory military testing at age 18. This runs on a scale of $1-9$, where 1 is low and 9 is high. Lastly, the fraction born in Norway is reported.

On-time high school completers are positively selected relative to later in life completers: they have a higher fraction of parents with post-secondary education, a lower fraction of teenage births, and higher ability levels (for men). The difference in fertility between males and females is particularly striking. For women who complete high school from $26-30$, almost $10 \%$ of them gave birth between 16-20 while the same fraction for men is only 1.1\%. Having a child at young ages is more detrimental to women finishing high school on-time than men. 
Table A: Describing who completes high school at different ages

\begin{tabular}{|c|c|c|c|c|c|c|c|c|}
\hline & \multicolumn{4}{|c|}{ Female } & \multicolumn{4}{|c|}{ Male } \\
\hline & $\begin{array}{c}(1) \\
\text { On-time }\end{array}$ & $\begin{array}{c}(2) \\
21-25\end{array}$ & $\begin{array}{c}(3) \\
26-30\end{array}$ & $\begin{array}{l}(4) \\
\text { Not Completed } \\
\text { by } 45\end{array}$ & $\begin{array}{c}(5) \\
\text { On-time }\end{array}$ & $\begin{array}{c}(6) \\
21-25\end{array}$ & $\begin{array}{c}(7) \\
26-30\end{array}$ & $\begin{array}{c}\text { Not Completed } \\
\text { by } 45\end{array}$ \\
\hline Frac. Less than HS & $\begin{array}{c}0.435 \\
(0.496)\end{array}$ & $\begin{array}{c}0.564 \\
(0.496)\end{array}$ & $\begin{array}{c}0.608 \\
(0.488)\end{array}$ & $\begin{array}{c}0.674 \\
(0.469)\end{array}$ & $\begin{array}{c}0.402 \\
(0.490)\end{array}$ & $\begin{array}{c}0.586 \\
(0.492)\end{array}$ & $\begin{array}{c}0.636 \\
(0.481)\end{array}$ & $\begin{array}{c}0.659 \\
(0.474)\end{array}$ \\
\hline Frac. Post-Secondary & $\begin{array}{c}0.325 \\
(0.469)\end{array}$ & $\begin{array}{c}0.226 \\
(0.418)\end{array}$ & $\begin{array}{c}0.179 \\
(0.383)\end{array}$ & $\begin{array}{l}0.0816 \\
(0.274)\end{array}$ & $\begin{array}{c}0.335 \\
(0.472)\end{array}$ & $\begin{array}{c}0.194 \\
(0.395)\end{array}$ & $\begin{array}{c}0.155 \\
(0.362)\end{array}$ & $\begin{array}{l}0.0894 \\
(0.285)\end{array}$ \\
\hline Frac. Missing & $\begin{array}{l}0.0765 \\
(0.266)\end{array}$ & $\begin{array}{c}0.0352 \\
(0.184)\end{array}$ & $\begin{array}{c}0.0432 \\
(0.203)\end{array}$ & $\begin{array}{c}0.114 \\
(0.318)\end{array}$ & $\begin{array}{c}0.105 \\
(0.306)\end{array}$ & $\begin{array}{l}0.0347 \\
(0.183)\end{array}$ & $\begin{array}{c}0.0422 \\
(0.201)\end{array}$ & $\begin{array}{c}0.128 \\
(0.334)\end{array}$ \\
\hline \multicolumn{9}{|l|}{ Fertility: } \\
\hline first birth $26-30$ & $\begin{array}{c}0.308 \\
(0.462)\end{array}$ & $\begin{array}{c}0.297 \\
(0.457)\end{array}$ & $\begin{array}{c}0.152 \\
(0.359)\end{array}$ & $\begin{array}{c}0.180 \\
(0.384)\end{array}$ & $\begin{array}{c}0.242 \\
(0.428)\end{array}$ & $\begin{array}{c}0.271 \\
(0.444)\end{array}$ & $\begin{array}{c}0.241 \\
(0.428)\end{array}$ & $\begin{array}{c}0.211 \\
(0.408)\end{array}$ \\
\hline first birth $31-35$ & $\begin{array}{c}0.161 \\
(0.367)\end{array}$ & $\begin{array}{c}0.133 \\
(0.339)\end{array}$ & $\begin{array}{c}0.119 \\
(0.324)\end{array}$ & $\begin{array}{l}0.0643 \\
(0.245)\end{array}$ & $\begin{array}{c}0.200 \\
(0.400)\end{array}$ & $\begin{array}{c}0.170 \\
(0.376)\end{array}$ & $\begin{array}{c}0.153 \\
(0.360)\end{array}$ & $\begin{array}{c}0.112 \\
(0.315)\end{array}$ \\
\hline first birth $36-40$ & $\begin{array}{l}0.0574 \\
(0.233)\end{array}$ & $\begin{array}{l}0.0499 \\
(0.218)\end{array}$ & $\begin{array}{c}0.0406 \\
(0.197)\end{array}$ & $\begin{array}{l}0.0214 \\
(0.145)\end{array}$ & $\begin{array}{l}0.0895 \\
(0.285)\end{array}$ & $\begin{array}{l}0.0711 \\
(0.257)\end{array}$ & $\begin{array}{c}0.0671 \\
(0.250)\end{array}$ & $\begin{array}{l}0.0478 \\
(0.213)\end{array}$ \\
\hline first birth $41+$ & $\begin{array}{l}0.0132 \\
(0.114)\end{array}$ & $\begin{array}{c}0.0108 \\
(0.104)\end{array}$ & $\begin{array}{c}0.0104 \\
(0.102)\end{array}$ & $\begin{array}{l}0.00432 \\
(0.0656)\end{array}$ & $\begin{array}{c}0.0321 \\
(0.176)\end{array}$ & $\begin{array}{c}0.0254 \\
(0.157)\end{array}$ & $\begin{array}{c}0.0256 \\
(0.158)\end{array}$ & $\begin{array}{l}0.0186 \\
(0.135)\end{array}$ \\
\hline no first birth & $\begin{array}{c}0.134 \\
(0.341)\end{array}$ & $\begin{array}{c}0.130 \\
(0.337)\end{array}$ & $\begin{array}{c}0.128 \\
(0.334)\end{array}$ & $\begin{array}{c}0.137 \\
(0.344)\end{array}$ & $\begin{array}{c}0.212 \\
(0.409)\end{array}$ & $\begin{array}{c}0.174 \\
(0.379)\end{array}$ & $\begin{array}{c}0.183 \\
(0.387)\end{array}$ & $\begin{array}{c}0.292 \\
(0.455)\end{array}$ \\
\hline
\end{tabular}

Sample: 1960-1969 birth cohorts. All first births measured up until and including age 45. IQ score measured for all men at age 18 in military testing. Sample is balanced and includes individuals who appear in the data from ages 20-45. 


\section{B Adolescent Fertility Across OECD Founding Member States \&}

\section{Finland}

Figure A: Fertility Rates of 15-19 Year Olds in 1990

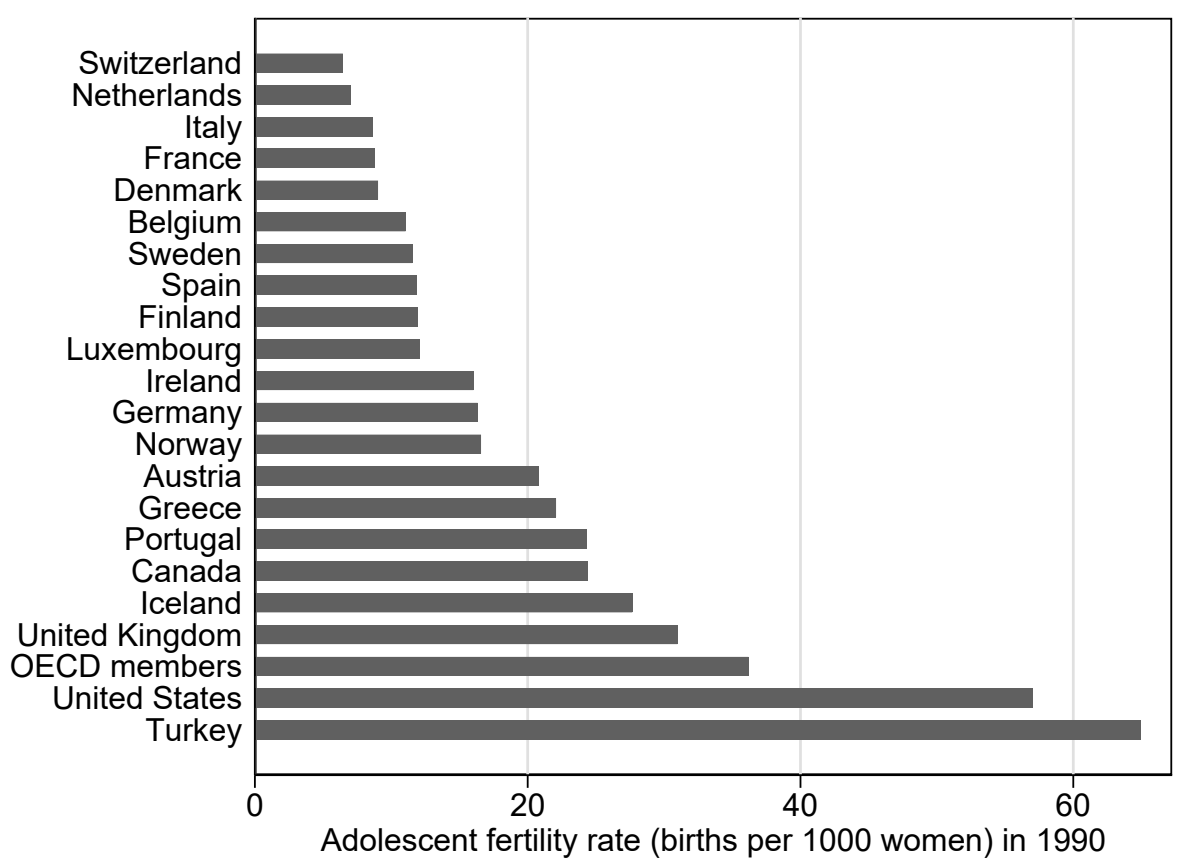

Births per 1000 women aged 15-19 in 1990. Source - World development indicators, World Bank, (https://datacatalog.worldbank.org/dataset/world-development-indicators). World bank defines adolescent as ages 1519. Founding OECD member countries and Finland reported, OECD average calculated as average across all OECD members in 1990. 


\section{Returning to University Education}

Figure B: Fraction of Birth Cohort Completed Relevant Margin of Education - Any Post-Secondary Education

(a) Females

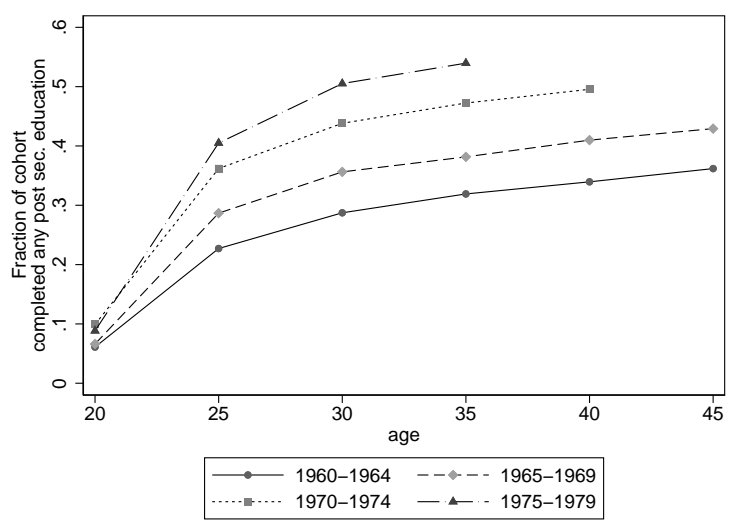

(b) Males

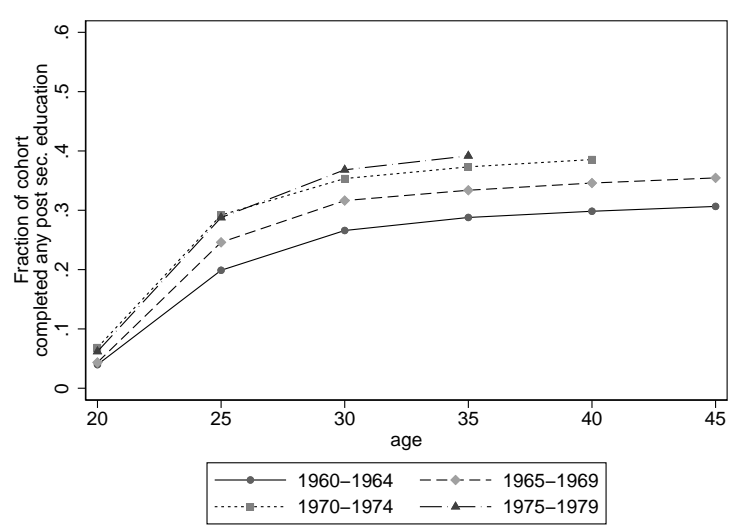




\section{Describing Lifetime Earnings - Academic/Vocational and by Gen- der}

\section{D.1 Academic}

Figure C: Evolution of average earnings by different ages completed final year of upper secondary education, academic

(a) Females, Ages 24-26, 27-29

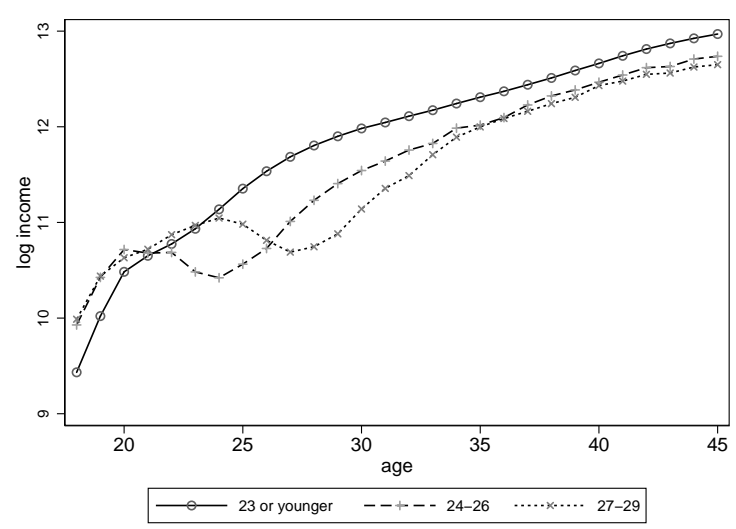

(b) Males, Ages 24-26, 27-29

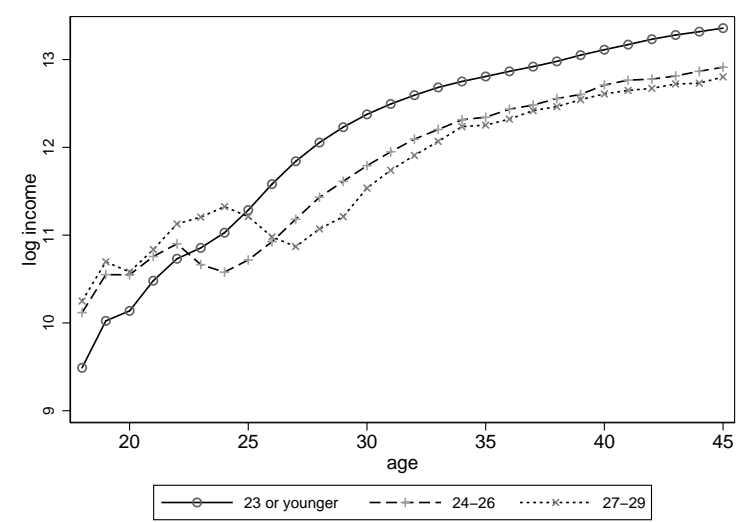

Sample - birth cohorts 1965-1969. Note - y-axis is not the same

Figure D: Evolution of average earnings by different ages completed final year of upper secondary education, academic

(a) Females, Ages 27-29, 30-32

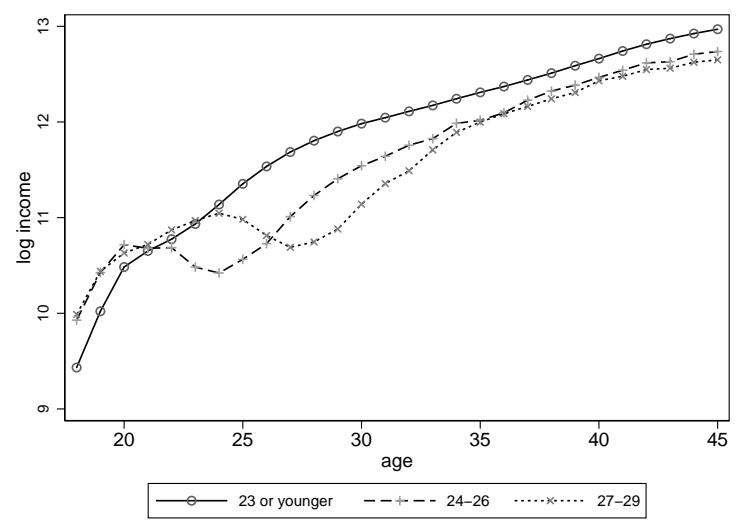

(b) Males, Ages 27-29, 30-32

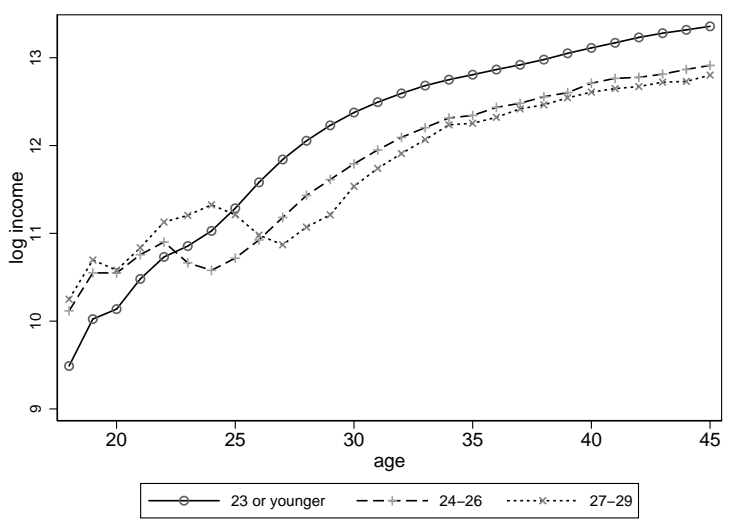

Sample - birth cohorts 1965-1969. Note - y-axis is not the same 


\section{D.2 Vocational}

Figure E: Evolution of average earnings by different ages completed final year of upper secondary education, vocational

(a) Females, Ages 24-26, 27-29

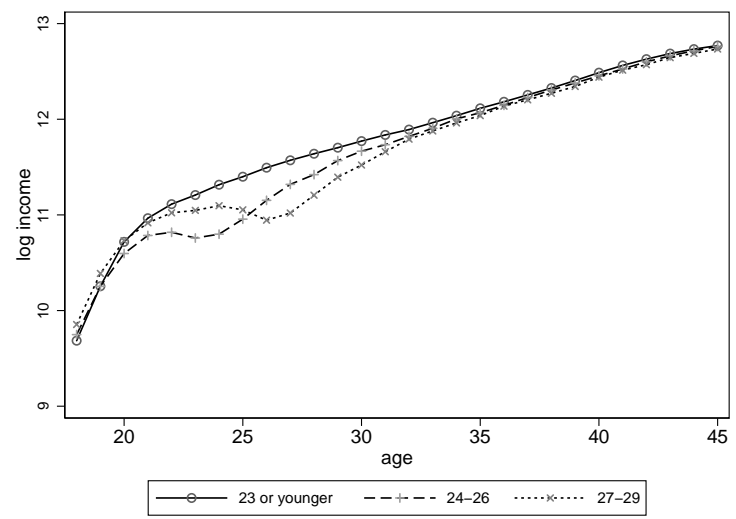

(b) Males, Ages 24-26, 27-29

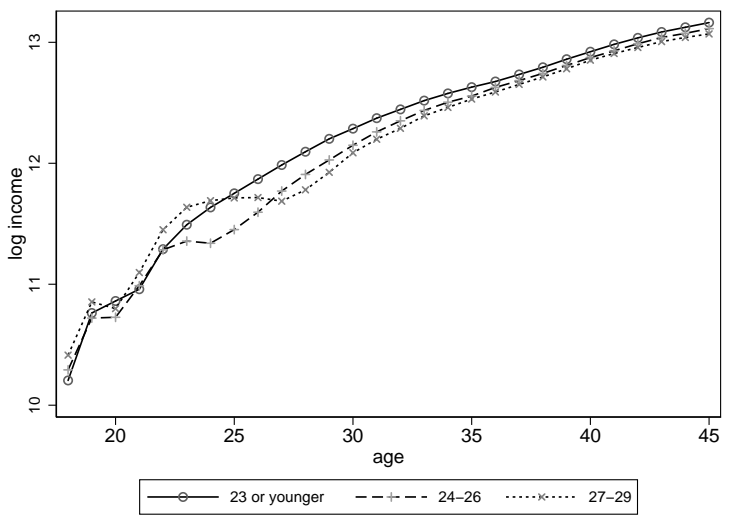

Sample - birth cohorts 1965-1969. Note - y-axis is not the same

Figure F: Evolution of average earnings by different ages completed final year of upper secondary education, vocational

(a) Females, Ages 27-29, 30-32

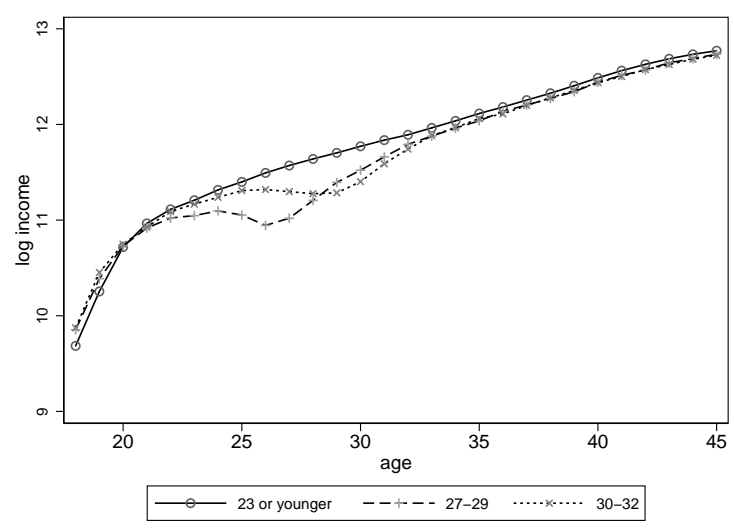

(b) Males, Ages 27-29, 30-32

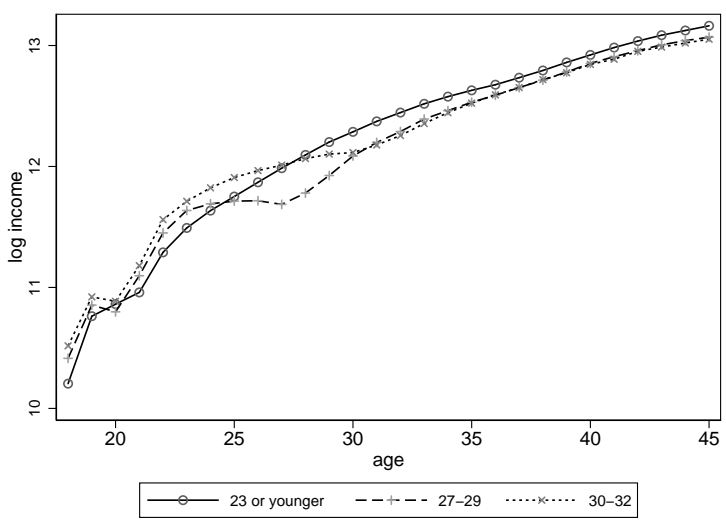

Sample - birth cohorts 1965-1969. Note - y-axis is not the same 


\section{E Distribution of Labor Earnings}

Figure G: National Distribution of Labor Earnings in 1999 by Gender

(a) Female

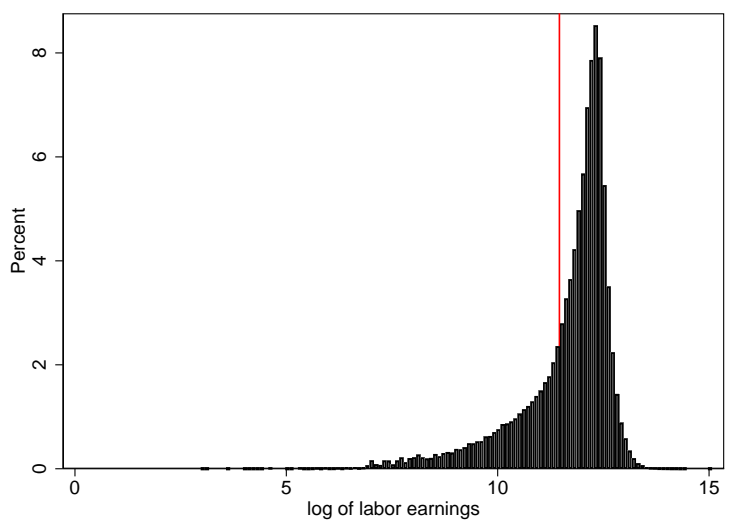

(b) Male

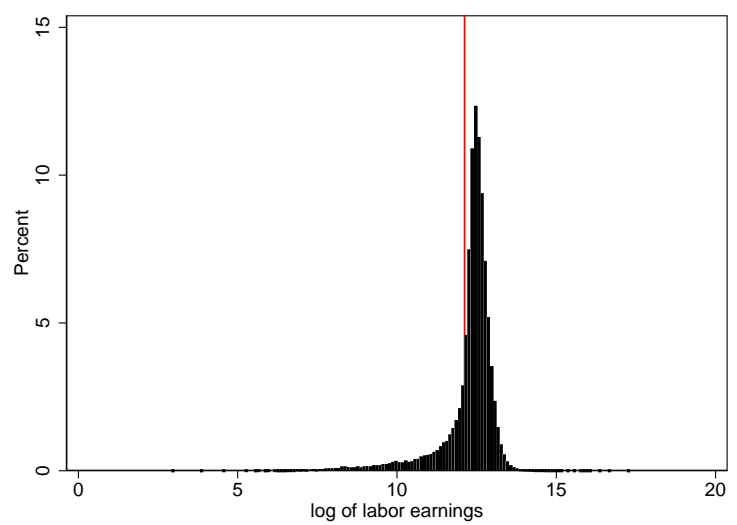

Vertical line corresponds to average log of labor earnings in the estimation sample as described in Table 3. Average log of labor earnings corresponds to $28^{\text {th }}$ percentile for women and $22^{\text {nd }}$ percentile for men. Sample corresponds to any person aged 30-33 in 2000 , irrespective of previous educational attainment. 


\section{F Estimated Propensity Scores}

Figure H: Distribution of propensity score

(a) Female

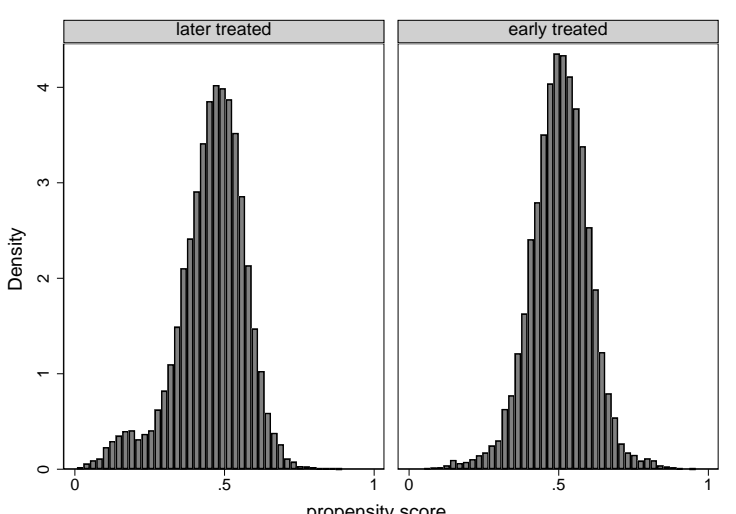

(b) Male

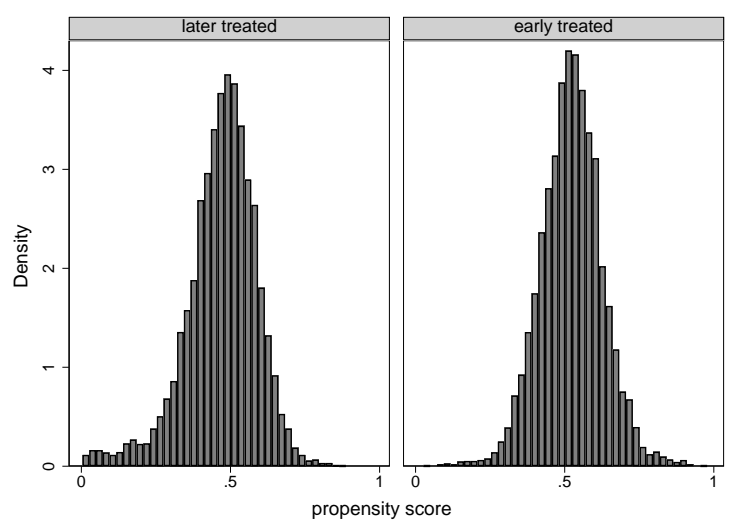

We estimate the propensity score by matching early and later treated individuals in time $=-1$ on: 3 binary variables indicating at least one highly educated parent, first birth at age 25 or younger, and married; binary variables for age of first drop outs $(5$ categories, 16-20); binary variables for broad field of study left high school with (10 broad categories); the number of children (including zeros); birth municipality; 2 digit industry dummies; and base age. 


\section{G Baseline Results for Men-Education}

Figure I: Education

(a) Completion of High School

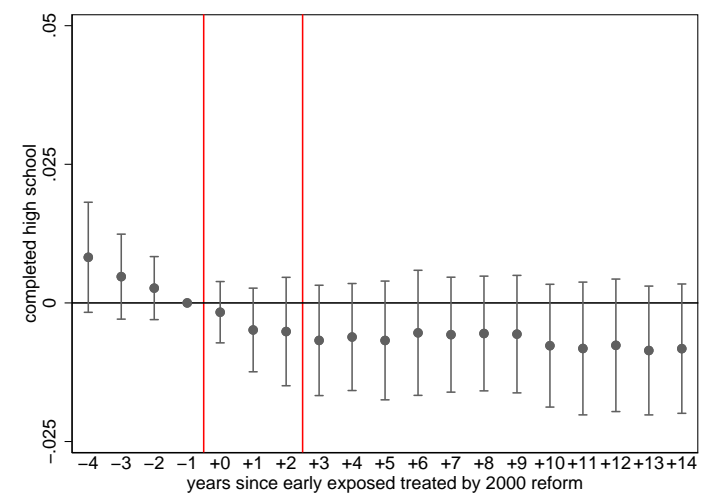

(b) Years of Education

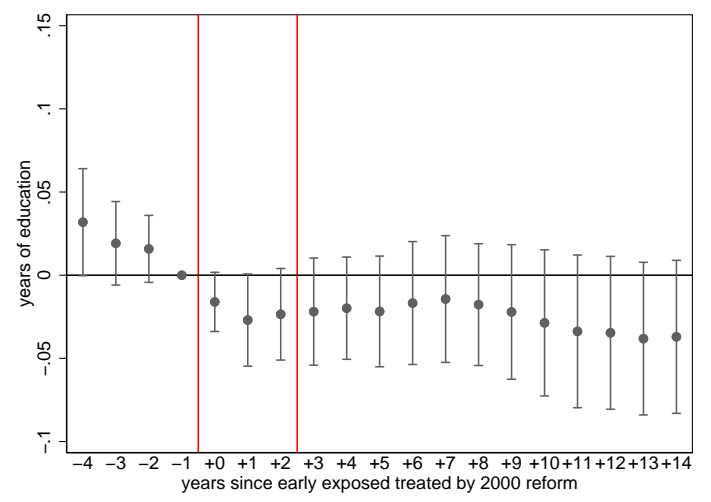

(c) Completion of Higher Education

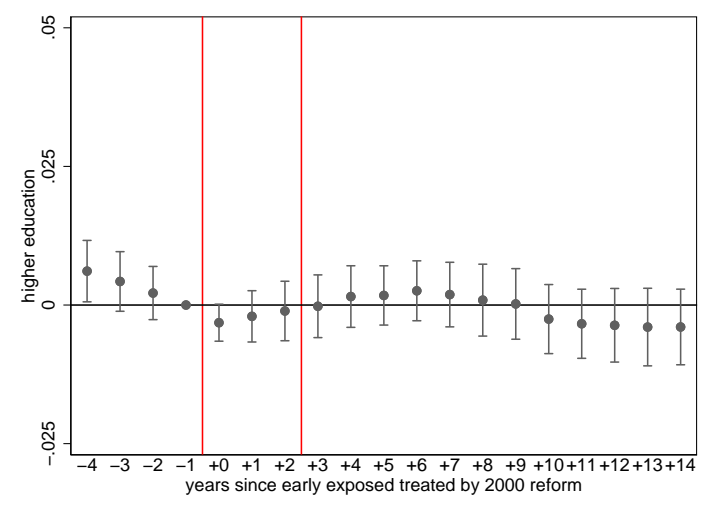




\section{H The cumulative effect on earnings}

Figure J: Cumulative Impact on Labor Income

(a) Annual Labor Earnings

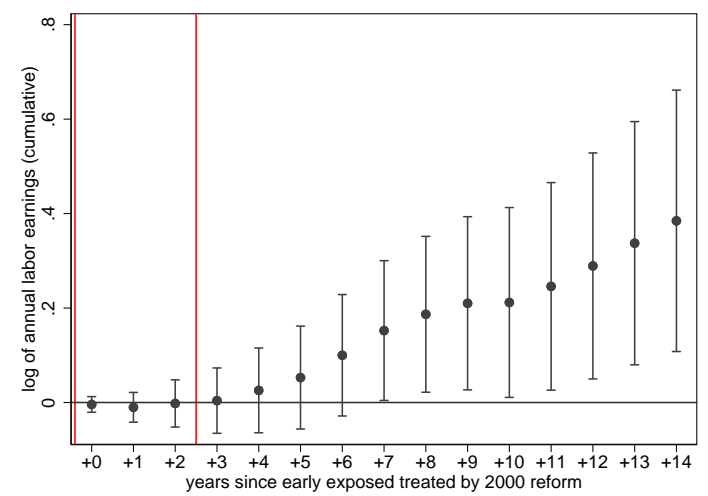

(b) Hourly Labor Earnings

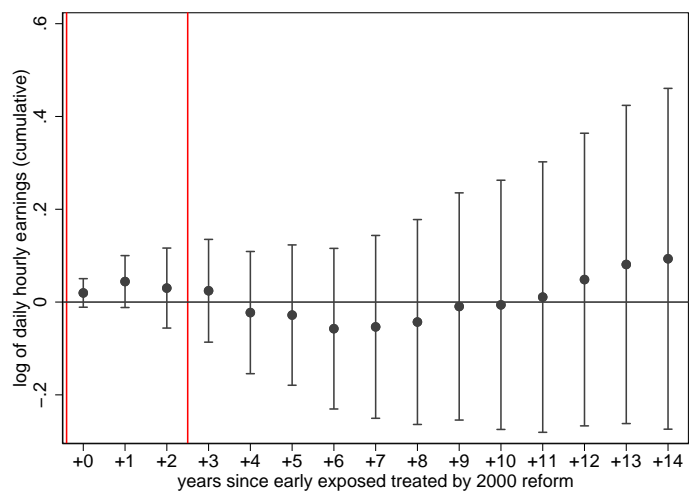

Plots reduced form regression of Figure 13a cumulative over time. Point at any given point in time corresponds to the reduced form impact on earnings in that period as well as any previous post-reform periods. As such, an estimated coefficient corresponds to the cumulative effect of all previous points in time. Panel (a) defines the log of annual labor earnings while (b) defines the log of hourly labor earnings. 
I The Correlation Between Employment and Children

Figure K: Relationship Between Employment and Children for Women

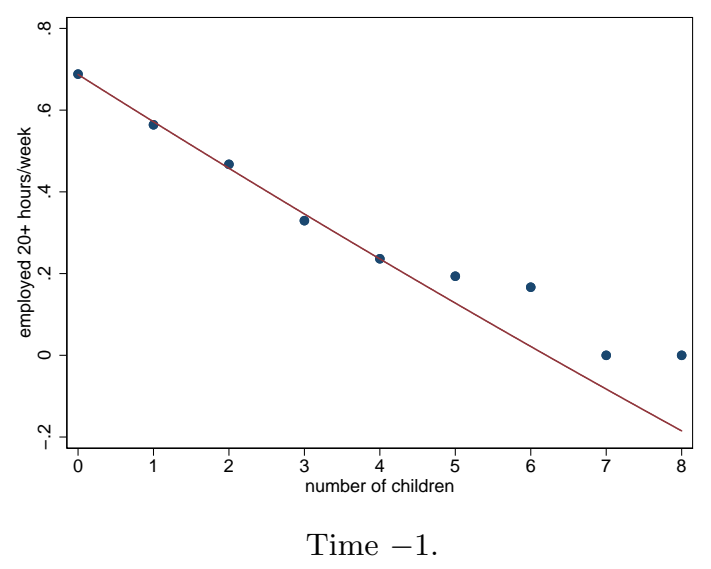




\section{J Completion of Higher Education}

Table B: Distribution of Education in +14 by Counterfactual/Treated Status, Females

\begin{tabular}{lccc}
\hline & counterfactual & treated & Total \\
\hline upper secondary education (basic) & 73.65 & 71.99 & 72.86 \\
upper secondary education (final year) & 8.98 & 9.96 & 9.44 \\
post-secondary education (non-higher education) & 1.93 & 2.05 & 1.99 \\
undergraduate higher education & 14.76 & 15.26 & 15.00 \\
graduate higher education & 0.68 & 0.74 & 0.71 \\
post-graduate education & 0.01 & 0.00 & 0.00 \\
Total & 100.00 & 100.00 & 100.00 \\
& $(12565)$ & $(11358)$ & $(23923)$ \\
\hline
\end{tabular}

Table C: Distribution of Education in -1 by Counterfactual/Treated Status, Females

\begin{tabular}{lccc}
\hline & counterfactual & treated & Total \\
\hline upper secondary education (basic) & 88.52 & 87.22 & 87.91 \\
upper secondary education (final year) & 4.98 & 7.91 & 6.37 \\
post-secondary education (non-higher education) & 2.24 & 0.98 & 1.64 \\
undergraduate higher education & 4.19 & 3.84 & 4.03 \\
graduate higher education & 0.06 & 0.05 & 0.05 \\
Total & 100.00 & 100.00 & 100.00 \\
& $(12565)$ & $(11358)$ & $(23923)$ \\
\hline
\end{tabular}




\section{K Occupations}

Table D: Distribution of Occupations in +14 by Early/Later Treated

\begin{tabular}{lcc}
\hline & later treated & early treated \\
\hline Managers & 3.72 & 3.93 \\
Professionals & 11.66 & 12.04 \\
Technicians and associate professionals & 12.17 & 11.47 \\
Clerical support & 10.33 & 8.87 \\
Service and sales & 33.14 & 35.50 \\
Skilled agriculture, forestry, and fishery & 0.29 & 0.29 \\
Craft and related trades & 0.45 & 0.45 \\
Plant and machine operators & 1.66 & 1.66 \\
Elementary occupations & 2.75 & 2.70 \\
No occupation (not employed) & 23.83 & 23.08 \\
Total & 100.00 & 100.00 \\
\hline$N$ & 12565 & 11358 \\
\hline
\end{tabular}

Table E: Distribution of Public/Private Sector in +14 by Early/Later Treated

\begin{tabular}{lcc}
\hline & later treated & early treated \\
\hline private sector & 42.16 & 43.36 \\
public sector & 57.84 & 56.64 \\
Total & 100.00 & 100.00 \\
\hline$N$ & 9571 & 8737 \\
\hline
\end{tabular}

Sample of those who are employed in an occupation in Table D. 


\section{Importance of Additional Factors}

Figure L: Years of Education, Separating by Cognitive Ability

(a) Male

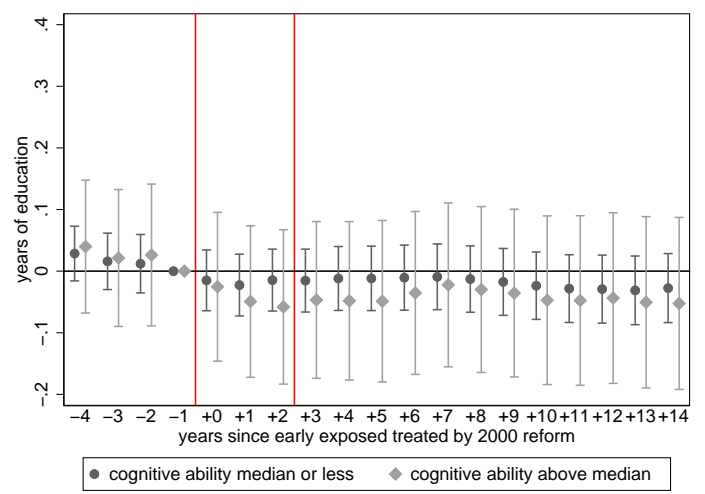

Panel (a) plots separate estimates by above/below cognitive ability for males. Data only available for males.

Figure M: Years of Education, Separating by Oil

(a) Female

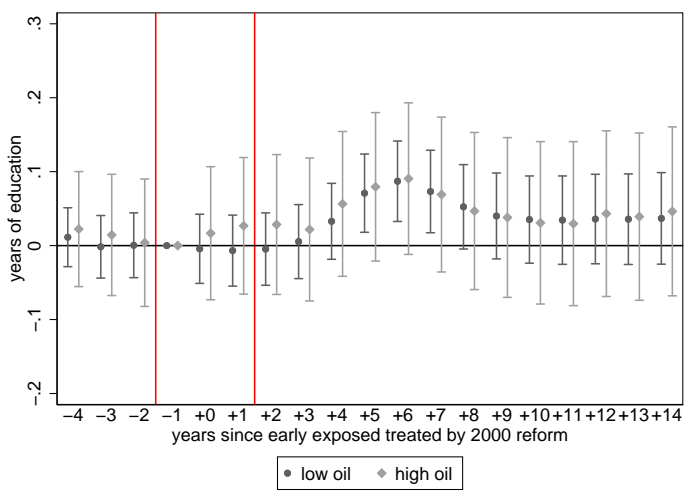

(b) Male

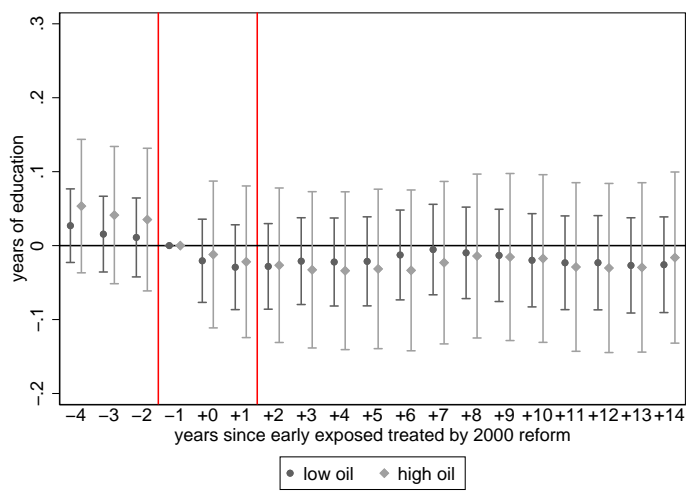

Panel (a) plots separate estimates by oil exposure at birth local labor market for females. Panel (b) plots separate regression estimates by oil exposure at birth local labor market for males. High, middle, and low oil defined as in Bütikofer, Dalla-Zuanna, and Salvanes (2018) as a local labor market with employment in oil industry in 1980 greater than $10 \%$, between 7.5 and $10 \%$, and less than $7.5 \%$ respectively. 46 local labor markets as defined in ?. 


\section{Baseline Results for Men-Labor Market Outcomes}

Table F: Reduced-Form and First-Stage Regressions Over Post-Reform Period

\begin{tabular}{|c|c|c|c|c|c|c|}
\hline & \multicolumn{2}{|c|}{ Labor Earnings } & \multicolumn{4}{|c|}{ Employment } \\
\hline & $\begin{array}{c}(1) \\
\text { Log } \\
\text { Annual } \\
\text { Earnings }\end{array}$ & $\begin{array}{c}(2) \\
\text { Log } \\
\text { Hourly } \\
\text { Earnings }\end{array}$ & $\begin{array}{l}\text { (3) } \\
\text { Outside } \\
\text { of L.F. }\end{array}$ & $\begin{array}{c}(4) \\
\text { Employed } \\
\text { less than } \\
20 \text { hrs/week }\end{array}$ & $\begin{array}{c}(5) \\
\text { Employed } \\
20-29 \\
\text { hrs/week }\end{array}$ & $\begin{array}{c}(6) \\
\text { Employed } \\
30+ \\
\text { hrs/week }\end{array}$ \\
\hline $\begin{array}{l}\text { Reduced-Form Regression: } \\
\text { Early Treated } \times \text { Post }\end{array}$ & $\begin{array}{c}0.0081 \\
(0.0120)\end{array}$ & $\begin{array}{c}0.0027 \\
(0.0091)\end{array}$ & $\begin{array}{l}-0.0001 \\
(0.0058)\end{array}$ & $\begin{array}{c}0.0007 \\
(0.0030)\end{array}$ & $\begin{array}{l}-0.0020 \\
(0.0029)\end{array}$ & $\begin{array}{c}0.0028 \\
(0.0059)\end{array}$ \\
\hline $\begin{array}{l}\text { First-Stage (Years of Educ.): } \\
\text { Early Treated } \times \text { Post }\end{array}$ & $\begin{array}{l}-0.0249 \\
(0.0158)\end{array}$ & $\begin{array}{l}-0.0247 \\
(0.0222)\end{array}$ & $\begin{array}{l}-0.0249 \\
(0.0158)\end{array}$ & $\begin{array}{l}-0.0249 \\
(0.0158)\end{array}$ & $\begin{array}{l}-0.0249 \\
(0.0158)\end{array}$ & $\begin{array}{l}-0.0249 \\
(0.0158)\end{array}$ \\
\hline $\begin{array}{l}\mathrm{N} \\
\text { Avg. Reduced Form Outcome in }-1\end{array}$ & $\begin{array}{l}271876 \\
12.162\end{array}$ & $\begin{array}{c}221456 \\
5.015\end{array}$ & $\begin{array}{l}291042 \\
0.255\end{array}$ & $\begin{array}{c}291042 \\
0.045\end{array}$ & $\begin{array}{c}291042 \\
0.031\end{array}$ & $\begin{array}{c}291042 \\
0.670\end{array}$ \\
\hline
\end{tabular}

Sample of early and later treated men, base ages 30-33, from -1-+14. Reduced-form regresses one of 6 labor market outcomes on the interaction between early treated and a post-reform indicator equal to 1 from time +0 +14 . First-stage regresses years of education on the same interaction using the sample from the reduced-form regressions. Column (1) measures labor earnings as the total annual earnings from employment. Column (2) measures hourly labor earnings, ( $\left.\frac{\text { annual earnings }}{\text { annual hours worked }}\right)$. Column (3) measures outside the labor force as equal to 1 if working 0 hours. Columns (4)-(6) measure employment as equal to 1 if working less than 20, 20-29, and more than 30 hours per week respectively. Coefficients interpreted relative to omitted -1 . Employment outcome variables measured as hours worked per week in a worker's main employment relationship at end of November. 
N Robustness

\section{N.1 Varying Delta}

Figure N: Changing Delta

(a) High School

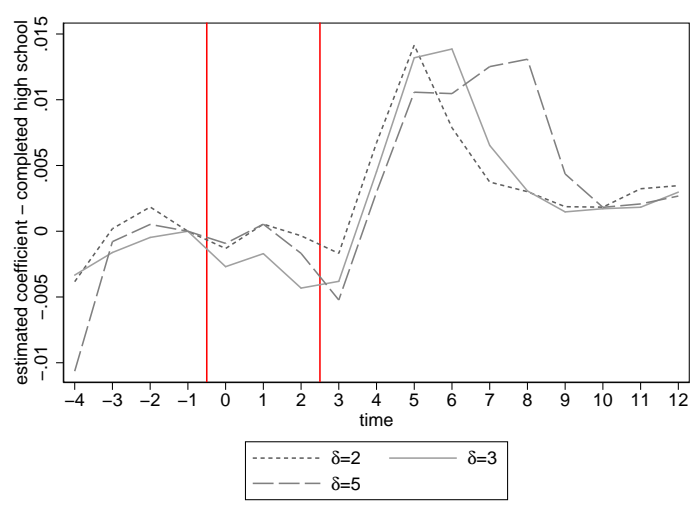

(b) Higher Education

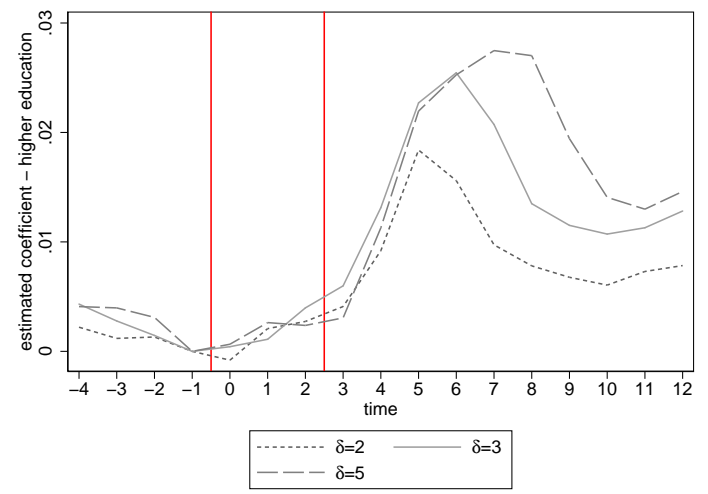

\section{N.2 Using Older Birth Cohorts}

Figure O: Completion of High School

(a) Female - base ages 30-33

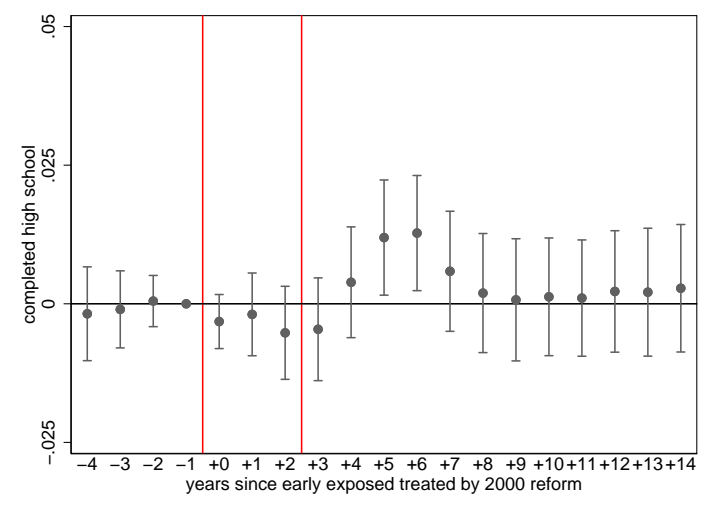

(b) Female-base ages 38-41

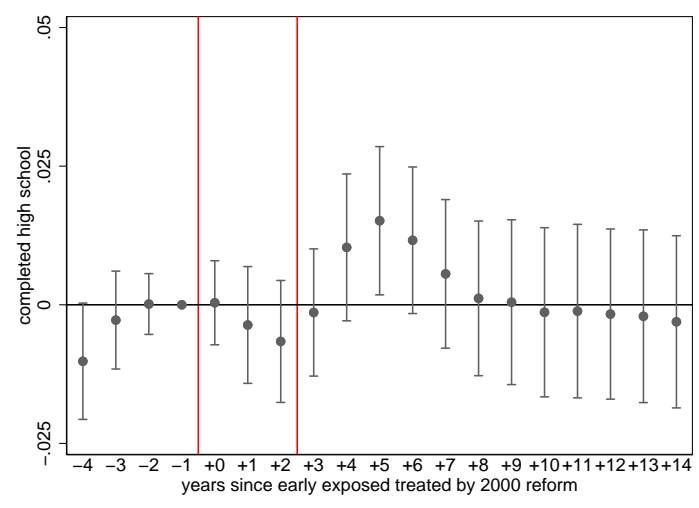


Figure P: Completion of Higher Education

(a) Female - base ages 30-33

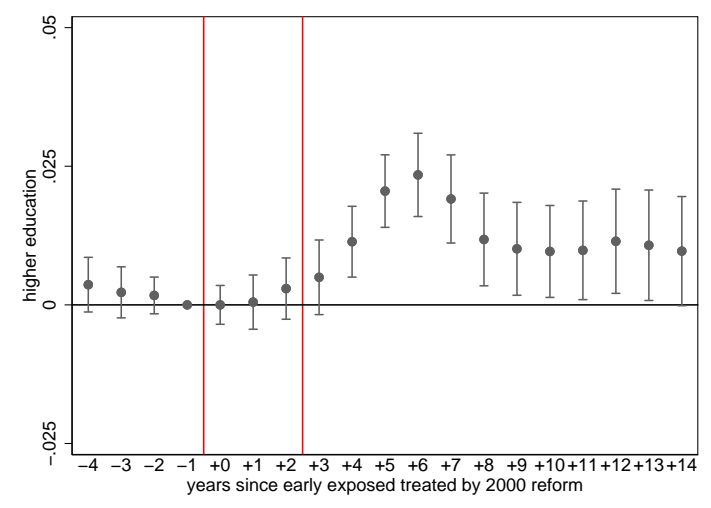

(b) Female-base ages 38-41

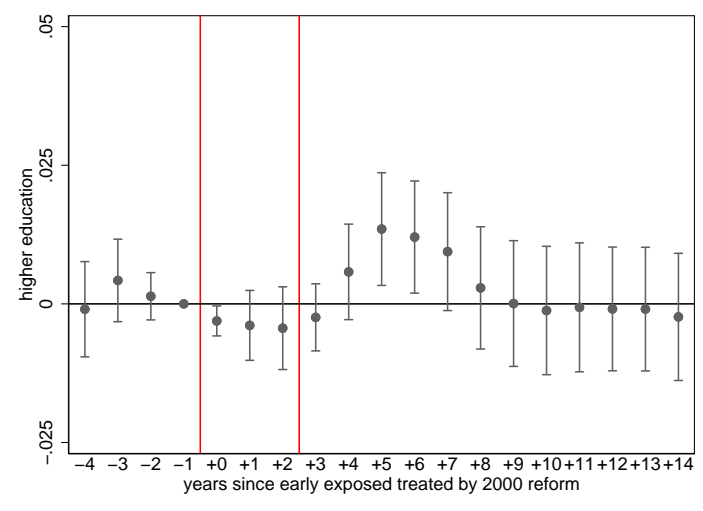

